\title{
Organizing for Destruction: How Organizational Structure Affects Terrorist Group Behaviour
}

by

\section{Joshua Kilberg}

\author{
A Thesis submitted to \\ the Faculty of Graduate Studies and Research \\ in partial fulfilment of \\ the requirements for the degree of \\ Doctor of Philosophy \\ in \\ International Affairs
}

Norman Paterson School of International Affairs

Carleton University

Ottawa, Canada

(C) 2011

Joshua Kilberg 
Library and Archives

Canada

Published Heritage

Branch

395 Wellington Street

Ottawa ON K1A ON4

Canada
Bibliothèque et

Archives Canada

Direction du

Patrimoine de l'édition

395 , rue Wellington

Ottawa ON K1A ON4

Canada
Your file Votre référence

ISBN: 978-0-494-89313-5

Our file Notre référence

ISBN: 978-0-494-89313-5

\section{NOTICE:}

The author has granted a nonexclusive license allowing Library and Archives Canada to reproduce, publish, archive, preserve, conserve, communicate to the public by telecommunication or on the Internet, loan, distrbute and sell theses worldwide, for commercial or noncommercial purposes, in microform, paper, electronic and/or any other formats.

The author retains copyright ownership and moral rights in this thesis. Neither the thesis nor substantial extracts from it may be printed or otherwise reproduced without the author's permission.
AVIS:

L'auteur a accordé une licence non exclusive permettant à la Bibliothèque et Archives Canada de reproduire, publier, archiver, sauvegarder, conserver, transmettre au public par télécommunication ou par l'Internet, prêter, distribuer et vendre des thèses partout dans le monde, à des fins commerciales ou autres, sur support microforme, papier, électronique et/ou autres formats.

L'auteur conserve la propriété du droit d'auteur et des droits moraux qui protege cette thèse. $\mathrm{Ni}$ la thèse ni des extraits substantiels de celle-ci ne doivent être imprimés ou autrement reproduits sans son autorisation.
In compliance with the Canadian Privacy Act some supporting forms may have been removed from this thesis.

While these forms may be included in the document page count, their removal does not represent any loss of content from the thesis.
Conformément à la loi canadienne sur la protection de la vie privée, quelques formulaires secondaires ont été enlevés de cette thèse.

Bien que ces formulaires aient inclus dans la pagination, il n'y aura aucun contenu manquant. 


\section{Abstract}

A terrorist group must strike a balance between efficiency and security. For licit groups, organizational theory posits that efficiency is a primary goal. Unlike licit groups, terrorist groups place a much higher value on security, often at the expense of efficiency. There has been little systematic work on the affect of terrorist group structure on a group's target selection and effectiveness. Using the Global Terrorism Database, the 254 most prolific terrorist groups from 1970-2007 are coded as one of four organizational structures: market, all-channel, hub-spoke and bureaucracy. Environmental factors like political rights, civil liberties, polity durability and state wealth all help shape a group's structure. Internal factors like hard target selection, operational pace, ideology and stated goals also seem to help shape a group's structure. Target selection is influenced by structure in complex and unexpected ways; highly decentralized market groups are just as likely as bureaucratic groups to select hard targets. Results also suggest that loosely networked all-channel organizations are the least likely to select sophisticated targets. Lethality per attack is used as a simple measure of effectiveness. Bureaucratic groups are the most lethal structure. In terms of ideology, right-wing and religious groups are the most lethal. Groups are also more lethal in states with low political rights and civil liberties. 
For Jess. 


\section{Summary}

All terrorist groups face a challenge to balance their need for security with their need for efficiency. But how do they achieve this balance? The answer to this question has enormous implications for counter-terrorism strategy.

This study is the first time the effects of terrorist group organizational structure has been investigated in detail. The evidence from examining the 254 most prolific terrorist groups since 1970 indicates that structure plays an important and complex role in shaping a terrorist group's behaviour.

In Chapter 2 a model is developed that explains the factors influencing a terrorist group's structure. Environmental factors, such as operating in rich, free, durable democratic states, push groups to adopt a decentralized structure. Internal factors acting on a terrorist group suggest that narrow goals, willingness to attack hard targets and high operational pace all push a group to adopt a centralized structure.

Chapter 3 examines the effect of structure on terrorist group's target selection. The results, from a multinomial logistic regression are instructive. Contrary to the hypothesis that centralization and capability are linked, the results indicate that market groups, the most decentralized structure, are at least as capable, if not more so, as centralized groups in attacking hardened targets such as police and military outposts. The other key finding from this chapter is that loose, all-channel networks are, in many ways, the least effective, least threatening type of organization. 
A case study of the Basque separatist group Euzkadi Ta Askatasuna (ETA) reveals that when a group changes its structure, it has a dramatic effect on the group's target selection. Findings further suggest that decentralizing, from hub-spoke to all-channel (a loose, networked structure), result in a decrease in sophisticated targeting. When ETA decentralized its structure it became less likely to attack hardened targets and more likely to attack easy targets; in effect, the group became less of a threat when it became less centralized. ETA decentralizes in response to a heightened security environment; the group sacrifices efficiency for security.

Chapter 4 looks at effectiveness. Lethality is a simple, policy-relevant measure for effectiveness. The results indicate that bureaucratic groups are the most lethal type of structure. In terms of ideology, religious and right-wing groups are more lethal than left-wing and nationalist groups. If a group is state sponsored its lethality is 2.3 times higher. Groups are more lethal in states with low political rights and civil liberties.

Al Qaeda in Iraq (AQI) provides a good case study to illustrate what happens to the effectiveness of a group when it is forced to change its organizational structure. AQI serves as a reminder that effective counter-terrorism strategy often results in the disruption and restructuring of a terrorist group, diminishing its lethality.

While this study raises more questions than it answers, the policy implications suggest that pushing a group away from a centralized structure would help reduce a group's lethality and overall output. 


\section{Table of Contents}

Abstract

Summary iv

Table of Contents $\quad$ vi

List of Tables $\quad$ x

List of Figures $\quad$ xii

1 Introduction 1

1.0.1 What is terrorism? .............. 3

1.1 Level of Analysis . . . . . . . . . . . . . . . 5

1.1.1 Individual Level of Analysis . . . . . . . . . . . . . 5

1.1.2 Societal Level of Analysis . . . . . . . . . . . . . 7

1.1.3 Group Level of Analysis . . . . . . . . . . . . . . 8

1.2 Previous Research . . . . . . . . . . . . . . . . . . . . 10

1.2.1 Constraints on the group . . . . . . . . . . . . . . . 10

1.2.2 Previous Research on the End of Terrorism . . . . . . . . . . . 11

1.2.3 Measuring Terrorist Group Success . . . . . . . . . . . . 15

1.2.4 Previous research on structure . . . . . . . . . . 17

1.2.5 Previous research on terrorist group structure . . . . . . . 25 
1.3 Dataset and methodology . . . . . . . . . . . . . 30

1.3.1 Methods of coding for structure . . . . . . . . . 31

1.3.2 Other coding parameters . . . . . . . . . . 38

1.3.3 Looking ahead . . . . . . . . . . . . . . 40

2 Explaining Terrorist Group Structures 41

2.1 Introduction and Motivation . . . . . . . . . . . . . . . . 41

2.1 .1 Operating in secrecy ................ 41

2.1.2 Forces acting on terrorist groups . . . . . . . . . . . . 44

2.1.3 Testing Hypotheses in the literature . . . . . . . . . . 45

2.2 Description of Data and Sample . . . . . . . . . . . . . 48

2.2.1 External Factors ................. . . 49

2.2 .2 Internal Factors . . . . . . . . . . . . . 53

2.3 Regression Analysis . . . . . . . . . . . . . . . . . 56

2.4 Results . . . . . . . . . . . . . . . . . 57

2.4 .1 External Variables ................. 57

2.4 .2 Internal Variables . . . . . . . . . . . . 63

2.4 .3 Diagnostics ......................... 67

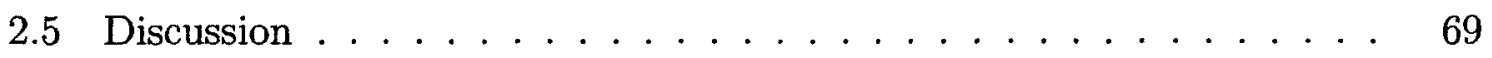

2.6 Conclusion . . . . . . . . . . . . . . . . 74

3 How Structure affects Group Targeting $\quad 76$

3.1 Introduction and Motivation . . . . . . . . . . . . . 76

3.2 Literature Review . . . . . . . . . . . . . . . . . . . 77

3.2 .1 Organizational Explanations . . . . . . . . . . . 77

3.3 Categorizing targets . . . . . . . . . . . . . . 82

3.3.1 Coercive Target Selection ... . . . . . . . . 84

3.3.2 Attention-seeking Target Selection . . . . . . . . 86 
3.3.3 Infighting target selection $\ldots \ldots \ldots \ldots \ldots$

3.4 Results: Target Categories . . . . . . . . . . . . . . . . . . 90

3.4 .1 Group Ideology . . . . . . . . . . . . . . . . . . . . 92 92

3.4 .2 Calendar year, group age and peak size . . . . . . . . . 96

3.4.3 GDP per capita and Freedom House . . . . . . . . . . 97

3.4.4 Organizational Structure . . . . . . . . . . . . . . . . . 102

3.5 Diagnostics . . . . . . . . . . . . . . . . . . . . 108

3.6 Discussion . . . . . . . . . . . . . . . . . . 111

3.7 Case Study: Euzkadi Ta Askatasuna (ETA) . . . . . . . . . . . . 115

3.7 .1 Selection Criteria . . . . . . . . . . . . . . . 115

3.7 .2 Background . . . . . . . . . . . . . . . 116

3.7.3 Command and Control . . . . . . . . . . . . . . . 117

3.7.4 Targeting Preferences . . . . . . . . . . . . . . . . . . . 119

3.7 .5 Conclusion . . . . . . . . . . . . . . . . . . 123

4 Structure and Effectiveness $\quad 125$

4.1 Introduction and Motivation . . . . . . . . . . . . . . 125

4.1.1 Lethality as a measure of effectiveness $\ldots \ldots \ldots \ldots$

4.1.2 Previous research on terrorist group learning . . . . . . . . 127

4.1.3 Previous Research on Terrorist Group Lethality . . . . . . . 130

4.2 Data and Methodology . . . . . . . . . . . . . . . . . 133

4.3 Estimating the Lethality of Attacks . . . . . . . . . . . . . 136

4.3.1 Estimating lethality - Main Model . . . . . . . . . . 136

4.3 .2 Diagnostics . . . . . . . . . . . . . . . . . . . . . . . 141

4.3.3 Alternate Models: By Organizational Structure . . . . . . . 143

4.3 .4 Diagnostics . . . . . . . . . . . . . . . . . . 146

4.3.5 Alternate Models: Lethality of armed assaults versus bombings 147 
4.4 Discussion ............................ 150

4.5 Case Study: Al Qaeda in Iraq (AQI) . . . . . . . . . . . . . 157

4.5.1 Background ........................ 158

4.5.2 Command and Control . . . . . . . . . . . . 160

4.5.3 Attack Lethality . . . . . . . . . . . . . 163

4.5.4 Conclusion ...................... 165

5 Conclusions and Implications for the Future $\quad 167$

5.0.5 Implications for the Future . . . . . . . . . . . . . . . . 174

$\begin{array}{ll}\text { List of References } & 177\end{array}$

$\begin{array}{ll}\text { Appendix A } & 198\end{array}$ 


\section{List of Tables}

1 Coding for Structure $\ldots \ldots \ldots \ldots$. . . . . . . . . . 37

2 Sample Terrorist Group Structures . . . . . . . . . . . . . . . 37

3 Variables, operationalization and sources . . . . . . . . . . 50

4 Multinomial Logit: Complete model . . . . . . . . . . . . . . 58

5 Multinomial Logit- Basic Model . . . . . . . . . . . . . . . . . 59

6 Base Model - Ordered Probit ${ }^{a} \ldots \ldots \ldots \ldots \ldots 60 \ldots$

7 Descriptive Statistics - Base Model . . . . . . . . . . . . . . . 69

8 Frequency Table: Target Category and Lethality . . . . . . . . . . . 89

9 Multinomial Logit (Part I): Attention-seeking Category . . . . . . . . 98

10 Multinomial Logit (Part II): Coercive Category . . . . . . . . . . 99

11 Multinomial Logit (Part III): Infighting Category . . . . . . . . 100

12 Target Selection by ETA in 5-Year Periods (\% of total) . . . . . . 121

13 Target Selection by ETA $(\%$ of total $) \ldots \ldots \ldots$. . . . . . . . 123

14 Variables, operationalization and sources . . . . . . . . . . 134

15 Lethality of attacks - Main Model . . . . . . . . . . . . . . 138

16 Descriptive Statistics - Base Model . . . . . . . . . . . . . . . 142

17 Lethality of armed assaults . . . . . . . . . . . . . . . . . . 151

18 Lethality of bombing/explosions . . . . . . . . . . . . . . 152

19 Different Measures of AQI Lethality . . . . . . . . . . . . . . . 164

20 List of Group Names and Organizational Structure $\ldots \ldots \ldots \ldots$ 
21 List of Ten Most Deadly Attacks (according to GTD) . . . . . . . . . 208

22 Attention-Seeking Targets: Economic (Part I) ${ }^{a}$. . . . . . . . . . . . 209

23 Attention-Seeking Targets: Economic (Part II) ${ }^{a}$. . . . . . . . . . . 210

24 Attention-Seeking Targets: Economic (Part III) ${ }^{a}$. . . . . . . . . . 211

25 Coercive Targets: Hard Targets ${ }^{a}$. . . . . . . . . . . . . . . 212

26 Coercive Targets: Soft Targets (Part I) ${ }^{a}$. . . . . . . . . . . . 213

27 Coercive Targets: Soft Targets (Part II) ${ }^{a} \ldots \ldots$. . . . . . . . . . . 214

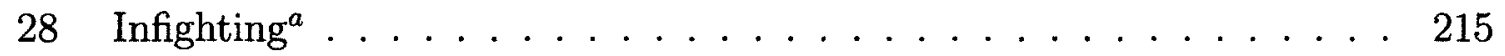

29 Attention-Seeking Targets: Political (Part II) ${ }^{a}$. . . . . . . . . . 216

30 Attention-Seeking Targets: Political (Part II) ${ }^{a} \ldots$. . . . . . . . . . 217

31 Lethality of market structures . . . . . . . . . . . . . . . 217

32 Lethality of all-channel structures . . . . . . . . . . . . . . . 218

33 Lethality of hub and spoke structures . . . . . . . . . . . . . 219

34 Lethality of bureaucratic structures . . . . . . . . . . . . . . 220 


\section{List of Figures}

$1 \quad$ Market Structure . . . . . . . . . . . . . . . . . . 33

2 All-Channel Structure $\ldots \ldots \ldots \ldots \ldots \ldots$

3 Hub-Spoke Structure . . . . . . . . . . . . . . . 35

4 Bureaucratic Structure . . . . . . . . . . . . . . 36

5 Frequency of Organizational Structure by Country Wealth . . . . . 61

6 Organizational Structure by Motivation Type . . . . . . . . . . 70

7 Target selection $(\%$ of total $) \ldots \ldots \ldots \ldots$

8 Infighting targets $(\%$ of total attacks $) \ldots \ldots \ldots \ldots$

9 Target category by group structure $\ldots \ldots \ldots \ldots$

10 ETA Attacks Per Year (1986 obs.) . . . . . . . . . . . . . . 120

11 Attack Lethality Range by Group Ideology . . . . . . . . . . . . . . 140

12 Al Qaeda in Iraq monthly lethality $(2004-2008) \ldots \ldots$

13 Change in Attack Profile for Al Qaeda Iraq . . . . . . . . . . . . 161

14 Attack type: Al-Qaeda in Iraq . . . . . . . . . . . . . . . . 165 


\section{Chapter 1}

\section{Introduction}

In a famous scene from the film, The Battle of Algiers, Colonel Mathieu, commander of the French paratroop regiment sent to quell the terror campaign in Algeria, sketches out on a blackboard the organizational structure of the Front de la Liberation Nationale (FLN) (Pontecorvos, 1966). Colonel Mathieu outlines a classic pyramidal cell structure, where each member only has knowledge of two members: the person that recruited them and the person they themselves recruited. The scene is a potent illustration of the importance a terrorist group achieving security - or lack thereof - through its organizational structure. Through a campaign of torture and brutal reprisal against FLN attacks, the French soldiers under Colonel Mathieu's command are able to identify and destroy the FLN leadership. The success of the French would not have been assured without identifying the FLN's organizational structure and systematically dismantling it.

Had the FLN adopted a more decentralized structure, one in which no central leader 
or council exists, where decisions are delegated to the cells themselves, the French could have used any type of torture they wanted but they still would have had great difficulty in dismantling it. This example illustrates a crucial and often misunderstood aspect of the study of terrorism: organizational structure. The structure of the FLN was ultimately its undoing. A terrorist organization, with the right structure for its environment, has adapted to the challenges it faces and reached a compromise between security and efficiency.

In this research project I investigate the structure of terrorist groups. This study asks: what is the effect of organizational structure on a terrorist group's behaviour and success? This is an under-explored area within the field but one which, I argue, has great potential for developing effective counter-terror policies.

The area of study in this project is bounded in several ways. First, I take it as given that a group has decided to use violence for ideological reasons. The reasons why a group radicalizes and descends into violence, while an important part of understanding the terrorist group life cycle, is not the subject of the current study. Second, as this is an under-explored area, the current research is intended to serve as a theorybuilding tool. While policy-relevant findings are discussed, this line of investigation is still in its infancy and should be treated as such.

In the proceeding pages, I endeavour to lay out a methodical and wide-ranging study of terrorist groups and their organizational structures from 1970 through 2007 . Fortunately, the difficulty here is not identifying a small lacunae in the literature yet 
to be explored but setting feasible boundaries for a thesis within a large chasm of understudied, potential work.

This study is divided into five main sections. In this chapter, I introduce the basic concepts, theories and coding methodology relevant to this study. Chapter 2 examines the effects of internal and external environmental factors on a group's structure. Building on these results, in Chapter 3, I turn the question around and ask what is the effect of structure on shaping a group's strategic priorities through its target selection. The targets a group selects says a lot about what the group is about. In Chapter 4, I turn to the effect of structure on a group's effectiveness as measured by lethality. Finally, I offer conclusions and suggest some potential future work.

\subsubsection{What is terrorism?}

Terrorism has no universally accepted definition. Often it is a pejorative term, to label someone or some group "terrorist" is to pass judgement of the illegitimacy of their actions. That does not mean, however, that settling on a definition is impossible. In fact, many scholars agree that terrorism is, broadly conceived, as a tactic used by an organization or an individual (Crenshaw, 2007; Neumann, 2007; Weinberg et al., 2009; Hoffman, 2006). For the purposes of the research herein, the definition of terrorism is in large part pre-determined by the database used. The Global Terrorism Database (GTD) employs the following definition: 
The threatened or actual use of illegal force and violence by a non-state actor to attain a political, economic, religious, or social goal through fear, coercion, or intimidation (START, 2010).

In addition to these criteria, for an incident to be included in the GTD dataset - and therefore in this study - at least two of the following criteria must be met:

1. The act must be aimed at attaining a political, economic, religious, or social goal.

2. There must be evidence of an intention to coerce, intimidate, or convey some other message to a larger audience (or audiences) than the immediate victims.

3. The action must be outside the context of legitimate warfare activities (START, 2010).

This definition will not satisfy everyone - terrorism is after all an essentially contested concept. However, in a study of more than fifty scholarly definitions of terrorism, Schmid and Jongman (1988) found that while there is great divergence, almost every definition includes the basic idea that terrorism is a violent tactic used to intimidate or coerce an audience for the purpose of advancing a political or social goal. The above definition satisfies these tenets and since it is used by the GTD in its selection criteria, it is employed here as well. 


\subsection{Level of Analysis}

As a subject that looms large in modern history, the study of terrorism has been examined from virtually every academic discipline. Since $9 / 11$ there has been a virtual explosion of terrorism research. Each discipline tends to follow its own set of objective. Academics theorize about human behaviour and long term trends while policy-makers focus on the more immediate challenges (Gupta, 2008). It is, therefore difficult to provide a broad outline from a disciplinary perspective. Rather, I provide an overview of the recent trends of terrorism research based in the level of analysis.

\subsubsection{Individual Level of Analysis}

At an individual level, the decision for a person to employ violence in the pursuit of a political or social goal remains shrouded in uncertainty. There exists no single psychological trait, no one personality type that reliably leads a person to terrorism (Crenshaw, 1995; Ross, 1999; Post et al., 2002; Post, 1990; Horgan, 2005). Some scholars, such as Horgan (2008) and Stern (2004) posit explanations for why an individual decides to become a terrorist. Others examine this issue as a process of radicalization (Alonso and Reinares, 2006; Atran, 2010; McCauley, 2008). Still others examine the individual in the process of deradicalization (Gunaratna and Ali, 2009; Horgan and Braddock, 2010).

Within this level of analysis rests questions of psychology: What makes a terrorist? 
These investigations attempt to explain why an individual turns to terrorism. Explanations at the individual level include psychological forces justifications (Post, 1990; Horgan, 2005; Victoroff, 2005b; Ross, 1996). Other individual explanations include sociological factors, in particular justifications for suicide (Boyns and Ballard, 2004; Hudson and Majeska, 1999; Laqueur, 1987; Pedahzur et al., 2003). In this way an individual makes a choice to use their body as a weapon as a part of a larger struggle (Krueger and Maleckova, 2002; Atran, 2006; Pedahzur and Perliger, 2005).

Political radicalization is preparation for - and commitment to - intergroup conflict. Radicalization means a "change in beliefs, feelings, and behaviours in directions that increasingly justify intergroup violence and demand sacrifice in defence of the ingroup." (McCauley and Moskalenko, 2008a, p. 416). Much of the literature on radicalization is focused on individual mechanisms (Sageman, 2004; McCauley and Moskalenko, 2008b; Jenkins, 2010).

There are two mechanisms for individual radicalization. The first is radicalization due to personal victimization. The so-called Chechen Black widow suicide bombers, for example, are described as seeking revenge against Russians for their own experience of sexual violence or the death of family members (Nacos, 2005; Bloom, 2004, 2007). The second mechanism is individual radicalization through politics. An example of this type is the Unabomber, Ted Kaczynski. A 'lone wolf' terrorist, this type of individual radicalization is the most likely to be attributable to some kind of psychopatholgy and are relatively rare (McCauley and Moskalenko, 2008b). 
Another focus is on examining individual terrorist leaders. This field examines the importance of a group's leader and the effect one single person can have on a terrorist campaign (Post, 1987; Post and George, 2004; Victoroff, 2005a). While the individual level of analysis is an important aspect of the study of terrorism, it leaves out broader processes that help explain the terror phenomenon.

\subsubsection{Societal Level of Analysis}

At the other end of the spectrum is the societal level of analysis. The goal from this perspective is to identify a particular combination of socio-economic factors which predisposes a segment of the population to terrorism. Some researchers have attempted to broadly describe political violence emerging from a movement (DeNardo, 1985; Della Porta, 1995; Heger et al., 2008; Tarrow, 2011; McAdam et al., 2001; Davies, 1962). Others seek to find a link between terrorist and socioeconomic indicators such as education and poverty (Krueger and Maleckova, 2003; Berrebi, 2003; Piazza, 2006; Abadie, 2006).

There is another body of work examining the quality and type of a polity and its effect on terrorism (Eubank and Weinberg, 1994, 2001; Piazza, 2008; Pedahzur et al., 2003; Schmid, 1992; Weinberg and Eubank, 1998; Wilkinson, 2006; Li, 2005). The focus of these authors is on the effect of democracy on inducing a terrorist group to give up violence. While also a necessary and important level of analysis of terrorism, the societal level loses specificity as it gains generalizability. 


\subsubsection{Group Level of Analysis}

As is so often the case, it is the middle way that provides the best opportunity to gain insight into the phenomenon of political violence, the group level of analysis. The importance of group dynamics is crucial for explaining why some groups of individuals decide to use violence while others do not; why some groups struggle peacefully to advance a political cause while others descend into violence (Asal and Rethemeyer, 2008; Eilstrup-Sangiovanni and Jones, 2008). Since neither individual nor societal explanations are sufficient for this, the answers must be found in the group level of analysis.

It is the group level of analysis that has proven the most fruitful in terms of academic study. A key way to explore the variance in group dynamics is to examine how the group adapts to external events and challenges such as policing and competition from other groups. Recent research indicates that once an individual becomes a part of a group that uses violence, the use of violence itself becomes as much - or more - about maintaining group identity as it does about the instrumental ability for violence to influence opinion in pursuit of a goal (Sageman, 2004, 2008; Horgan, 2008; Post, 1990). It is within this group pressure-cooker that individuals dedicated to a cause seek reinforcement and justification for their actions (Post, 1990, p. 26).

Joining a radical group seems to be the most popular pathway into terrorism. Individual radicalization by joining a radical group has received the most attention of late (see Sageman, 2004, 2008; Horgan, 2008; Horgan and Braddock, 2010; Jenkins, 
2010). Recruitment is frequently done through personal connections to maintain security. The process can occur locally, or online (Stevens, 2009; Weimann, 2005). Once recruited into a group, the individual fosters a sense of loyalty, and group cohesion increases greatly as members share common goals and common threats - as well as the potential for isolation from society (Della Porta, 2006). Finally, once a group descends into violence, it is very difficult to transition out of it. Understanding how a group functions will help scholars and policymakers alike understand how to stop the cycle of violence.

Most terrorist groups are short-lived. One study observed that 90 percent of organizations ceased to exist before the first year (Rapoport, 1992). The question of why some groups wither and others flourish is, in part, tackled in the current study. Previous research points to several reasons for growth and transformation.

First, if a group enjoys a popular base of support, it will have a better chance of surviving and even prospering (Gupta, 2008). Mao Tse-Tung's theory of guerilla warfare depends on the same support when he wrote: "It is only undisciplined troops who make the people their enemies and who, like the fish out of its native element cannot live" (Tse-Tung and Griffith, 2000, p. 93). Another way for a group to succeed is for the group to tie itself ideologically to the prevailing political movement - whatever that may be. Hezbollah was initially formed to forment revolution in Lebanon and to set in motion a repeat of the 1979 Iranian Revolution however, it soon shifted to another issue with broad appeal in multiethnic Lebanon, defending the 
country from Israel (Byman, 2003). Another way to flourish is to provide services to the people. This strategy is particularly effective in places with ineffective goverments and this is a strategy that Hamas has used to great effect (Gupta, 2008, p. 126).

Finally, the growth and transformation of all successful terrorist groups follow a similar pattern. They formed around some longstanding institutional or historical grievances. These grievances represent a failure of government or an inequitable socioeconomic system

\subsection{Previous Research}

\subsubsection{Constraints on the group}

There are several different types of constraints that generally act to impede or shape a group's behaviour. As one scholar observes, "terrorists are constrained materially by the resources that they have and ideologically by the preferences of their supporters" De la Calle et al. (2006, p. 1).

Material resources constrain a group's ability to attack. The equipment and implements for destruction are often easily procured or made but the it is, thankfully, much more difficult to obtain certain weapons such as chemical, biological, radiological and nuclear (CBRN). The materials a group can procure will affect the attack profile of the group. 
Training and information resources are also constraining forces acting on a group as it plans attacks. Without adequate military training, attacking certain targets such as a military outpost would be suicide. Groups attempting a bombing campaign must have the knowledge and skill in bomb-making in order to be successful.

Organizational constraints are equally, if not more important than the above constraints because they dictate not only capability but the level of sophistication a group is capable of.

\subsubsection{Previous Research on the End of Terrorism}

The end of terrorism literature - for the most part a recent development - is useful for the current study because it usually attempts to catalogue the historical record. Moreover, by putting aside the pathway into terrorism, it focuses on the conditions that hasten a group's demise - which is often different from the way the group began (Alterman, 1999; Hutchinson, 2007; Dugan et al., 2008). It is these same conditions and pressures that help explain the impact of structure on terrorist groups. This literature review will help situate the current study by showing recent relevant work and will also identify the existing research relating to terrorist group behaviour and structure.

Most often, it is the causes and the roots of terrorism that are studied. This is because terrorism studies are often reactive to the public policy concerns of the day. Police 
and intelligence services place a high priority identifying and stopping violence before it begins. This focus occurs at the expense of looking back at the historical record in a systematic way.

Ross and Gurr (1989) make an important contribution to the literature in their study of North American terrorist groups and how they decline. Among the first to address the need for research on how terrorism ends, they distinguish between military and political strength of terrorist groups and observe that terrorists can compensate for weakness in one area with strength in the other. They argue that four conditions contribute to the decline of terrorism: preemption (external, military), and deterrence (internal, military) can reduce the terrorist's capacity for coercion; backlash (external, political) and burnout (internal, political) can reduce political power (Ross and Gurr, 1989). This is an elegant model but the external versus internal distinction the authors make is not always clear.

Crenshaw has probably done the most work in this field (Crenshaw, 1991a,b, 1996, $2000,2007)$. She bemoans the general lack of focus for the decline in terrorism and places the blame on the reactive nature of the field. This lack of focus is explained by the researchers search for funding and the policymakers need for timely research on emerging threats. Crenshaw identifies three factors that play a role in the decline of terrorism: "physical defeat of the extremist organization by the government, the group's decision to abandon the terrorist strategy, and organizational disintegration" (Crenshaw, 1991a, p. 71). She concludes that no theory exists to explain the decline 
of terrorism but suggests that hypotheses about the outcomes of terrorism can be inferred from "conceptions of the origins of terrorism" (Crenshaw, 1991a, p. 73).

Crenshaw (1996) makes two key distinctions in understanding when terrorist groups move away from terrorism: an instrumental approach versus an organizational/psychological interpretation. An instrumental approach to violence suggests that the decision to abandon violence is based on calculations of diminishing utility. The organizational and psychological interpretation suggests that once the decision to use violence is made, and so long as the organization continues to exist, there are forces that encourage using violence even if it becomes counterproductive to achieving the goal. In other words, terrorism can become independent of its original motivations.

Crenshaw (1999) offers three reasons for abandoning terrorism: terrorism may have succeeded, terrorists may face increasing costs and decreasing benefits, or terrorists see new options. Crenshaw also makes a distinction between internal and external factors affecting terrorist groups. Internal factors are those that relate to the dynamics of a group while external factors are about the situation the groups faces such as government strength and constituent support, among others. She offers the following taxonomy of how terrorism ends: success, preliminary success, organizational breakdown, dwindling support, and new alternatives (Crenshaw, 1999).

More recently Cronin $(2006,2009)$ has taken up studying the decline of terrorism. She disagrees with Crenshaw's assertion that the end of terrorism has anything to 
do with the origins of it (Cronin, 2006, p. 10). For her, the nature of the grievance has some influence on the time span of a group. Ethno-nationalist groups tend to last the longest while ideological groups, from both the left and right wing - tend to be much shorter. She goes on to identify seven elements which may have an impact on a group's decline: capture or kill the leader, unsuccessful generational transition, success, transition to legitimate political process, loss of popular support, repression, or transition to crime or insurgency (Cronin, 2006, p. 19). If these elements can lead to the end of a group, they must also have an impact on the behaviour and structure of the group.

The issue of terrorist groups reaching a negotiated end to violence can be affected by the group structure. In this way, there are several points of view to consider. First, reaching and enforcing a politically negotiated settlement is more difficult without a central decision-making body within the terrorist group (Neumann, 2007). Second, counter-terrorism efforts tailored to a hierarchical organization may be entirely unsuccessful when deployed against a group that employs a flattened, horizontal structure. Jones and Libicki (2008) conduct one of the most comprehensive empirical studies on the end of terrorism. ${ }^{1}$ This study looks at 648 terrorist groups active between 1968 and 2006. Each group is coded based on size, ideology, goals, and the group's demise (splintered, ended by military force, ended by policing, ended in political negotiation, or ended in victory). They conclude that 41 percent of groups have

\footnotetext{
${ }^{1}$ Although Ross and Gurr (1989) is a notable exception, they only examine North American terrorist groups.
} 
stopped using terrorism, 21 percent have splintered and 38 percent are still active (Jones and Libicki, 2008, p. 41). Jones and Libicki go on to do three case studies: Japan's Aum Shinrikyo, Farabundo Marti National Liberation Front (FMLN) in El Salvador and Al Qaeda in Iraq. Through regression analysis they also conclude that the predominant explanation for group longevity is a group's size

Their focus is on policy prescriptions, particularly for Iraq, and this is reflected in each of their case studies. Each case study is taken as an example of policing, intelligence and/or political engagement as a means to ending terrorism. Their research is probably the most similar work to my own in terms of methodology. In fact, I employ the coding methology used by Jones and Libicki (2008) for determining the beginning and end of terrorist groups. My own work is different in that it is focused on organizational structure, not group demise.

\subsubsection{Measuring Terrorist Group Success}

Rapoport (1992) observes that 90 percent of all terrorist groups have a life span of less than one year and of those that make it to one year, more than half disappear within a decade. The implication of these statistics is that researchers should be cautious when delving into research of particular groups based simply on public policy imperatives. An important element of terrorist group structure is measuring which groups maintain the ability to sustain themselves. Groups that show a robust lasting power are well equipped to deal with counter-terror forces and are, therefore, more dangerous. Short 
of achieving a political goal, a group must at the very least maintain some support for its cause and the ability to conduct operations over time.

Terrorist groups have vastly different goals - many of which are ambiguous or even existential. As Ross and Gurr (1989, p. 409) observe: "some groups seek revolution, others demand greater autonomy for their community, others still seek to draw attention to a particular issue." It is very difficult to judge a terrorist group on the merits of any measure of "success" - either by a group's own stated goals or by using some kind of external criteria of evaluation. Moreover, it is not plausible to expect that success, however measured, will lead terrorists to forgo violence. That is not to say that measuring success is impossible. Indeed Ross and Gurr (1989) argue that measuring success is possible, not by measuring whether a group has achieved its political objectives, but by observing that some progress has been made toward their announced objectives. In this way, progress can be measured, albeit indirectly.

Governments will rarely, if ever, openly acquiesce to the demands of a terrorist group, but this does not mean that it will not respond to a group's political grievances. Usually this response is incremental, done well after after the campaign of violence has ended (Neumann, 2007). Ross and Gurr (1989) suggest that these policy changes in favour of a terrorist group actually serve to undermine the terrorist group by narrowing the political gap between the terrorist's ideal and reality. 


\subsubsection{Previous research on structure}

Understanding how violent groups organize themselves is an understudied yet important component of confronting and defeating these groups. ${ }^{2}$ It is crucial, then, to detail the building blocks of organizational structure as they are used here. While the structure of violent groups remains understudied, the study of organizational structure for legal groups, especially the structure and power of networks, has been among the most popular topics of study within the past several decades (see Raab and Milward, 2003; Asal et al., 2007; Mannes, 2008).

In this study I employ a typology set forth by Arquilla and Ronfeldt that is geared toward illicit groups in particular (Arquilla and Ronfeldt, 2001; Arquilla et al., 1999). ${ }^{3}$ Much of the existing organizational theory literature focuses on legal organizations which, I argue, face vastly different challenges and motivations than illegal groups. Nevertheless, building on the previous work of organizational theorists is important and necessary for the current study.

In his classic work on group structure, Coase (1937) conceives of firms and markets as alternative forms of organizing similar kinds of transactions. This dichotomous view was popularized in the 1970 s with transaction costs economics and changed the thinking of a firm from that of a black box to a governance structure which has an effect in its output (Powell, 1990, p. 296). Williamson (1975) argues that transactions

\footnotetext{
${ }^{2}$ Notable exceptions include Crenshaw (1991, 1999); Cronin (2006, 2009); Jones and Libicki (2008).

${ }^{3}$ They themselves derive their theory from the other sources described here.
} 
involving uncertainty about their outcome, especially when they frequently recur and require high investment, ${ }^{4}$ are more likely to take place within hierarchically organized firms. On the other hand, those exchanges that are straightforward, non-repetitive and require low investment will take place within a market structure (Williamson, 1975; Powell, 1990).

In this relationship, transactions occurring in markets move into hierarchies as knowledge specific to the transaction builds up. This transition occurs at the point when the efficiency of the market incurs too many costs and transactions are better off done through an internal process - the firm. At this point, the inefficiencies of a bureaucracy with specialized knowledge of the transactions are preferred to the ad-hoc market (Powell, 1990, p. 297). This view held much sway in the fields of economics, political science and sociology. In many cases, such as the study of collusion in business, it remains relevant today (Baker and Faulkner, 1993). Yet, between these two poles of organization - one highly ordered and hierarchical; the other loose, one-off interactions - lie a great deal of organizations not captured by either typology. ${ }^{5}$

A hierarchical group structure is characterized by a centralized decision-making structure and clear command structures. Child (1972) finds that large organizations tend to be more rule-bound and require greater documentation of their efforts. A hierarchy

\footnotetext{
${ }^{4}$ These investments could be time, energy or money.

${ }^{5}$ Pertinent to any study on illegal group structure - and overlooked by Powell and others - is clandestinity. Terrorist groups operate in secret and this places considerable constraints on the possible group types and how actors interact to share information. This complication discussed further below.
} 
is defined here as having: "clear departmental boundaries, clean lines of authority, detailed reporting mechanisms, and formal decision making procedures" (Powell, 1990, p. 303).

A market structure offers choice, flexibility and opportunity and is best suited for fast, simple communication (Powell, 1990; Coase, 1937; Williamson, 1975; Child, 1972). Individual behaviour is not dictated and lacks oversight, systemwide governance or control is not necessary. Powell observes that "markets are a form of non-coercive organization, they have coordinating but not integrative effects" (Powell, 1990, p. $302)$.

Both hierarchical and market structures have advantages and disadvantages. This fact is as true of licit organizations such as businesses, non-governmental organizations, or governments as it is of illicit groups such as organized crime and terrorism. However, the similarities between licit and illicit stop there. When one evaluates the goals of a business organization (for profit) and a terrorist group (for a political goal) it is clear that the differences are vast. Such is the case when evaluating a licit group's organizational challenges, such as competition from others or offering an appealing product, to those facing an illicit group, such as evading government attempts to capture and kill its members.

Ceteris paribus, groups that are more hierarchical possess a greater span of control and are therefore able to accommodate more members (Urwick, 1922). The more hierarchical the group, the more specialized it can become, and the more efficient 
it can become. In its ideal form, a bureaucracy serves to formally divide power, anticipate needs and improve efficiency (Weber, 1952). However, because bureaucratic organizations are centralized, the gains in efficiency are offset somewhat by a slower adaptability. Those groups which form a hierarchical structure have a clearly defined centralized command structure - much like a military command where information and commands flow from the leadership down to the 'soldiers' who take action. The relationship between the agenda-setting leadership and its subordinate units is clearly defined and unidirectional (Heger et al., 2008, p. 7). In sum, the literature tells us that a bureaucratic organization will be better equipped to deal with a varied, specialized workforce or with a large number of personnel. Market groups are best for higher adaptability with non-complex or repeatable tasts.

The notion of a middle way is put forward by Powell (Powell, 1990, 1987). He describes a network that differs from a market and a hierarchy:

Many firms are no longer structured like medieval kingdoms, walled off and protected from hostile outside forces. Instead, we find companies involved in an intricate latticework of collaborative ventures with other firms, most of whom are ostensibly competitors. The dense ties that bind [industries] cannot be easily explained by saying that these firms are engaged in market transactions for some factors of production, or by suggesting that the [business] is embedded in the international community (Powell, 1990, p. 303). 
Powell argues for a third structure to describe those groups which do not fit in the dichotomous view of market versus hierarchy: a network. Nohria and Eccles (1992) further argue that a network is more than a set of organizational characteristics and constitutes a particular form of organization. A later effort by DeSanctis and Fulk (1999, p. 498) argues that while networks are a distinct organizational form, much work needs to be done since the study of organizational forms still tends "to be dominated by such dichotic concepts as market versus hierarchy". Networks, groups that are lighter on their feet than hierarchies yet more cohesive and capable than markets, offer this middle way. A network is defined as "a specific set of relations making up an interconnected chain or system for a defined set of entities that forms a structure" (Thompson, 2003, p. 54). Powell conceives of networks as a distinct form of organization, different than hierarchies and markets, which "link actors working toward common goals" (Powell, 1990; Eilstrup-Sangiovanni and Jones, 2008).

Decentralized networked groups lack the large span of control and specialization enjoyed by hierarchical groups but enjoy more flexibility. These networked groups are further divided into different network structures (detailed below) each of which possess different strengths and weaknesses (Krebs, 2002). Overall, networked groups remain smaller and flatter than bureaucracies. What these groups give up in centralization and efficiency, they gain in enhanced security and nimbleness. Markets and some network structures lack a centralized command. Agenda-setting capacity is weak in these groups and the organization may lack a clear point of origin for agenda-setting 
(Heger et al., 2008). Horizontally organized (decentralized) groups are prone to losing sight of the agenda and working toward a clear goal. Furthermore, since these groups lack centralized command, their constituent cells may diverge from the groups stated goals. Indeed as a group moves along a scale from centralized to decentralized (from vertical to horizontal) it approaches a market environment where transaction costs become higher but membership is more open. Thus, while a market-type organization has low standards for membership, adaptability is high and coordination is sparse.

Gerlach provides further precision to the network concept when he examines several social movements and finds that the most common type of organization is neither centralized and bureaucratic nor amorphous and market-based, but rather are segmentary, polycentric and integrated networks, or SPIN (Gerlach, 2001). These SPIN groups are segmentary in that they are composed of many diverse units. They are polycentric because they have multiple, often temporary, and sometimes competing leaders or centres of influence. They are networked because they form a loosely integrated network with multiple linkages and shared ideals (Gerlach, 2001; Gerlach and Hine, 1970, 1973).

Another important contribution to this field is Keck and Sikkink's work on transnational advocacy networks, or TANs (Keck and Sikkink, 1998). ${ }^{6}$ This is an important

\footnotetext{
${ }^{6}$ The field of social network analysis (SNA) also shows great promise for understanding terrorist groups. SNA emphasizes the social relations that exist outside and beyond any formal structural features of an organization. In a way this allows a different story to be told, in some cases familial or clan ties can be stronger than any hierarchical positions within an organization. Unfortunately, social network analysis is limited to the quality of the information that can be collected. With clandestine, illegal groups it is extremely difficult to obtain reliable information until well after the group has ended. Even then, obtaining good data can prove impossible. In my view, this type
} 
work because unlike organizational theory from economics, which argues that groups are driven by efficiency and profit, Keck and Sikkink's advocacy networks are motivated by values. This feature is especially attractive for its application to terrorist groups because, usually, terrorist groups are motivated by politics, not by profits. Asal et al. (2007) argue in favour of comparing TANs to terror TANs and observe that terrorist groups are more like not-for-profit organizations than businesses.

In another important work, Lichbach (1995) tackles the problem of collective action in dissident and rebel groups. This work asks what appeal is most effective in getting people to contribute to a public good: dissident organizations. Lichbach's rebel's dilemma looks at dissidents:

That wish to upset an existing social order... [they] seek a public good of capturing the state or forcing the existing authorities to redress their grievances. Rational dissidents will not voluntarily contribute to this public good. Unless free riding is overcome, however, the rebels are in a prisoner's dilemma (Lichbach, 1995, p. xii).

Lichbach's view is interesting in that it applies rational actor theories to the particular case of rebellion - not dissimilar to terrorism in many ways. He describes how social order in a dissident group is possible through various possibilities. Market approaches to collective action are unplanned and spontaneous. Community approaches assume that institutions exist and are effective enough that social planning is not needed. of investigation is best left to intelligence analysts who, presumably, have better, richer data. See Sageman (2004, 2008), Krebs (2002), Pedazhur and Perliger (2006) and Ressler (2006). 
Contract approaches to collective action assume individuals plan their society. Finally, a hierarchy approach assumes that a preexisting institution coerces members to contribute to the public good (Lichbach, 1995, p. 21). The theories posited by Lichbach describe how rebel groups are kept from power due to the collective action problem while regimes "know that they stay in power as a result (emphasis added) of their opponents collective action problem" (Lichbach, 1995, p. 22).

The categories proposed by Lichbach (market, community, contract and hierarchy) are similar in several general ways to the organizational structures laid out here. First, both describe mechanisms of how a dissident group functions and interacts with its members and supporters. Second, both Lichbach and the structures derived from (Arquilla et al., 1999) (used here) place an emphasis on how leadership, or lack thereof, facilitates action within a group. For Lichbach, a group often takes action through, and as a result of, existing institutions that overcome the collective action problem inherent in social groups. The collective action question explored by Lichbach is an important mechanism in explaining why some groups become effective dissidents while others do not. In particular Lichbach's work highlights a potential source of inefficiency in some structures; some structures have better mechanisms in place to overcome the free-riding problem. However, the focus of my study is on groups that have already formed and have already demonstrated the ability to mount at least ten attacks. (Lichbach, 1995) is concerned more with how a group gets to the point of using violence while I am more concerned with groups that have already 
reached that point.

As discussed above, there exists a large and active literature of the study of group structure in the fields of sociology, economics and business. In spite of the obvious difference that terror groups use violence while legal groups do not, some commonalities do exist. Little work has been done on developing theory to help explain terrorist group structures. Arquilla et al. (1999) develop a typology of structures and this is the model I employ below. In the next section I build on previous theories of structure and argue that terrorist groups, as illegal and clandestine organizations present unique challenges for assessing structure.

\subsubsection{Previous research on terrorist group structure}

Far from being a theoretical irrelevancy, the issue of terrorist organizational structure is intimately linked to the issue of strategy and ultimately, success (DeNardo, 1985, p. 144). A centralized structure such as a bureaucracy can form specialized units, thereby increasing its effectiveness, but it is often rigid and slow to adapt. Since it has a centralized decision-making structure, it is also susceptible to leadership decapitation (Mannes, 2008). ${ }^{7}$ A networked terrorist group, on the other hand, has a more flexible, informal structure, often with multiple and ever-shifting decision-making locations that make it adaptable to new challenges. By not having centralization, however, illegal networked groups tend to be less efficient for certain tasks and more

\footnotetext{
${ }^{7}$ This assumption is tested in Chapter 3.
} 
difficult to control (Baker and Faulkner, 1993).

Beyond serving as an enabling tool for violent extremism as discussed above, the affiliations between group members becomes routinized and crucial to the functioning and activities of the organization. The ties between members of a group strengthen and shape attitudes (Granovetter, 1973). In a terrorist group this process serves to isolate group members from outside - and potentially moderating influences (Allison, 1971; Janis, 1972; Gupta, 2008; Horgan and Braddock, 2010).

At some point - with increased support and popularity - a group may need to grow beyond its initial size. This growth will have consequences on the activities of the group since there is a limit to the span of control any organization may have (Urwick, 1922).

Mayntz argues that while hierarchy, organization and networks are crucial categories in the terrorism literature, they do not form one single cohesive analytical dimension (Mayntz, 2004, p. 8). To the political scientist, he argues, the primary feature of networks is that they are not hierarchies. To the sociologist, the crucial feature is the differences between formal organizations and networks. According to organization theory, formal organizations (such as a hierarchical group) are "clearly bounded, and internally differentiated both in a horizontal (functional) and a vertical (differential distribution of rights and duties) direction" (Mayntz, 2004, p. 8).

Mayntz also provides some good guidelines of structural features which he argues are found in the typical terrorist group. First, a typical terrorist group has a clearly 
defined leadership. ${ }^{8}$ Second, it is differentiated both vertically and functionally. In other words there are specialized units under the leadership level and these specialized units can take the shape of a military, political and/or support branch, among others. Finally, vertical communication is the most common type of communication in Maytz's typical group (Mayntz, 2004, p. 12). As I argue below, this generalization of terrorist groups does not hold up to scrutiny, I argue that there are indeed a variety of terrorist group structures, and that these typologies each show varied, predictable behaviour.

One difficulty in identifying terrorist group structures is that rarely, if ever, is an idealized vertical or flat organization observed. Rather groups have features of both types of groups. One study argues that the point that distinguishes vertical from flat organizations is when:

Cells start to look like organizations that, when summed, do not add up to one unitary actor, but rather a collection of different veto-points that replicate similar actions (Heger et al., 2008, p. 8).

A strong charismatic leader can also drive a group's organizational design. These groups are often highly dependent on her or him to provide motivation and justification for attacks. These groups, argues Mannes, are therefore greatly influenced by the loss of their leader (Mannes, 2008).

\footnotetext{
${ }^{8}$ As described below, I find that some groups studied violate this basic rule and opt of a virtually leaderless collective. While relatively rare, market-type structures do occur.
} 
Prior to the attacks on the United States in 2001, little research focused on what Raab and Milward (2003) call "dark networks". They argue that central to any claims for a new terrorism since 2001, is the ethereal quality of the organization of some terrorist groups (Raab and Milward, 2003). If this is true - that post-2001 there is a new terrorism made up of new, ethereal groups - then there should be a study to confirm or refute this hypothesis. Regrettably, while Al Qaeda has received a lot of attention, there exists few case studies of terrorist group organizational structures; fewer still are studies which evaluate the available evidence in a systematic way.

Arquilla and Ronfeldt (2001) have done, by far, the most research in the field of organizational structures as they pertain to political violence. They develop a theory envisioning the future of conflict, they call it netwar:

An archetypal netwar actor consists of a web (or network) of dispersed, interconnected "nodes (or activity centres) - this is its key defining characteristic. It may resemble the bounded "all-channel" type of network. These nodes may be individuals, groups, formal or informal organizations, or parts of groups or organizations. The nodes may be large or small in size, tightly or loosely coupled, and inclusive or exclusive in membership. They may be segmentary or specialized; that is, they may look quite alike and engage in similar activities, or they may undertake a division of labor based on specialization. The boundaries of the network may be sharply defined or blurred in relation to the outside environment (Arquilla and 
Ronfeldt, 2001, p. 279).

Arquilla and Rondfelt also put forward a coordinated view of other organizational structures and their effects on groups that use low-intensity conflict (Arquilla and Ronfeldt, 1996, p. 274). Their network, netwars theory is based on two main assumptions. First is that the importance of technology will increasingly be felt in conflicts. In other words, their use of the terms cyberwar and netwar indicate types of conflict that are about knowledge:

about who knows what, when, where, and why, and about how secure a society, military, or other actor is regarding its knowledge of itself and its adversaries. (Arquilla and Ronfeldt, 1996, p. 275-6).

The second assumption is that the information revolution favours networked (or flattened) forms of organization and makes operating a hierarchical organization more difficult. This research would therefore suggest that over time, along with the information revolution, would come terrorist groups opting for an increasingly networked organizational structure. Conversely, those groups which operated in the 1970s and 1980s (and earlier) would be less networked and more hierarchical because they did not have access to this technology. ${ }^{9}$

Kenney employes a similar typology in his study comparing narcotics networks and terrorist groups (Kenney, 2003, 2007). Kenney (2003) details the similarities between

\footnotetext{
${ }^{9}$ This assertion is refuted in the current study, but the structure categories hold much analytic promise and are similar to those put forward by organizational sociologists.
} 
terrorist groups and narcotics networks. In particular, he describes wheel networks which are similar to the hub and spoke structure used here - as having clear leadership and functional differentiation (Kenney, 2003, p. 188).

\subsection{Dataset and methodology}

Data for this research is from the Global Terrorism Database (GTD) a repository of more than eighty-thousand terrorist incidents since 1970. This dataset was originally compiled by the Pinkerton Global Intelligence Services (PGIS). PGIS researchers from 1970 to 1997 identified and recorded terrorism incidents from wire services, government reports, and major international newspapers for the purposes of assessing the risk of terrorism for their clients. ${ }^{10}$ In 2006, the PGIS was transferred to the National Consortium for the Study of Terrorism and Responses to Terrorism (START) at the University of Maryland and the dataset was updated until $2007 .{ }^{11}$ This dataset continues to be maintained by START and it provides yearly updates to the dataset. It is open-source and includes both international and domestic terrorism events. ${ }^{12}$

Many of the terror incidents in the GTD are, unfortunately, logged as attacks where the perpetrator is unknown. Since I am interested in the behaviour of particular group structures, those incidents where the perpetrator is unknown have been eliminated

\footnotetext{
${ }^{10}$ During an office move, Pinkerton lost the data for much of 1993 and this was never recovered.

${ }^{11}$ It has subsequently been updated to 2008 and annual updates are planned.

${ }^{12}$ This is one feature that makes the GTD preferable to other open-source datasets such as the RAND Database of Worldwide Terrorism Incidents which counts only international terrorism incidents.
} 
from the study. For incidents where the perpetrator of the attack was identified, a threshold of ten or more attacks was established. Groups above this threshold demonstrate a particular level of organizational effectiveness much greater than groups with only a few attacks. This selection criteria left approximately 350 groups remaining. Of these groups, through extensive research and verifying, initial coding errors were corrected. These errors - such as multiple spellings of the same group or the same group given two names ${ }^{13}$ - further reduced the number of groups in the sample size to 254 .

\subsubsection{Methods of coding for structure}

Following the selection criteria detailed above, terrorist groups were coded for organizational structure. This coding was done by examining government databases on terrorism, news archives, Jane's World Insurgency and Terrorism, and the Terrorist Organization Profile (TOPs) dataset maintained by the University of Maryland. Whenever possible, prior to making a coding decision pertaining to organizational structure, information was verified by a secondary and tertiary source.

Unfortunately, it remains an ever-present challenge when conducting research on terrorist groups that information can often be contradictory or missing. While a rigorous coding methodology is used, in cases where ambiguity exists, the researcher ultimately

\footnotetext{
${ }^{13}$ For example, Lashkar-e-Taiba, an active Pakistani group, has been known to operate under the alias AI Mansoorian. The original GTD coding had these as separate groups, when they are, in fact, the same group.
} 
makes a coding judgement. In several cases, particularly those groups which have persisted for many years, the organizational structure of a group has changed over time. Whenever possible I code the structure of a group dynamically over time.

For many other groups information about leadership and structure is sparse and it is difficult to assess if or when a group changed from one structure to another. I addressed this matter in two ways. First, whenever possible information was verified with corroborating sources. Second, when it was possible to code a group's change in structure, this was done but only when it was quite clear when and to what extent this change occured. ${ }^{14}$

The remaining groups were coded for several structural characteristics: leadership type, command and control, and functional differentiation as shown in Table 1. For a group to be coded as having 'leadership' it is required that it show a clear leader or leadership structure. This could include a leadership council, but where there was no evidence for a leader, the group was coded as 'no leader'; if there was no available information, it was coded as missing. For centralized command and control, evidence is required to show that the group coordinates its actions (violence, communication and/or politics) from a central executive. For a group to be coded as having functional differentiation it is required to have at least one clearly separate department or cell that is dedicated to a specialized function such as a political wing, a bomb-making centre or a communications department. When there was insufficient evidence for a

\footnotetext{
${ }^{14}$ There are 31 groups identified with changes in structure. The empirical models in Chapters 3 and 4 take full advantage of this coding parameter as do the two case studies.
} 


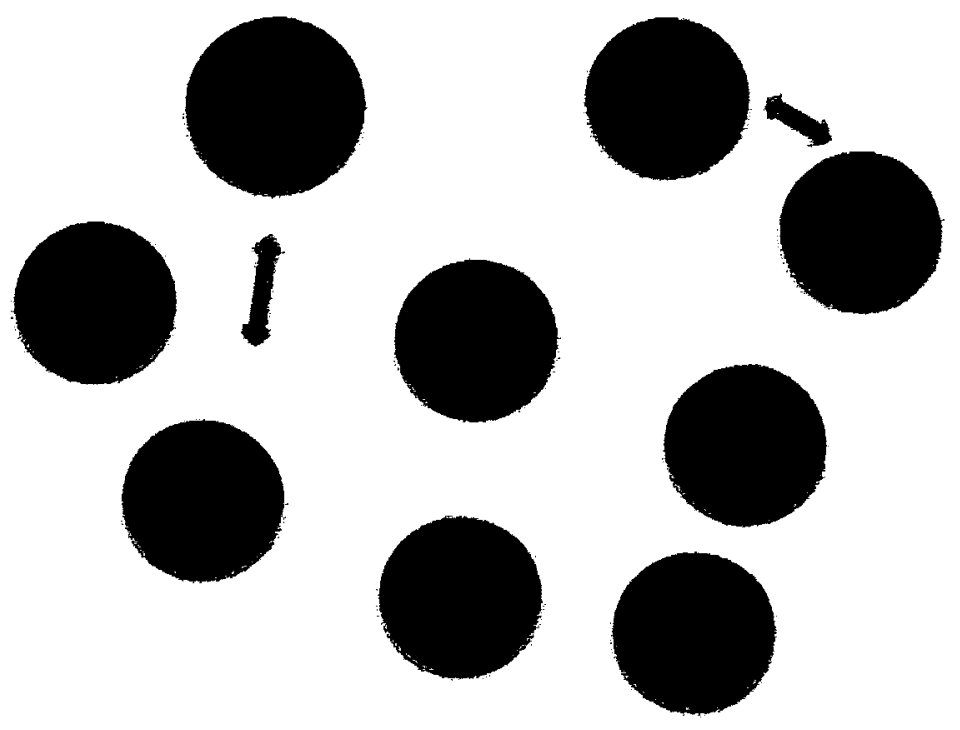

Figure 1: Market Structure

determination, it was coded as indeterminate.

Four clear patterns in the results emerge from this coding and these patterns make up the four structures used in the current study.

A market structure is a group that has a very loose organization. It has no discernible leadership, is not centrally controlled, and has a low level of functional differentiation. These group types are almost more of a movement than they are a typical organization. However, these type of terrorist groups do exist and are characterized by a diverse and decentalized group of individuals sharing little more than common cause and committing acts of violence under the aegis of a particular group. An example of a market structure terrorist group is the Earth Liberation Front (ELF). Under the ELF banner "distributed cells of environmental activists claim acts of sabotage, vandalism, and eco- terrorism" (Jane's, 2009a). 


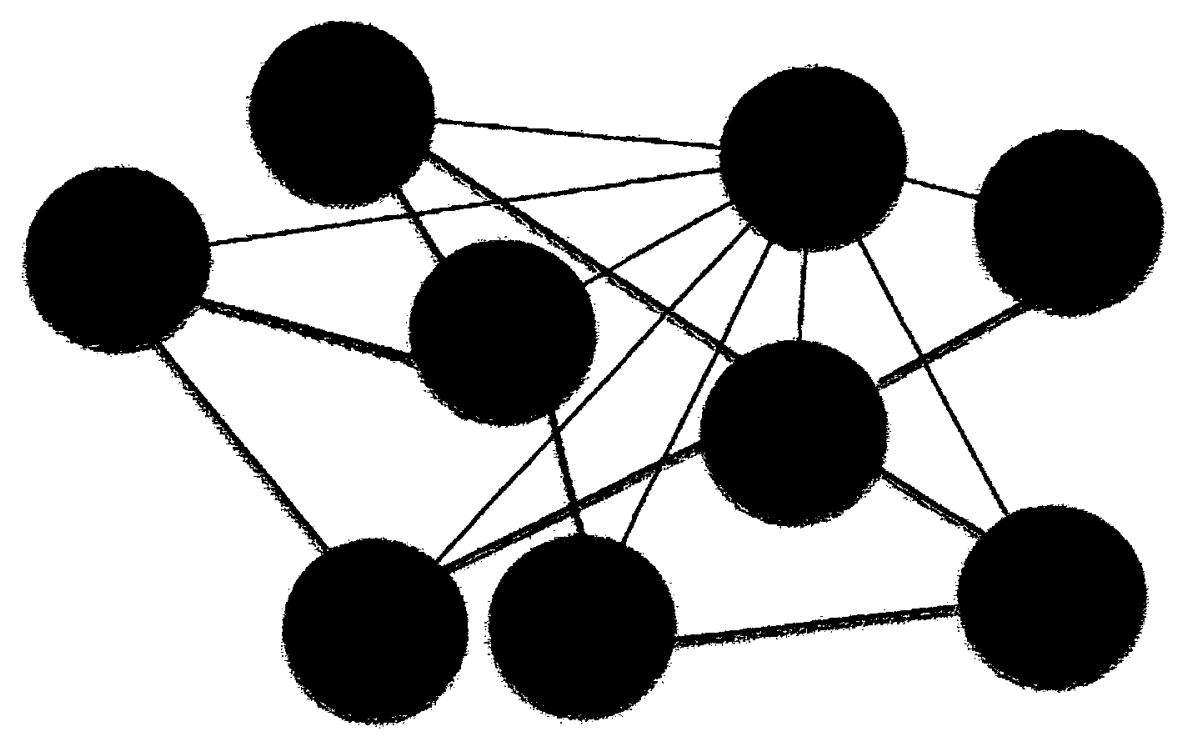

Figure 2: All-Channel Structure

An all-channel network requires "rapid, dense, multidirectional communications to function well and endure" (Arquilla and Ronfeldt, 1996, p. 287). It is for this reason that all-channel networks require the most multidirectional communication. However, with the advent of new technologies such as advanced communications (email, mobile phone, satellite phone and data) this multidirectional communication is more easily achieved. In contrast with the past, diverse and dispersed actors can regularly and easily coordinate and take action across great distances where previously this was not possible. As Arquilla and Ronfeldt (2001) posit, the rise of the network form and in particular, the all-channel network - is tied with the information revolution. All-channel networks do have a leader, but there is little hierarchy, no central control or functional differentiation in these groups. An example of an all-channel network is the Abu Sayyaf Group (ASG). ASG operates in small cells of four or five people. The leadership is loosely coordinated and hydra-headed. 


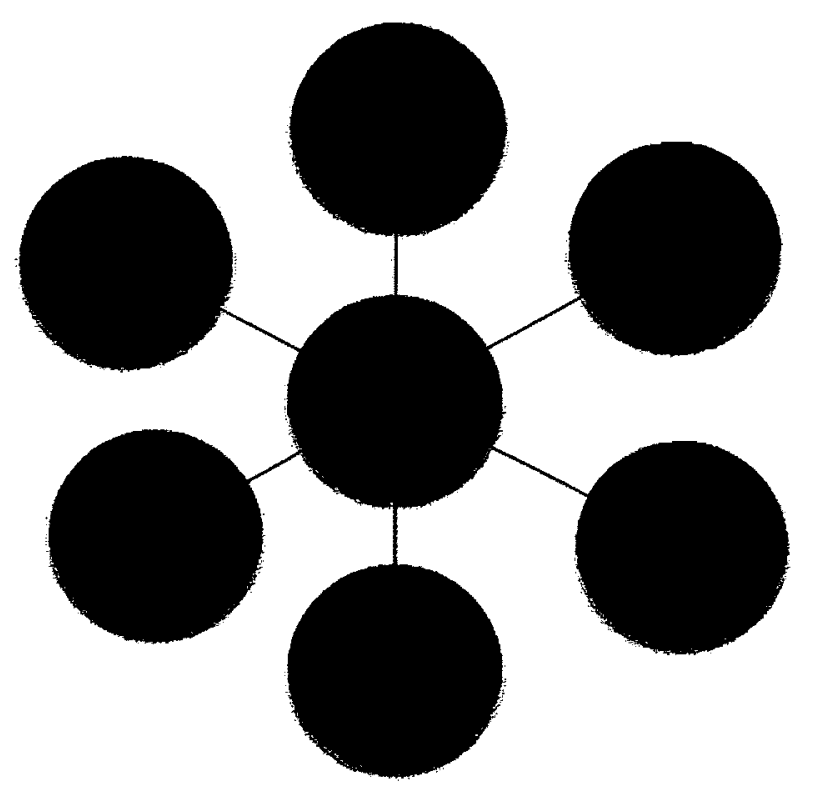

Figure 3: Hub-Spoke Structure

The hub and spoke network as in a franchise or a cartel where a set of actors are "tied to a central (but not hierarchical) node or actor, and must go through that node to communicate and coordinate with each other" (Arquilla and Ronfeldt, 2001, p. 7). These types of groups have a leader and employ functional differentiation but they are not centrally controlled. Rather, the nodes of this group have more individual autonomy to plan and carry-out attacks. An example of a hub and spoke network is pre-2001 Al Qaeda.

A bureaucratic structure is the most hierarchical of all the structures. These groups have clearly defined leadership, multiple levels of management, functional differentiation and specialization and the whole organization is centrally controlled. An example of this type of group is Hezbollah. The command structure is dense, elaborate and centrally controlled (Ranstorp, 1994). Like other large organizations Hezbollah has 


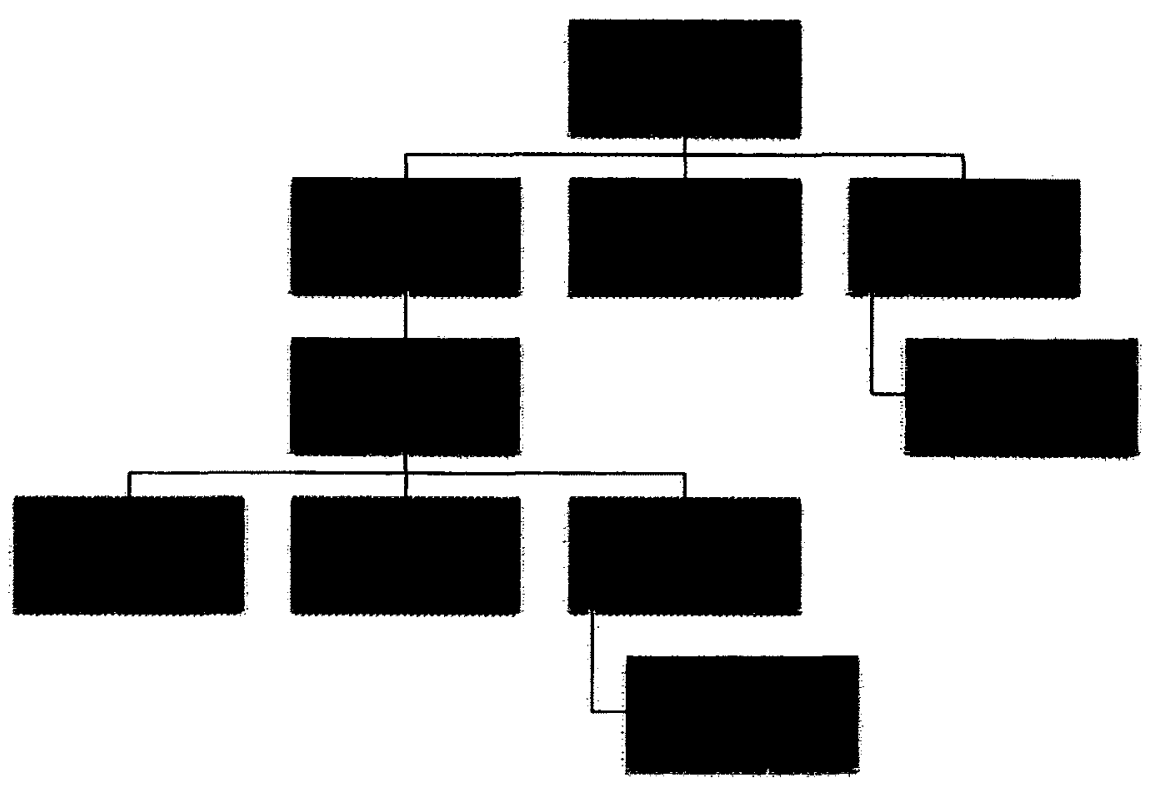

Figure 4: Bureaucratic Structure

separate departments, each with its own specialization.

On a continuum of centralization these four structures can be described as follows. A market structure is the most decentralized and loosely organized group type. The allchannel groups are, after market structure, the most decentralized. They differ from a market structure in that they possess some type of leadership but the group is not centrally controlled nor does it have different parts serving specialized functions. The hub-and-spoke groups have a leader but the group is not centrally controlled. It does exhibit functional differentiation such as forming a political wing or a communications wing. The most centralized and hierarchical structure is the bureaucratic type. It has clearly defined leadership that centrally controls the group and the organization exhibits specialized functions. 
Table 1: Coding for Structure

\begin{tabular}{lccc}
\hline Structure & Leadership? & Func. Differentiation? & Central Command? \\
\hline Market (1) & X & X & X \\
All-channel (2) & $\checkmark$ & X & X \\
Hub/Spoke (3) & $\checkmark$ & $\checkmark$ & X \\
Bureaucracy (4) & $\checkmark$ & $\checkmark$ & $\checkmark$ \\
\hline
\end{tabular}

Table 2: Sample Terrorist Group Structures

\begin{tabular}{ll}
\hline Structure & Notable Historical Examples \\
\hline \multirow{3}{*}{ Market } & Action Directe \\
& Animal Liberation Front (ALF) \\
& Earth Liberation Front (ELF) \\
& Real Irish Republican Army (RIRA) \\
All-Channel & Abu Hafs al-Masri Brigades \\
& Al-Qaeda (post 9/11) \\
& Kach \\
& Muslim Brotherhood \\
& Red Army Faction (Baader-Meinhof Group) \\
& Weather Underground \\
& Al-Qaeda (pre 9/11) \\
& Basque Fatherland and Freedom (ETA) \\
& Hamas (Islamic Resistance Movement) \\
& Popular Front for the Liberation of Palestine (PFLP) \\
& Sendero Luminoso (Shining Path) \\
& Zapatista National Liberation Army (EZLN) \\
& African National Congress (ANC) \\
& Armed Islamic Group (GIA) \\
& Hezbollah \\
Irish Republican Army (IRA) \\
Lord's Resistance Army (LRA) \\
Moro National Liberation Front (MILF) \\
Tupamaros
\end{tabular}

\footnotetext{
${ }^{a}$ These are illustrative examples, not a comprehensive list.
} 


\subsubsection{Other coding parameters}

In addition to the above coding for organizational structure, I also coded several other variables that provide further context to each terrorist group in the sample. The basic methodology is the same as coding for structure, a general search for sources was done. For each group included in the study there is a minimum of three or four sources that I found. For some groups, there is ample analysis and media coverage available. For others a more exhaustive search was required. This included examining declassified intelligence documents from the National Security Archive at George Washington University or, where possible, examining primary source documents and websites of the groups themselves (GWU, 2011). Obviously, each source needs to be evaluated for its accuracy. This is the job of the researcher. The other variables coded are detailed below.

Evidence of alliances or cooperation with other groups are recorded for each organization. Using basic social network analysis tools, this data can serve as a basic building block of mapping out the global connections between terrorist groups. ${ }^{15}$ Evidence of state sponsorship of the terrorist group are coded as a dummy variable. If there is evidence of a group having a cell structure where the cells are deliberately separate as a security measure, these groups are coded for a dummy variable of cell structure. Also, if there is evidence a group organizes along regional (geographic) divisions, it is also coded in a dummy variable. While some groups operate in one state and only attack targets in that same state, others attack targets beyond its home state and a dummy variable are coded along these parameters as well. ${ }^{16}$

\footnotetext{
${ }^{15}$ While a promising area of investigation, this data remains, as yet, unused. Future research in this area is needed as there has been little systematic work in the field of terrorist group cooperation. The few exceptions include Sageman (2004) and Krebs (2002) although both of these studies only look at Al Qaeda networks.

${ }^{16}$ In certain border situations such as Palestinian Territories and Israel both are considered to be 'local' attacks.
} 
Finally, to provide information on the political and socio-economic environment in which groups operate, I include data from Polity IV, Freedom House, the World Bank and the Penn World Tables (Marshall et al., 2003; House, 2009; World Bank, 2009; Heston et al., 2006). This includes all the component variables that make up Polity IV and Freedom House. Variables for the World Bank include population data economic indicators such as technology penetration and conflict data such as civil conflict casualties. All of the Penn World Table variables are also included.

Moreover, in order to have the flexibility of testing variables on either the group's home country or the country in which attacks occur, all of the Polity IV, Freedom House, World Bank and Penn World table data were included for each case. Therefore, contained in the incident dataset, there is the political and economic data contained within all of these sources for each attack twice; first the data is included for the state where the attack takes place, second, the data is included for the terrorist group's home state. The result of this work is that on top of the variables from the GTD, the dataset employed in this study has an additional 300 variables for each terrorist attack.

With the coding and verification complete, data was compiled into three databases: organized by group, with attack features and information summed on a yearly basis, organized by group over its lifetime, and organized by individual attack. The dataset I use here, with the addition of the aforementioned coding is quite large. There over 80,000 incidents from the GTD; with the extra coding work detailed above, my dataset has more than 45 million data points. ${ }^{17}$

\footnotetext{
${ }^{17}$ An independent variable (IV) - dependent variable (DV) problem arises here; in Chapter 2 the IV is organizational structure while in Chapters 3 and 4 structure is used as a DV. There is a general problem when estimating IV/DV's interchangeably. In some cases it might be more efficient and consistent to estimate such equations jointly. Moreover, a specification problem arises if in one equation where the the DV is $\mathrm{Y}$ and is regressed on $\mathrm{X}$ the IV and in another equation if $\mathrm{X}$ is regressed on $Y$. However, this is not the case here. In Chapter 2, organizational structure is the DV
} 


\subsubsection{Looking ahead}

In this chapter I reviewed the relevant and important previous work within the literature. As this is an inter-disciplinary study, the literature review required a somewhat wide-ranging discussion of structure, terrorist groups, and criminal networks, among others. I also detail the coding methodology and basic dataset information above. This provides the reader with a better understanding of where this study comes from and where it is going.

With the foundation built for this study, Chapter 2 examines the determinants of structure.

and all IV's are limited to the first year of the group only, as proxies for initial group objectives. So while the IV/DV can pose a problem in theory, it is not the case in this project. 


\section{Chapter 2}

\section{Explaining Terrorist Group Structures}

\subsection{Introduction and Motivation}

In this chapter, I explore the internal and external factors that affect a group's structure. A first attempt at building a model for understanding the forces that shape a group's structure is detailed below.

\subsubsection{Operating in secrecy}

Like any illegal organization, terrorist groups require secrecy to survive. This places challenges and constraints on how the group can communicate and conduct its business. Secrecy reduces efficiency and reconfigures the overall goals of an organization by dictating what the group can, and cannot do, in order to ensure its secrecy. Simmel (1906) argues that for secret groups where risk exists - such as terrorist groups - the abiding interest is on trust, not efficiency. The higher the risk to a group's members, 
the more valued trust becomes (Simmel, 1906, p. 440-1). Therefore, in the terrorism environment, the more effective the counter-terror efforts, the more discerning a terrorist group will be in terms of recruiting new members. Erickson (1981), using Simmel's theories, investigates six cases of varying organizational complexity and concludes that for groups facing risk, recruitment proceeds along lines of trust which, in turn, sets the limits of the secret society. From this analysis it can be inferred that, based on recruiting practices, groups in a strong counter-terror environment will be smaller than those in a weak counter-terror environment.

Baker and Faulkner (1993) examine the organizational structures of illegal networks in a case study of price-fixing in the heavy electrical equipment industry. Like Simmel before they find that, for groups operating outside of the law, group structure is driven primarily by the need to maximize concealment (to mitigate risk) at the expense of maximizing efficiency. This claim is supported by organizational theorists who argue that for small groups, ceteris paribus, high information-processing requirements within a group are best met by decentralized organizations while low information-processing (such as simple and routine tasks) are performed more efficiently in centralized structures (Baker and Faulkner, 1993; Goffman, 1969; Shapiro, 1987; Collins and Preston, 1969). ${ }^{1}$

\footnotetext{
${ }^{1}$ Unlike the research by Coase, Powell and others, Baker and Faulkner's work applies only to small groups.
} 
Baker and Faulkner study three secret price-fixing conspiracies, each one with different information-processing requirements. If maximizing efficiency was the overriding imperative, one would expect to observe decentralized organizations for high information-processing groups and hierarchical organizations for low informationprocessing groups. In fact, what they observe is that each group had the same "sparse, decentralized network," suggesting that these illegal groups place more emphasis on clandestinity and security than on efficiency (Baker and Faulkner, 1993, p. 844). Interpreting this conclusion more broadly suggests that any illegal group, for it to be successful and elude authorities, must adopt a structure that is best suited to its operational requirements as well as the external security environment in which it operates.

Further to this observation, Drake (1998b) points out that the pressures within a small group involved in terrorism varies based on the level of clandestinity they must invoke in order to evade capture. In this way, introspection is less necessary in groups such as Hezbollah who are able to operate overtly in relatively safe-havens in the southern Bekaa Valley of Lebanon (Drake, 1998b). For groups that operate in states where the degree and extent of state surveillance is high - such as the Red Army Faction in West Germany or the Red Brigades in Italy - their members live clandestine, isolated lives (Drake, 1998b).

Taking these different views into account, two conclusions emerge. First, terrorist groups, while still subject to the forces acting on any type of organization, exist as 
a small subset of groups. They are distinguished by an imperative for security over efficiency. Second, the clandestine nature of some terrorist groups compared to the more overt nature of others is likely due to permissive conditions in the group's home country.

\subsubsection{Forces acting on terrorist groups}

Two sets of forces are at play in shaping a terrorist group: agency and context. Agency is the set of forces that arise from the choices a group makes while planning and executing attacks; these forces can also be called internal factors. Context refers to the set of forces that act upon the group that are beyond its control; these are external factors that describe the environment in which the group operates. How a group deals with both sets of factors will dictate its ability to survive and prosper. This process, in turn, shapes the way the group itself is organized. For example, why a group selects one target over another involves a myriad of structural, personnel and operational factors. The choice of targets informs the observer about who the groups are trying to influence and also who they may seek retribution from; groups that exclusively target business establishments, yet ignore all apparatus of government, indicates a particular focus. Perhaps the group seeks economic revolution and attacking industry is the best way to achieve this goal. Indeed, agency - or internal factors - is at play in many ways, all of which, I posit, have a real and measurable affect on the character 
and behaviour of the organization. ${ }^{2}$

Not only do terrorist groups have agency over their target choices and types of attack for ideological reasons, but they are also constrained by the structure of the counterterrorism environment. Terrorist groups are shaped by the character and capacity of the society and government of the state in which they operate. Groups must therefore successfully cope with the security, communication and environmental challenges they face if they are to succeed.

Beyond targeting, the relative effectiveness of the state in which a group operates will have a profound affect on the structure and functioning of the group. Weak states with poor counter-terrorism capacity will enable a more rigid, organized terror structure to form because terrorist groups feel less threatened. Conversely, strong states with a robust counter-terror policy will produce decentralized terrorist groups.

\subsubsection{Testing Hypotheses in the literature}

Sageman's work in social network analysis of the Al Qaeda network was pathbreaking when it was published (Sageman, 2004). In particular, Sageman distinguishes between 'traditional' hierarchical groups and networked groups. He argues that unlike a hierarchical network, small world networks (his term) resist fragmentation because of their dense interconnectedness. It is precisely the multiple connections between the cells within a network that enable this robustness. Sageman posits that in a networked

\footnotetext{
${ }^{2}$ The affect of structure on targeting is examined in greater detail in Chapter 3.
} 
environment under stress from government counter-terror efforts, when "enough hubs are destroyed, large-scale attacks would be reduced to small attacks by singletons" (Sageman, 2004, p. 141).

In order to test this assertion, one would first need to look at how Sageman's research lines up with this study. In terms of networks, Sageman describes Al Qaeda as a small world network which has distinct properties and behaviours. Small world networks are:

...composed of nodes linked to well-connected hubs. Hubs receive the most communications from the more isolated nodes. Because of their larger numbers, innovations are more likely in nodes. The nodes link to hubs who, in turn, send the information along their numerous other links (Sageman, 2004, p. 164).

This most closely corresponds to an all-channel structure in the current research. ${ }^{3}$ Sageman's assertion could be more broadly interpreted as follows: those all-channel groups which find themselves in a harsh counter-terrorism environment would be reduced to more sporadic, lower casualty attacks that are not coordinated.

According to Della Porta (1995, p. 198), the process of radicalization in both Germany and Italy is more widespread when certain environmental factors are available. These environmental factors include the ability for groups to assemble, openly recruit new members, distribute propaganda and generally operate openly. Therefore, in an

\footnotetext{
${ }^{3} \mathrm{Al}$ Qaeda is coded as hub-spoke until late 2001 when it changes its structure to all-channel.
} 
environment with strong counter-terrorism, the path to violence may have something to do with the robustness of counter-terrorism efforts and state strength. Della Porta (1995) also states that the more open and transparent a terrorist group is, the more short-lived it is. While it may achieve early success and attention from its openness, in the end, state power will shorten the group's lifespan.

While there is some disagreement in the literature detailed above, a story begins to emerge of how certain factors shape a terrorist group's structure. On the one hand, a strong counter-terrorism environment will result in decentralized groups. On the other hand centralized groups have clear lines of communication and centralized command and control that make them susceptible to disruption by a capable government; they will be found in low capacity counter-terror environments. Moreover, bureaucratic groups - and to a lesser extent, hub-spoke groups - will be able to maintain a higher operational tempo, especially in its first year of operation than decentralized groups. ${ }^{4}$ In states with low political rights and civil liberties on structure, measured here by Freedom House, terrorist groups are expected to be more highly centralized. In low freedom states, political opposition will have very little recourse in the public sphere. Consequently, it is expected that there will be greater support for terrorist activity than in a state with more political freedoms.

\footnotetext{
${ }^{4}$ To eliminate problems of endogeniety, I focus only on the group's first year.
} 


\subsection{Description of Data and Sample}

The data for terrorist group activity in this study comes from the Global Terrorism Database (GTD) maintained by the University of Maryland. This database contains both transnational and domestic-focused terrorism incidents which are of particular relevance when considering structure as it allows for comparison between the two.

This dataset is appropriate because it is incident-based and therefore provides the flexibility of examining the change of a group's attack profile over time. For this chapter the original incident-based GTD is aggregated into a one-row-per-group dataset. This format allows comparisons between groups for such variables as number (and target) of attacks, regime type and group goals, among others.

The dependent variable, structure, is coded using the Global Terrorism Database (GTD). For incidents where the perpetrator of the attack was identified, a threshold of ten or more attacks was established. Groups above this threshold demonstrate a particular level of organizational effectiveness much greater than groups with only a few attacks. As detailed in Chapter 1, groups above this threshold are coded for one of four structures: market, all-channel, hub-spoke and bureaucratic.

In order to empirically assess the links between structure and terrorist groups, a multinominal logistic regression is performed. To ascertain if there is evidence to support the ordering of organizational structure in terms of centralization, an ordered 
probit is performed. 254 groups are studied for the period between 1970 and $2007 .{ }^{5}$

A summary of the variables used in the model are found below in Table 3.

\subsubsection{External Factors}

This study examines four independent variables that are used to measure the external forces acting on a terrorist group's structure. If the state in which a group decides to locate - or the state in which their attacks occur - mounts an effective counter-terror campaign against the group, it will have a limiting affecton the success of the group; it will also shape that group's structure.

Since there is no existing time-series database that assesses a state's counter-terror effectiveness - or even its level of spending, gross domestic product (GDP) per capita is used as a proxy. ${ }^{6}$ In countries which have a high GDP per capita, there are more resources available to dedicate to counter-terror should the need arise. In this way, GDP per capita is a lagged indicator of counter-terror capacity. For example, if there is a terror campaign in year $x$, the state will devote more resources to counterterror for year $x+1$. Wealthy states will therefore be able to devote more resources

\footnotetext{
${ }^{5}$ These are chosen since they are the most prolific groups identified in the GTD.

${ }^{6}$ This is an area for potential future work. At present it remains difficult, or even impossible, to accurately compare counter-terrorism capacity between states. Data exists for most states measuring percentage of GDP devoted to military spending but this is simply too broad. Some, such as Piazza (2008), have used a repression capacity index which uses the total number of armed forces multiplied by the total military budget divided by the population of the state. This measure, of course, leaves out the crucial counter-terror components of intelligence and policing. In addition, the resources actually devoted to counter-terrorism will reflect the absence or presence of terrorist activity, creating a problem of endogeniety. States with no previous problem of terrorism will not devote any resources towards suppressing it. However, by using GDP per capita as a lagged measure of counter-terror effectiveness, this overcomes the problem of endogeniety.
} 
Table 3: Variables, operationalization and sources

\begin{tabular}{|c|c|c|}
\hline Variable & Operationalization & Source \\
\hline Structure* & $\begin{array}{l}\text { Each group is coded based on leadership, com- } \\
\text { mand and control and functional differentia- } \\
\text { tion of group }\end{array}$ & Coded for the current study by the author \\
\hline State sponsor & $\begin{array}{l}\text { Dummy variable coded if group enjoys spon- } \\
\text { sorship (financial, capability, weapons or safe- } \\
\text { haven) from a state }\end{array}$ & Ibid. \\
\hline GDP per capita & $\begin{array}{l}\text { Chain series data for year terrorist group is } \\
\text { believed to have begun }\end{array}$ & $\begin{array}{l}\text { Summers R. et. al. Penn world table version } \\
6.3 \text {, Center for International Comparisons of } \\
\text { Production, Income and Prices at the Univer- } \\
\text { sity of Pennsylvania, August } 2009\end{array}$ \\
\hline Freedom House & $\begin{array}{l}\text { Average of political rights ('PR') and civil lib- } \\
\text { erties ('CL') indices for terrorist group home } \\
\text { country in the year they began }\end{array}$ & $\begin{array}{l}\text { Freedom House. 2004. Annual Freedom in the } \\
\text { World Country Scores }\end{array}$ \\
\hline Polity Durability & $\begin{array}{l}\text { Number of years since last change in polity, } \\
\text { scored from regimes's inception }\end{array}$ & $\begin{array}{l}\text { Marshall, M. G. and Jaggers, K. } 2004 . \\
\text { POLITY IV Project: Political Regime Char- } \\
\text { acteristics and Transitions }\end{array}$ \\
\hline $\begin{array}{l}\text { \% Attacks on Hard } \\
\text { Targets }\end{array}$ & $\begin{array}{l}\text { Attacks on police and military targets in } \\
\text { group's first year as a \% of total attacks }\end{array}$ & $\begin{array}{l}\text { START. Global Terrorism Database. Univer- } \\
\text { sity of Maryland }\end{array}$ \\
\hline 1st Year Attacks & $\begin{array}{l}\text { Number of attacks in first year of group activ- } \\
\text { ity }\end{array}$ & Ioid. \\
\hline Seek Narrow Goals & Coded for type of the group & $\begin{array}{l}\text { Jones S. G. and Libicki M. 2008. How Terror- } \\
\text { ist Groups End. RAND Corporation. }\end{array}$ \\
\hline Is Nationalist & Coded for primary motivation type of group & Ibid. \\
\hline Is Religious & Ibid. & Ibid. \\
\hline
\end{tabular}

$*$ Indicates dependent variable 
to counter-terrorism than poor states. ${ }^{7}$ The data for this variable comes from the PENN World Table (Heston et al., 2009). It is expected that groups operating in a state with a high GDP per capita will be more decentralized in structure. Groups whose home country has a low GDP-per-capita will, conversely, have a bureaucratic structure.

The Freedom House index measures the level of both political rights and civil liberties in a state. ${ }^{8}$ It is an important measure of the external constraints put on a terrorist group. The reflexivity of a state's polity is a component not only of the existence of terrorist groups, but also how the group adapts. Some argue that lack of political and civil freedoms are directly linked with the incidence of terrorism (Walsh and Piazza, 2010).

The mean of these two measures combined provide an overall measure of freedom within the state. There are two competing claims within the literature of what this could mean with regard to terrorist group organizational structure. First, when the political and civil rights of a population are diminished it reduces access to decisionmakers and the ability of citizens to express themselves. It can be interpreted that in states classified as 'regime not free', ${ }^{9}$ citizens will be more likely to resort to terrorism

\footnotetext{
${ }^{7}$ In subsequent interpretations of GDP per capita I refer to wealth rather than the security capability for a state. While GDP per capita is used as a simple proxy for counter-terror effectiveness, I interpret this variable more narrowly as state wealth with the assumption that wealth and security effectiveness are positively correlated.

${ }^{8}$ Each measure is based on a scale of 1 to 7 where 1 indicates the highest level of civil or political rights. For some groups the home country is quite obvious, for others it is far from clear. This variable is coded based on media and academic sources, the group's ideological motivation and a judgement of the group's location based on the distribution of attacks.

${ }^{9} \mathrm{~A}$ Freedom House classification when the combined mean of both political rights and civil liberties is between 5.5 and 7 .
} 
because they do not have more legitimate access to public debate. Consequently, it is expected that groups with a decentralized structure will be more prevalent in regimes that are free because these state promote other avenues for airing political and ideological grievances thereby eliminating the need for large scale political violence. ${ }^{10}$ By contrast, a polity that is not regularly accountable to its citizens will have more latitude over how it deals with threats to the state, provided it has a capable counterterrorism policy. A totalitarian state, for example, will be free to use harsh methods when dealing with terrorism whereas a democratic state will be more reluctant to do so. Terrorist groups, as always, adapt to the environment. An autocratic regime can drastically limit public opposition to the regime and increase the opportunity costs of participating in terrorism (Abadie, 2006). In such a situation, for a terrorist group to be successful, it may have to adopt a decentralized structure with autonomous cells. This type of structure holds up better to strong resistance than centralized structures. In this interpretation, it can be expected that the more autocratic the state, the more decentralized the terrorist group. ${ }^{11}$ However, if an autocratic regime lacks capability, then it may not be able to successfully repress a wave of terror. It is important to note that the affect of democracy levels and counter-terrorism

\footnotetext{
${ }^{10}$ Moreover, competition from alternative licit groups will be much higher. While the hardliners may still prefer violence over peaceful protest, a majority of the population will be more moderate and will prefer to support more peaceful groups.

${ }^{11}$ The Polity IV dataset was also considered; it measures the authority characteristics of both democratic and autocratic governing institutions on a scale from -10 to 10 , from strongly autocratic to strongly democratic, respectively. There is a relatively high degree of correlation between Freedom House and Polity IV. Freedom House data is used here because Polity IV reflects periods of interregnum or transition in a state in an abrupt manner than can distort time-series results; Freedom House data is less prone to shocks.
} 
effectiveness is unsettled in the literature (see, among others, Piazza, 2008; Abrahms, 2007; Helliwell, 1994; Piazza, 2007).

The durability of any polity indicates the level of instability in a state. This variable is measured as a subset of the Polity IV dataset as a running count of the number of years a particular polity has existed in a country. While this is not a measure of the type of polity, it does represent how stable the current polity has been. The durability of any polity implies several forces acting on structure. First, any polity - totalitarian, democratic and everything in-between - that has endured for decades demonstrates that it is adept at dealing with threats and maintaining power. Second, for those states which have a low durability, there is an opportunity for change since the ruling polity is relatively new and has therefore wrested power from another polity in recent history. For large political change to occur there must be a high level of support. In states where military coups and revolution are a regular occurrence, it can be expected that there will be several competing factions vying for power. It is expected that less durable polities will find themselves confronting terrorist groups that are more organized and larger. In more durable polities, conversely, one will find less hierarchically organized groups.

\subsubsection{Internal Factors}

While it is certainly true that a group's structure is chosen due to external factors acting upon the group, forces within the organization also shape its structure. For 
example, certain targets (such as hard targets) and certain attack types (such as armed assaults) require coordination and a relatively high number of terrorists in order to attack. Consequently, groups choosing these attack features will only do so if their internal structure permits it; the choices a group makes speaks to the internal forces at work.

A group's target selection will shape the structure it adopts. Groups that successfully attack hard targets, such as police and military outposts, in their first year of existence arguably need to possess a more complex set of organizational characteristics. Groups which do not attack hard targets do so for one of two reasons: either their mission does not require attacking hard targets or they do not possess the aptitude to attack them. This variable is measured as a percentage of attacks on hard targets in a group's first year. ${ }^{12}$ It is expected that hierarchical groups will be more likely to attack hard targets.

Finally the stated goals of any organization speak volumes about how it is structured. A group likely begins with a goal - a grievance of some sort - and individuals coalesce around it. ${ }^{13}$ From here, the group may begin to assess the external challenges it faces, keeping in mind its own assets and shortcomings, and assign tasks

\footnotetext{
${ }^{12}$ The first year only is used to mitigate the endogeniety problem: does structure dictate the attacks or vice-versa? If a group has a centralized structure then it has the capacity to pull off hard target attacks. But does the group attack hard targets because it can? Or does it want to attack them and therefore develops a structure capable of these attacks. By taking the first year only, this variable mitigates this problem. I also develop a basic model that excludes variables due to potential endogeniety (see Table 5).

${ }^{13}$ The question of why groups turn to terrorism is beyond the purview of this study.
} 
in response. The variation in the goals of terrorist groups vary widely. This variation, I posit, affects the chosen structure of the group. Some seek broad goals such as complete social revolution, seeking a new empire, or regime change; others have far more narrow goals such as preserving the status quo, forcing a policy change or securing territorial change. In a way, the more esoteric and far-fetched the goal, the more loosely organized the group since there is no operational imperative that selects a more centralized structure. In other words, if the goal is broad, then it is likely to be unachievable. A group with little hope of achieving its goal will be more likely to simply express its grievance through violence, than take the organized steps necessary toward achieving its goal.

Groups with broad goals simply wish to express their grievances in a most forceful way. Conversely, groups that have narrow goals, such as maintaining the status quo or seeking territorial change, are much more likely to believe that they will achieve their goals and therefore will adopt a more hierarchical structure in anticipation of achieving their goal. Jones and Libicki (2008, p. 19), in a study about the end of terrorism conclude that less than ten percent of all groups ever achieve victory. However, I posit that if the goal is narrow and, therefore, more achievable then the group will still adopt a structure best suited in anticipation of reaching their goal. Since more hierarchical groups have a greater organizational capacity, it is expected that the more narrow the goal, the more hierarchical the group. 
Linked to the goal of an organization is the type of terrorist group. This broad categorization places groups in: left-wing, right-wing, religious and nationalist categories. While a relatively simplistic categorization, it is informative about the particular features of a group. For example, left-wing groups in Europe in the 1960's and 70's had a particular character and some common tactics. ${ }^{14}$ Nationalist struggles, owing to their large well of potential support, tend to represent the longest lasting groups. ${ }^{15}$ It is expected that nationalist groups will have a hierarchical structure. Religiouslymotivated groups are expected to take a structure similar to nationalist groups since they too have a built-in deep pool of support (Post, 2005, p. 56). It is further expected that left-wing and right-wing groups will be more loosely organized since attracting supporters to these groups is much more difficult and there is no natural well of support.

\subsection{Regression Analysis}

The dependent variable, structure, takes four forms; in order of least to most formally organized they are: market, all-channel, hub-and-spoke, and bureaucratic. ${ }^{16}$ The goal of this estimation is to determine whether a relationship exists between structure and one or more of the independent variables detailed above.

A maximum-likelihood multinomial (polytomous) logistic regression and an ordered

\footnotetext{
${ }^{14}$ Rapoport calls this the New Left wave of terror (Rapoport, 2004, p. 39).

${ }^{15}$ These include groups such as the IRA, ETA and LTTE.

${ }^{16}$ For a more detailed discussion of these four structures, see Chapter 1.
} 
probit are performed. This type of regression is used since the dependent variable, structure, may not be ordered in any meaningful way. ${ }^{17}$ The results are described below in Tables 4 to 6 . There are 9 variables correlated with terrorist group structure, only six of these are statistically significant. ${ }^{18}$ Due to similarities in the results between right and left-wing ideologies, these are combined and used as the base case.

In order to eliminate any variables that may pose a problem in terms of endogeniety, a basic model is developed. The variables: GDP per capita, Freedom House, polity durability and group ideology are all measured in the first year of the group's existence and represent a baseline of the factors with a terrorist group's home state that may influence its structure. The variables listed in the Basic Model (Table 5) are chosen because the causality is clear; in the first year of a group's existence, these variables will shape a group's structure, not the other way around.

\subsection{Results}

\subsubsection{External Variables}

As shown in Table 4, when GDP per capita increases, market groups are 1.17 times more likely than bureaucratic groups, holding all other variables constant. The higher

\footnotetext{
${ }^{17} \mathrm{~A}$ multinomial logit (mlogit) is used for maximum robustness of the results. An mlogit is used when the dependent variable has more than two outcomes and the outcomes have no natural ordering. The ordered probit suggests that there may in fact be a natural ordering to structure, in order to maximize the robustness of the results, I show both estimations.

${ }^{18}$ See the complete model displayed in Table 4.
} 
Table 4: Multinomial Logit: Complete model

\begin{tabular}{|c|c|c|c|}
\hline Term & RRR & Standard Error & p-value \\
\hline \multicolumn{4}{|l|}{ Market Structure (1) } \\
\hline GDP per capita & 1.1741 & 0.0538 & $0.000 * * *$ \\
\hline Freedom House & 0.6564 & 0.0901 & $0.002 * * *$ \\
\hline Polity Durability & 1.0223 & 0.0070 & $0.001 * * *$ \\
\hline$\%$ Attacks on Hard Targets & 0.7154 & 0.1191 & $0.044 *$ \\
\hline 1st Year Attacks & 1.0043 & 0.0074 & 0.563 \\
\hline Seek narrow goals & 0.3182 & 0.1495 & $0.015 *$ \\
\hline Is Nationalist & 0.3818 & 0.1923 & $0.056 \dagger$ \\
\hline Is Religous & 1.0179 & 1.1454 & 0.987 \\
\hline State sponsor & 0.1327 & 0.0952 & $0.005 * *$ \\
\hline \multicolumn{4}{|l|}{ All-Channel Structure (2) } \\
\hline GDP per capita & 1.0758 & 0.0427 & $0.066 \dagger$ \\
\hline Freedom House & 0.7314 & 0.0847 & $0.007 * *$ \\
\hline Polity Durability & 1.0240 & 0.0068 & $0.000 * * *$ \\
\hline$\%$ Attacks on Hard Targets & 1.0347 & 0.0215 & 0.101 \\
\hline 1st Year Attacks & 1.0073 & 0.0067 & 0.269 \\
\hline Seek narrow goals & 0.4463 & 0.1769 & $0.042 *$ \\
\hline Is Nationalist & 0.4453 & 0.1891 & $0.057 \dagger$ \\
\hline Is Religous & 6.0800 & 3.9265 & $0.005^{* *}$ \\
\hline State sponsor & 0.5996 & 0.2459 & 0.212 \\
\hline \multicolumn{4}{|c|}{ Hub and Spoke Structure (3) } \\
\hline GDP per capita & 1.0662 & 0.0455 & 0.133 \\
\hline Freedom House & 0.7251 & 0.0974 & $0.017 *$ \\
\hline Polity Durability & 1.0089 & 0.0080 & 0.266 \\
\hline$\%$ Attacks on Hard Targets & 0.9511 & 0.0713 & 0.504 \\
\hline 1st Year Attacks & 0.9980 & 0.0080 & 0.811 \\
\hline Seek narrow goals & 0.5412 & 0.2291 & 0.147 \\
\hline Is Nationalist & 1.1241 & 0.4971 & 0.791 \\
\hline Is Religous & 8.6673 & 6.0045 & $0.002 * * *$ \\
\hline State sponsor & 0.6827 & 0.3034 & 0.390 \\
\hline
\end{tabular}

Note: Pseudo R2 is 0.1612 . Number of observations is 245. Comparator is bureaucracy (4) $\dagger: p<.1 ;^{*}: p<.05 ; * *: p<.01 ;^{* * *}: p<.005$ 
Table 5: Multinomial Logit- Basic Model

\begin{tabular}{llll}
\hline Term & RRR & Standard Error & p-value \\
\hline Market Structure (1) & & & \\
GDP per capita & 1.1879 & 0.0452 & $0.000 * * *$ \\
Freedom House & 0.5342 & 0.0592 & $0.000 * * *$ \\
Polity Durability & 1.0200 & 0.0068 & $0.003 * * *$ \\
Is Nationalist & 0.4391 & 0.2034 & $0.076 \dagger$ \\
Is Religous & 0.9097 & 0.8701 & 0.921 \\
\hline All-Channel Structure (2) & & & \\
GDP per capita & 1.0868 & 0.0385 & $0.019 *$ \\
Freedom House & 0.6662 & 0.0664 & $0.000 * * *$ \\
Polity Durability & 1.0245 & 0.0068 & $0.000 * * *$ \\
Is Nationalist & 0.4876 & 0.1999 & $0.080 \dagger$ \\
Is Religous & 5.7153 & 3.4411 & $0.004 * * *$ \\
\hline Hub and Spoke Structure (3) & & & \\
GDP per capita & 1.0808 & 0.0413 & $0.042^{*}$ \\
Freedom House & 0.6317 & 0.0713 & $0.000 * * *$ \\
Polity Durability & 1.0087 & 0.0079 & 0.269 \\
Is Nationalist & 1.2988 & 0.5342 & 0.525 \\
Is Religous & 6.8069 & 4.3353 & $0.003 * * *$ \\
\hline Note Pseudo R2 is & 0.1303. & &
\end{tabular}

Note: Pseudo R2 is 0.1303 . Number of observations is 245. Comparator is bureaucracy (4) $\dagger p<.1 ; * p<.05 ; * * p<.01 ;^{* * *} p<.005$ 
Table 6: Base Model - Ordered Probit ${ }^{a}$

\begin{tabular}{lccl}
\hline Term & Coeffecient & Standard Error & p-value \\
\hline GDP per capita & -0.0515 & 0.0144 & $0.000 * * *$ \\
Freedom House & 0.0625 & 0.0983 & 0.525 \\
Polity Durability & -0.0053 & 0.0022 & $0.018 *$ \\
\% Attacks on Hard Targets & -0.0099 & 0.0059 & $0.092 \dagger$ \\
1st Year Attacks & -0.0024 & 0.0025 & 0.329 \\
Seek narrow goals & 0.3672 & 0.1751 & $0.036 *$ \\
Is Nationalist & 0.3532 & 0.1802 & $0.050 \dagger$ \\
Is Religous & -0.2008 & 0.2036 & 0.324 \\
State Sponsor & 0.4505 & 0.1621 & $0.005 * *$ \\
\hline
\end{tabular}

${ }^{a}$ : Ordered from least to most bureaucratic, pseudo R2 is $0.0970 . \mathrm{N}=245$.

$\dagger: p<.1 ;^{*}: p<.05 ;^{* *}: p<.01 ;^{* * *}: p<.005$

the income of a country, the more likely a terrorist group will be loosely organized. ${ }^{19}$ In other words, in rich countries, terrorist groups are more likely to have either a market or a network structure. By extension, one would therefore expect to find bureaucratically structured groups in those countries which have a lower income, holding all other variables equal. ${ }^{20}$

If lagged GDP per capita is taken as a reasonable proxy for state counter-terrorism effectiveness; this result suggests that rich countries have more resources available to deal with a terrorist campaign. This counter-terror capability results in decentralized groups being found mainly in rich countries. This hypothesis is supported by the

\footnotetext{
${ }^{19}$ This relationship is not only found in the relative risk for market structures but, with decreasing strength, in all-channel (a factor of 1.08 to a $90 \%$ confidence interval and hub/spoke structures (a factor of 1.07 to a $75 \%$ confidence interval), when compared to the bureaucratic structure.

${ }^{20}$ This argument is supported by the results in Table 4, in Figure 5 and in the ordered probit shown in Table 6. Although not displayed in Table 4 - since the comparator is the bureaucratic structure - there is a negative coefficient associated with GDP per capita in bureaucratic structures. While not a significant finding, in the statistical sense, on its own, this result supports the finding that GDP per capita is inversely related to the level of organization of a group.
} 
simple frequency graph shown in Figure 5 comparing the terrorist group structure distribution for low, middle and high income states. ${ }^{21}$

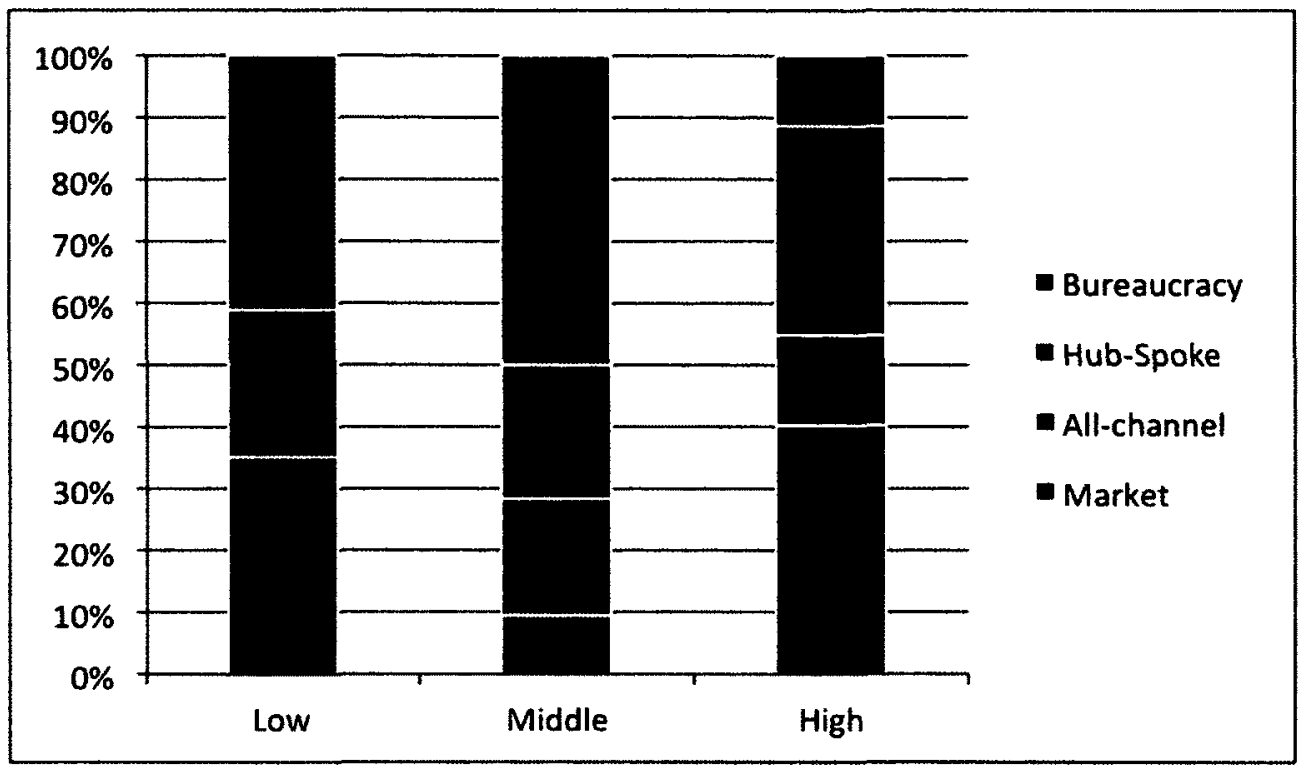

Figure 5: Frequency of Organizational Structure by Country Wealth

Greater counter-terror resources have the affect of disrupting any existing hierarchically-organized groups. More decentralized groups, however, are more difficult to disrupt. In the face of strong counter-terrorist efforts, it is mostly looselyorganized groups that survive. Conversely, in low-income countries, the capacity for fighting terrorism is low. Hierarchical groups - an organizational type more efficient but at the expense of security, prosper in poor countries. That the relative risk ratio (RRR) of GDP per capita for all-channel nor for hub and spoke structures are not significant suggests that a country's wealth has less impact over networked groups. It also suggests that there may be a pattern to the set of factors that affect the formation of a market structure that differs from network structures. These patterns are

\footnotetext{
${ }^{21}$ According to World Bank income group categories (World Bank, 2009).
} 
discussed further below. Finally this result also suggests that in terms of counterterror effectiveness, as measured by GDP per capita, there are high income states, and then there are all other states. ${ }^{22}$

As Table 4 shows, for every one point increase in Freedom House, the relative risk for market, all-channel and hub-spoke structures - when compared to bureaucratic groups - is expected to decline, by a factor of $0.65,0.73$ and 0.72 , respectively, holding all other variables constant. The results suggest that compared to highly centralized bureaucratic groups, all other structures are more likely to be found in free countries. The converse is also true. Bureaucratic groups are more likely to be found in states that are not free. Since, more often than not, political and civil rights are respected only in more wealthy, more stable democratic countries, this finding gives credence to the emerging narrative that decentralized groups are more likely to be found in rich, democratic countries. Moreover, this result is supported by re-running the multinomial logit with a subset that includes only groups that have a peak size larger than one thousand. While not shown here, this sample suggests that large groups in states with relative civil and political freedoms will tend to be more decentralized. By contrast, in states with low freedoms, large groups will tend to be organized as a bureaucracy.

For every one year increase in the polity durability, the relative risk of either market or

\footnotetext{
${ }^{22}$ Figure 5 shows that middle-income states do appear to be a somewhat distinct type, the real difference is observed between the types of terrorist group structures found in high income states compared to all others.
} 
all-channel structures, compared to bureaucracies, are expected to increase, both by factors of 1.02, holding all other variables constant. This finding suggests, for every year a polity gets older, the more likely it is that the group will be either market or all channel, as compared to bureaucratic. This result confirms the hypothesis that the more durable a polity, and therefore more entrenched, the more constraints it will put on terrorist group structure. It also confirms the more general hypothesis that terrorist groups are more likely to adopt a decentralized structure in the face of more capable government.

The relative risk for hub-spoke structures, compared to bureaucratic structures, was not statistically significant. It was expected that in more durable states - measured by the number of years a polity has endured - one would see more market and allchannel structures. The base model confirms this hypothesis. That the hub-and-spoke structure also had a positive relative risk ratio but was not found to be statistically significant may imply that as structure moves towards centralization, a lack of polity durability emerges. In other words, more centralized groups will be found in states that have a low polity durability, and therefore, a high level of instability. ${ }^{23}$

\subsubsection{Internal Variables}

For every one percent increase of the percentage of attacks on hard targets in the first year, compared to bureaucratic structures, market structures are expected to decline

\footnotetext{
${ }^{23}$ Polity durability is one facet of the Polity IV dataset which measures the quality and strength of governments (Marshall et al., 2003).
} 
by a factor of 0.72 , holding all other variables constant. This result implies that groups in their first year of operation intent on attacking hardened targets such as police and military installations would need to choose a more complex structure in order to be successful. This is consistent with the hypothesis that loosely-organized groups will be less capable, or willing, to attack hard targets.

It is important to understand that this equation is using the proportion of hard attacks in a group's early activities as an indicator of the type of targeting it would like to undertake. The inherent difficulties in attacking a target that is prepared for such an attack creates a disincentive for groups to adopt a market structure as their form of organization. Holding constant the other conditions used in this model as factors affecting the choice of structure, a group that initially plans to attack hard targets will be more likely to choose a more centralized, rather than a market, structure. ${ }^{24}$

For groups seeking narrow goals, compared to bureaucratic groups, both market and all-channel are expected to decline by factors of 0.31 and 0.44 , respectively, holding all other variables constant. This result suggests that groups with narrow goals will tend to be more hierarchically organized. These results also support the claim in the literature that groups with narrow, achievable goals will be more likely to have a hierarchical structure because the group expects to achieve their goal (Jones and

\footnotetext{
${ }^{24} \mathrm{As}$ discussed above, this variable is the percentage of all attacks in the first year that are directed towards hard targets; it is intended to be a measure of the organization's initial intention regarding preferred targets. The approach of using attacks in the first year goes some way to neutralize the potential endogeniety that may arise from trying to explain the effect of target selection of group structure. In Chapter 3 I reverse the direction of imputed causality because the data cover subsequent years of activity when structure has already been determined.
} 
Libicki, 2008). Groups with broad, and therefore more unreasonable goals, are far more likely to take on a decentralized structure and use violence more indiscriminately since their constituency is small and not likely to increase regardless of what they do. ${ }^{25}$

The estimated coefficient for the variable first year attacks was not found to be statistically significant for any structures.

For the variable is religious, compared to left and right-wing ideological groups, ${ }^{26}$ the relative risk for all-channel and hub and spoke structures would be expected to increase by a factor of 6.1 or 8.7 , respectively, holding all other factors constant. Compared to nationalism, all-channel and hub-spoke structures are 6.1 and 8.7 times more likely to be motivated by religion. This result is unexpected. It was posited that religious groups would take a similar structure to nationalist groups since they both have a large natural pool of supporters to draw from.

One potential explanation for this variance is that ethno-nationalist support may be more geographically-centred while religious support may be more global. Moreover, religious groups may have a built-in hierarchy corresponding to the theological structure. Maintaining an organization that is spread all over the world is inherently difficult and risky, all the more so if it is run centrally. Global groups must be more reliant on electronic communication than local groups which represents a security

\footnotetext{
${ }^{25}$ To push these results further, other goal types were tested within the base model and while the results were not statistically significant, broad goals such as seeking social revolution and seeking an empire were more likely to be positively associated with decentralized groups. Narrow goals such as seeking territorial change, seeking policy change and maintaining status quo were negatively associated with decentralized groups and positively associated with the bureaucratic type.

${ }^{26}$ This variable is both left-wing and right-wing groups combined since there was no variation between the two.
} 
concern. This may help to explain these results. Nationalist groups, by their nature, seek territorial change; a relatively narrow and therefore more achievable goal. Religious groups, on the other hand, can have a myriad of different goals, many of which are very broad and therefore unlikely (Lawrence, 2005, p. $15-18$ ). ${ }^{27}$

In a robust finding, as detailed in Table 4, for the variable is nationalist, the relative risk of market and all-channel structures, compared to bureaucracies is expected to decline by factors of 0.38 and 0.45 , respectively. ${ }^{28}$ Compared to the base case of bureaucracies, decentralized structures are less likely to be motivated by nationalism. Moreover, while not a statistically significant result, hub-spoke structures are positively associated with nationalist groups. This result shows a clear progression, from decentralized to centralized; that nationalist groups are far more likely to exist as bureaucracies than market structures.

For the variable state sponsorship the results are rather stark. For groups that are state sponsored, the relative risk for market, all-channel and hub-spoke groups, when compared to bureaucratic groups, are expected to decline by factors of $0.13,0.59$ and 0.69 , respectively, holding all other variables constant. This result suggests a clear link between bureaucratic groups and groups that enjoy state sponsorship. In an ordered probit regression, the estimated coefficient for state sponsorship was also statistically significant with a large $z$-value. This result is also consistent with the

\footnotetext{
${ }^{27} \mathrm{Al}$ Qaeda, for example, has narrow goals such as foreigners out of the Arabian Peninsula, but also very broad, existential goals, such as the destruction of western civilization

${ }^{28}$ Holding all other variables constant.
} 
hypothesis that groups with state sponsors tend to be hierarchically structured. ${ }^{29}$

\subsubsection{Diagnostics}

Testing for the Independence of Irrelevant Alternatives (IIA) assumption was done using the 'mlogtest' function in Stata (Long and Freese, 2005). Results of the SmallHsaio test indicates that the main model is congruent with the IIA assumption.

Heteroskedasticity is not a problem in the current dataset. First I inspected the data visually by plotting the residual values against the fitted values and observed an even width of distribution when plotted. The more formal Breusch-Pagan/Cook-Weisberg test revealed a low Chi-squared value of 0.12 suggesting that hereteroskedasticity is minimal and does not affect the results. Moreover, the base model uses robust standard errors which further mitigates any affect of heteroskedasticity that may be present. When the base model, with robustness, was compared to the same model without robust standard errors, there was no change in the results.

To test for multicollinearity an ordinary least squares (OLS) regression analysis was

\footnotetext{
${ }^{29}$ While not included in either the base of the main model due to problems of endogeniety, the relative risk estimate for the variable peak size was found to be was statistically significant to a 99\% confidence interval. Since the coefficient of peak size is negative for market structures this result implies that smaller-sized groups, in this case less than ninety-nine members, are more likely to be found in market or networked groups than in hierarchical structures. This result is highly intuitive in the sense that a bureaucratic structure by its nature has multiple layers of management and highly specialized departments. This structure would therefore require more members than a loosely-structured group. In fact, loosely-structured groups will likely never achieve great numbers precisely because they lack adequate leadership structures to control larger numbers of members.
} 
performed and the variance inflation factors (VIFs) were inspected for each independent variable. The VIF values for all independent variables were no higher than 1.62 , suggesting an almost total lack of multicollinearity. A common VIF tolerance range of 5 or less supports this finding (Sarkasian, 2011). ${ }^{30}$

Testing for linearity and additivity was performed visually using graphs with a locally weighted regression of structure on each independent variable, separately

Table 7 presents the descriptive statistics for the base model. Outliers were found in two independent variables, percentage of attacks on hard targets and number of attacks during the first year. When the outliers for the variable percentage of hard targets are removed, the sign changes to a negative in the multiple linear regression when comparing all-channel structures to bureaucracies. This result makes sense theoretically since it implies that groups targeting a higher percentage of hard targets in the group's first year are more likely to be centralized. The outlier was subsequently left into the analysis. The outlier for the number of attacks in the first year, when omitted, had little affecton the results. Consequently, the outlier was left in the analysis.

The dependent variable for the ordered probit, as shown in Table 6, is organizational

\footnotetext{
${ }^{30} \mathrm{Pairwise}$ correlation, a more informal test for multicollinearity, was also performed using pwcorr in Stata. Some variable pairs have traditionally been seen as highly correlated, especially measures such as Freedom House and political durability. In this study the pairwise correlation for these measures is 0.5284 , which is perhaps lower than what is found in other studies due to the nature of the sample used here, which is restricted to cases where terrorist activity has been present. The highest pairwise correlation, between regime durability and GDP per capita (chain series), is 0.5428 . Auxiliary regressions were also performed however, examining both auxiliary regressions and pairwise correlations are less preferred to the variance inflation factor test (see Sarkasian, 2009). Therefore, in subsequent chapters I focus on the more formal VIF method for testing multicollinearity.
} 
Table 7: Descriptive Statistics - Base Model

\begin{tabular}{lcllll}
\hline Variable & \# Obs. & Mean & Std. Dev. & Min & Max \\
\hline Structure $^{a}$ & 246 & 2.820 & 1.133476 & 1 & 4 \\
GDP Per Capita & 249 & 7675.463 & 7031.789 & 306.44 & 31109.3 \\
Regime Not Free & 249 & 0.157 & 0.364 & 0 & 1 \\
Polity Durability & 249 & 30.193 & 44.0313 & 0 & 183 \\
Level of Democracy & 249 & 3.040 & 6.848 & -10 & 10 \\
\% Attacks on Hard Targets & 249 & 0.959 & 6.663 & 0 & 83.333 \\
1st Year Attacks & 249 & 9.221 & 21.976 & 1 & 207 \\
Seek narrow goals & 249 & 0.329 & 0.471 & 0 & 1 \\
Is Nationalist & 249 & 0.386 & 0.488 & 0 & 1 \\
Is Religious & 249 & 0.145 & 0.352 & 0 & 1 \\
\hline$a$ denotes dependent variable & & & & &
\end{tabular}

structure, from least to most centralized centralized. The estimated coefficients for GDP per capita, Freedom House, polity durability, nationalist, religious and state sponsor are all consistent with the results of the multinomial logit base model. These results suggest that there is a natural ordering of structures, by increasing centralization: market, all-channel, hub-spoke and bureaucracy.

\subsection{Discussion}

A clear story emerges from the above results. Rich, free, durable, democratic states seem to push terrorist groups to adopt a decentralized structure. By contrast, the terrorist groups in poor, not free, unstable, autocratic states tend to be centralized. Groups in their first year, lack the expertise, and perhaps the will, to attack hard 
targets and are more likely to be decentralized. Those groups that possess the ability to keep a high operational pace going are more likely to have a centralized structure, even in their first year of existence.

The story continues when examining group type and goals. Decentralized groups are more likely to be religious, left-wing or right-wing and are more likely to have broad goals such as social revolution. Bureaucratic groups are highly likely to be nationalist groups with narrow goals such as territorial change. There are other conclusions beyond those concerning organizational type. First, is the unexpected result with respect to religious groups.

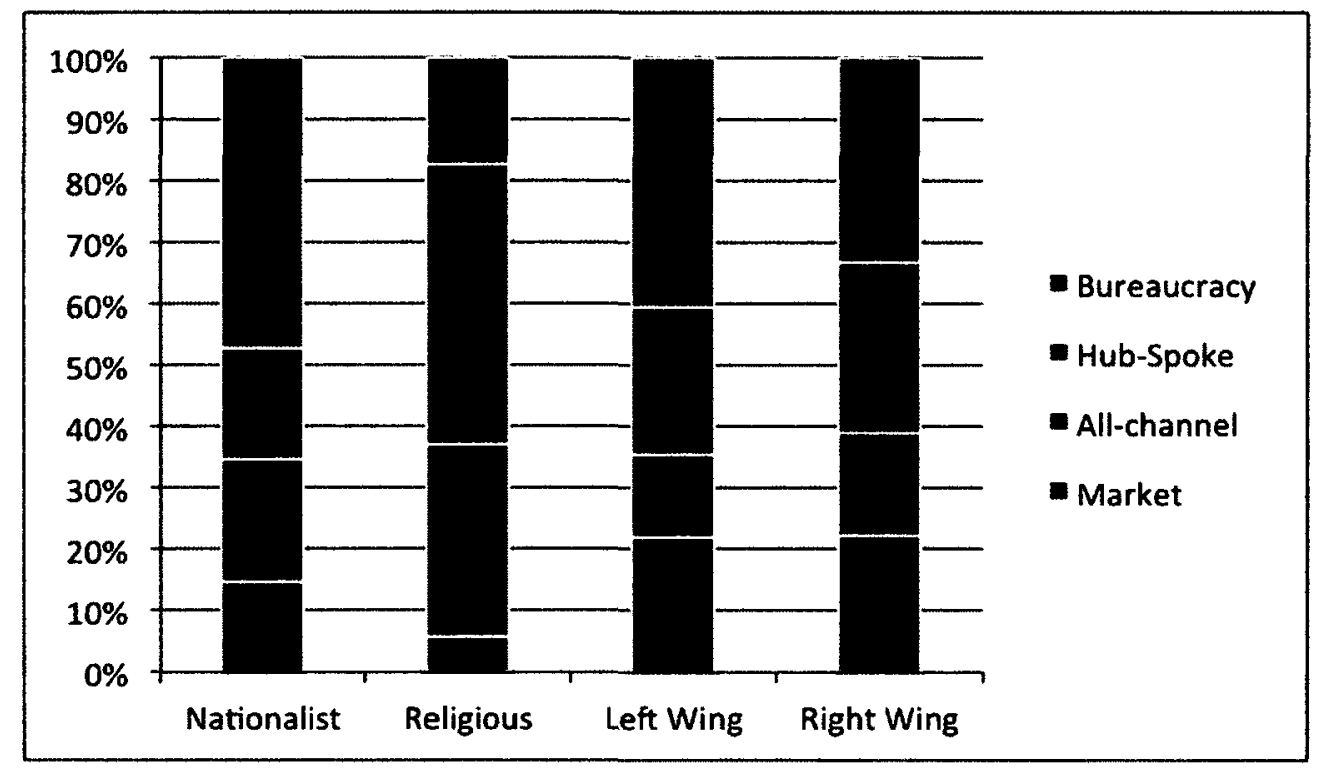

Figure 6: Organizational Structure by Motivation Type

It was posited that religious groups, due to their large potential number of supporters, would organize themselves in a similar manner to nationalist groups. The results, 
however, do not confirm this hypothesis. ${ }^{31}$ Nationalist groups, true to form, are most often bureaucratically organized. Religious groups are more likely to be one of the two networked forms of organization - all-channel and hub and spoke. On the surface, this result could be attributed to the fact that nationalist groups are more likely to have a strong geographic centre. While diaspora populations are often important in supporting the nationalist cause there is, more often than not, a geographic centre for support. This localized support is not necessarily enjoyed by religious groups. So while a religious group may have a large natural pool of support, it may not have a geographic centre. This lack of a centre puts religious groups at a disadvantage, in some respects, compared to nationalist groups (Heger et al., 2008; Lawrence, 2005). Without a geographic centre, a religious group may need to operate across long distances - a situation where security concerns arise. Communication is affected. Electronic communication - the modern answer to narrowing distances - is often monitored thus limiting the ability to control the group centrally. In this case, it is better for a group to operate as a decentralized network where local commanders are more free to make decisions and plan attacks.

The unexpected result involving religious groups requires further probing. Upon closer examination, those religious groups which have a bureaucratic structure all possess one or more of the following characteristics: a nationalist element, participation in state politics or operating in a weak or failed state. ${ }^{32}$ These characteristics embody

\footnotetext{
${ }^{31}$ See Figure 6.

${ }^{32}$ These bureaucratic religious groups with nationalist goals are: Lashkar-e-Taiba, Armed Islamic Group (GIA), Hezbollah, Hiz'bul Mujahideen (HM), Jama'atul Mujahideen Bangladesh (JMB),
} 
what is expected of nationalist groups. Indeed, characterizing any group as either nationalist or religious on occasion can prove to be difficult. This finding could be a case of applying an 'either-or' scenario when reality proves to be more complicated.

These results do, however, reinforce the general trend that the more nationalist the group the more hierarchically organized it will be. ${ }^{33}$ This result suggests another potential area for further research, if instead of four primary group types (left-wing, right-wing, religious, nationalist), in reality there are more types. Making this coding change could perhaps provide more precise results. However, given the relatively small sample-size of this chapter, this strategy was not possible.

The finding that religiously-motivated groups have statistically different structures than nationalist groups also raises the question of what difference, if any, there is between nationalist groups and religious groups? Aside from the obvious differences, does the structure between these two group types come down to the assessment of the group's main motivation? In coding this variable, religious groups are judged to have been religiously-motivated even if they display many nationalist characteristics. ${ }^{34}$ These results highlight the difficulties in trying to assign just one type to each group. There exist right-wing nationalist groups and left-wing religious groups thus blurring the lines between these group types.

Lord's Resistance Army (LRA) and the Moro National Liberation Front (MNLF).

${ }^{33}$ Another element investigated was the difference between the type of religion among groups and if that had an affecton their structure. Unfortunately, the sample size is too small to assess. Of the 35 religious groups included in this study, only three were not Islamic.

${ }^{34}$ Much of the coding for this independent variable was done by Jones and Libicki (2008). In those cases where groups in my study were not included in theirs, I followed their coding principles. 
Another possible explanation for the unexpected result of religious group structure comes down to the size of the group. Each of the bureaucratically-structured religious groups had, at their peak size, greater than 1000 members. Generally speaking, the larger the group, the more hierarchical the structure. This finding is consistent with Jones and Libicki's findings that peak size is an important variable. ${ }^{35}$ There is one common element between all of the nationalist-religious groups listed above: there is only one constituency, nationalism and religious are used interchangeably as a way to motivate support.

The second surprising conclusion is that the notion of democracy does not really have an affectas a determinant of group structure. Promoting democracy has long been seen from a policy perspective to lead to peace and prosperity; the current study finds that there is some evidence that a state's level of political and civil rights act as a predictor of a group's structure. In fact, while not a goal of this chapter, the current work serves to reinforce the proposition that there is no link between promoting democracy and preventing terror. Far more important are measurements of state capacity and counter-terror effectiveness. As a simple illustration to the lack of connection between democracy and terror, a count of active terrorist groups in democracies yields 159 while groups active in autocracies number only 87.36

\footnotetext{
${ }^{35}$ See Jones and Libicki's 2008 study on the end of terrorism. They found that peak size is the single most important factor in explaining success. Peak size is not included in the current model due to the endogeniety problem that peak size of a group does not necessarily occur at the start of the group's existence. However, peak size does help explain the unexpected finding of religious group structure and is therefore noted here.

${ }^{36}$ This count is accurate as of the end of 2007. It may be that the openness of a democracy provides the public space required for terrorist groups to operate. Absolute totalitarian regimes are able to keep this public space closed.
} 
This finding is supported by the results of polity durability. As described in Table 4, for every one year increase in polity durability, the relative risk of either market or all-channel, the two most decentralized groups, compared to bureaucratic groups, is expected to increase. This result supports the hypothesis that it is in fact polity effectiveness, not the type of government, that is a better predictor of terrorist group structure. Failed or unstable states cannot provide adequate policing and intelligence capability to monitor and prevent the activities of terrorist groups (Piazza, 2008, p. 86).

The third interesting conclusion is that there is evidence of a clear distinction between the network structures: all-channel and hub and spoke. The main model uses a multinomial logit, and thereby assumes that there is no logical ordering of the four structure-types. However, given the discrete variability between the two networked groups as well as the progressive variance of certain variables from decentralized to centralized structures, it can be concluded that not only are there two separate network structures, but that they can, to a large degree, be ordered. ${ }^{37}$

\subsection{Conclusion}

While still a basic model, this chapter represents a first attempt at developing a model for explaining the internal and external dynamics affecting terrorist organizational structure. As secret organizations, terrorist groups are not just driven by achieving

\footnotetext{
${ }^{37}$ The ordered probit results supporting this claim is shown in Table 6 .
} 
efficiencies in their organization but also by protecting themselves from infiltration and threats. The results suggest that the counter-terror environment shapes the structure of groups. The higher the political rights and civil liberties, the more decentralized the organization. A similar relationship is observed in terms of GDP per capita, a proxy for counter-terror effectiveness, and in polity durability.

In terms of internal factors, the behaviour of the group in its first year suggests that market groups, compared to bureaucratic groups are less likely to employ hard targets in their first year. This result implies that for a groups attacking hard targets, its choice of structure will tend to be centralized. The frequency of attacks in the first year, compared to a group's total number of attacks was not found to be statistically significant for any of the structures. It is possible that a similar pattern of first year attacks exists within all structures. Other internal factors all point to a clear demarcation between the four organizational structures.

With the conclusions of the chapter, it is now possible to turn the question around and ask what is the affect of structure on a group's strategic targeting. This is explored in Chapter 3. 


\section{Chapter 3}

\section{How Structure affects Group Targeting}

\subsection{Introduction and Motivation}

In Chapter 2, I develop a model that describes the internal and external forces that affect a group's organizational structure. In this chapter, I examine the affect of structure on one key aspect of a group's output: its targeting preferences.

The use of violence is the defining feature of any terrorist group. What you choose to attack says a lot about what your group is about. For the vast majority of groups, violence serves an instrumental purpose. It is a rational strategic choice and one that is used to communicate a message. ${ }^{1}$ The choice of target is therefore the starting point for most groups in terms of measuring behaviour. ${ }^{2}$

\footnotetext{
${ }^{1}$ However as discussed in the literature review below, there are competing views that place less emphasis on the instrumental nature of violence by terrorist groups.

${ }^{2}$ This is likely not valid for anarchist organizations, but since they are poorly organized they are probably excluded from my sample in any case. Second, it is absolutely true that the calculus for both of these facets of attack strategy are not totally separate from each other. Attacking a hard target necessitates certain attack types, for example. The point is that target choice is leading the way.
} 
Terrorist groups are constrained by the resources at hand and by the limits supporters place on them (De la Calle et al., 2006). Given these constraints, it follows that terrorist groups have a menu of possible target types from which to choose. How they do so and what affects, if any, structure has on this decision is the subject of this chapter.

\subsection{Literature Review}

It is important to note that there exists very few qualitative studies of terrorist group target selection. ${ }^{3}$ There are even fewer quantitative studies on terrorist target selection (see Asal et al., 2009). There are no known studies examining the affect of organizational structure on terrorist group targeting. ${ }^{4}$ Given the paucity of prior studies, it is difficult to derive many hypotheses from the literature. The literature focuses on the few group-level explanations of terrorist target selection.

\subsubsection{Organizational Explanations}

As the primary subject of the current study, the organizational level of analysis has been discussed in both previous chapters. In this view, a terrorist group is not perceived as a black box or a collection of individuals but rather as a coherent system, subject to a range of influences that may be only tangentially related, but which affect

\footnotetext{
${ }^{3}$ As detailed below, there are a few exceptions, see Libicki et. al (2007) and Drake (1998a, 1998b).

${ }^{4}$ Asal et al (2009) looks at connections between groups, but not the structure of groups themselves.
} 
its behaviour nonetheless. McCormick (2003, p. 483) posits that terrorist groups employ a reflexive dialogue through their attacks as follows: (1) an action is carried out against a target; (2) the action is interpreted and transmitted by the media; (3) the 'mediated' message is received and interpreted by the group's target audience; (4) the targets of influence respond in a way that advances group interests, hopefully. As Chapter 2 argues, terrorist group structure is constrained and shaped by the unique internal and external forces acting upon it. In terms of target selection, clandestinity is an important consideration since groups that ignore this rule are typically not around long enough to matter (Erickson, 1981). How far underground a group goes - a matter depending on ideology and the counter-terrorism environment - affects the group's connection to its constituency and appropriate perceptions of the affects of targeting (Crenshaw, 1985). As Gerlach and Hine (1970) and Della Porta (1995) posit, terrorists can lose their sense of reality, affecting their decision-making process and, therefore, their targeting preferences. This loss of reality is particularly true for groups with narrow, obscure ideologies incomprehensible to the general population. An example of such a group is the Red Brigades of Italy. A radical leftist group, they were increasingly isolated by the Italian authorities to the point that their communiques become so specialized they were incomprehensible to anyone but their own members (Della Porta, 1995).

Drake does the most significant work on terrorist group targeting from a qualitative perspective and develops a model that assumes, first and foremost, that the strategy 
of a group "operates within the constraints of what can be deemed as ideologically acceptable" (Drake, 1998b, p. 178). In other words only those targets that the terrorist group deems legitimate are attacked. ${ }^{5}$ He goes on to explain how targets are selected and how terrorists choose to proceed with the attack (Drake, 1998b,a, p. 173).

For Drake (1998), the key to target selection is the group's ideology; it lays down the initial parameters of acceptable behaviour and constraint that drive and sustain the group. He goes on to argue that ideology provides a "mental and moral framework within which terrorists operate" (Drake, 1998b, p. 173). However, ideology is rarely, if ever, the sole driver for achieving their political objectives. Rather, terrorism is usually the result of radicalization or reaction by a group and is shaped by the forces acting on it - ideology is rarely the necessary factor for employing violence. Beyond ideology, target selection is also driven by other factors. Drake posits that these are: group dynamics, external opinion, capability, security environment, protective measures, and the current situation facing the group (Drake, 1998b, p. 176).

From a more quantitative perspective, the tactical profile of terrorist groups has been studied before (Enders and Sandler, 1993; Heger et al., 2008; Clauset et al., 2006). Of particular note is the work of Heger et al. (2008) since this is the only previous work that examines organizational structure as a factor in shaping terrorist group behaviour. Heger et al. (2008) argue that the more complex the terrorist activity,

\footnotetext{
${ }^{5}$ At the core of Drake's (1998) work - and the current study - is the presumption that terrorism is a rational, strategic choice that a group makes. Some, such as Abrahms (2006) disagree.
} 
the more complex the organization needed. They argue that structure plays a role in the frequency and lethality of violence and investigate this claim by coding groups as either horizontal (market-like relations) or vertical (hierarchical firm) (Heger et al., 2008 , p. 4-5). The make this coding decision by categorizing groups as either nationalist, and therefore vertical, and non-nationalist, and therefore horizontal. ${ }^{6}$ This division of groups allows for general assertions to be made: vertical groups employ functional differentiation and centralized decision-making and enjoy the subsequent benefits of this division of labour. In these types of groups agenda-setting is clear: it comes from the top and is disseminated unilaterally to subordinate units.

Heger et al. (2008, p. 12) posit the following pattern: First, hierarchical groups will be more likely to sustain long-term campaigns, capable of coordinating multiple attacks in 'clusters'. Second, flatter groups will be less likely to sustain long-term campaigns relying instead on isolated, single attacks. Heger et al. (2008) also argue that nationalist and separatist groups are more likely to be hierarchical because they intend to replace the government, they need to project themselves as a credible alternative.

Conversely, horizontal groups operate in far more autonomous, discrete cells and coordination is much more ad-hoc than it is in vertically organized groups (Heger et al., 2008 , p. 7). For horizontal groups, agenda-setting capacity is weak and information flows in many directions. Moreover, Heger et. al posit that those groups which are hierarchical in nature have more specialized functions and as a result tend to

\footnotetext{
${ }^{6}$ The dataset they use contains 14,993 terrorist incidents of which $84 \%$ are nationalist.
} 
be more capable of successful attacks. Those groups which have a flattened, horizontal structure are less specialized and therefore each group member must act as jack-of-all-trades - which results in less deadly attacks (Heger et al., 2008).

Using the RAND MIPT database of international terrorist incidents, Heger et. al find support for the hypothesis that hierarchical groups are more lethal then decentralized groups. ${ }^{7}$ They also conclude that hierarchy leads to more destructive lethal attacks and that these groups are more likely to be able to sustain attacks over longer periods than horizontal, non-hierarchical organizations. However, this study did not code for organizational structure - it makes the assumption that all nationalist groups are vertically-structured while all non-nationalist groups are horizontally-structured. Indeed, as a suggestion for future research Heger et al. (2008, p. 14) observes that: "the most challenging aspect...is finding a way to operationalize group structure...to the best of our knowledge, no cross-national data on this variable exists." This study is therefore the closest previous work on the affect of organizational structure in terrorist groups.

The only other quantitative study of terrorist group targeting preferences is Asal et al. (2009). Their study focuses on the reasons why a group chooses soft targets and why a group continues attacking soft targets (Asal et al., 2009, p. 265). Using a dataset of domestic and international terrorist attacks between 1998 and 2005 the authors examine 395 groups during that period. ${ }^{8}$ Due to the rare nature of the

\footnotetext{
${ }^{7}$ The coefficient from this result - using a negative binomial regression - was found to be statistically significant to a $90 \%$ confidence interval.

${ }^{8}$ Unlike the GTD, the dataset Asal et. al (2009) use is not incident-based, so the number of
} 
dependent variable, soft target attacks, Asal et al. (2009) employ a zero-inflated negative binomial regression model. They find that religious, and to a lesser extent, ethno-nationalist, ideologies lead a group to soft target selection. They also find that larger and better networked organizations are determinants in repeated attacks of soft targets. ${ }^{9}$ Finally, they conclude that there is no link between democracy, measured by Polity IV, nor is there a link between group age and soft target attacks (Asal et al., 2009 , p. 275).

\subsection{Categorizing targets}

The GTD sorts each attack into 22 target types. ${ }^{10}$ Since the dependent variable studied in this chapter, target type, is categorical, I use a multinomial logistic regression. This type of estimation compares all categories against a base case. As is evident when examining the complete model, shown in the Appendix in Tables 12 to 20, interpreting a general story from such a complex estimation is extremely difficult. To observations for their study is $\mathrm{N}=395$.

${ }^{9}$ Organizational networking is measured by a simple network map of the number of links between terrorist groups.

${ }^{10}$ The others are business, government (general), police, military, abortion, airports/airlines, government (diplomats) educational institutions, food/water, journalists/media, NGOs, private citizens/property, religious, telecommunications, terrorist groups, tourists, transportation, utilities and violent political parties. Each one of these targets represents a rather broad categorization of what is often a highly variable target type. For example, a business target can represent a myriad of different commercial enterprises, from an oil derrick to a supermarket - both which may communicate something completely different the group perpetrating the attack. Two target types are not helpful for evaluating behaviour: those that are coded 'other' and those that are coded 'unknown'. As detailed below, the 'unknown' category is used as the comparator for the estimations. I tested other base cases and determined that the unknown target type was most appropriate and the results did not change if another base case was used. 
make it easier to interpret the results from a multinomial logistic regression, I develop a. grouping procedure. ${ }^{11}$

Terrorist groups use their attacks as a message generator. Grouping targets according to the message conveyed by a selected target is one way to categorize targeting preference. To simplify things, I divide these 22 targets into three broad categories: coercive targeting, attention-seeking targeting and infighting targeting. ${ }^{12}$ These three broad categories reflect the utility of each target selected. While there is a complex set of criteria that goes into how a group chooses a target to attack, the categories described in detail below are meant to measure the expected utility of targets.

For example, if a terrorist group is trying to achieve territorial autonomy, it may choose targets with the hope that these attacks will be enough to coerce the government to make concessions, or even grant autonomy. In this way, I expect that the targets attacked by a nationalist group, for example, are chosen with the intention of achieving the group's stated goals. By contrast, I argue that a left-wing group that seeks to overthrow the government and replace it with a one that has a MarxistLeninist ideology would select a different 'package' of targets entirely. By grouping target choices in such a way that the communicative aspect of an attack can be distinguished will help make sense of the complex interactions between 22 different target

\footnotetext{
${ }^{11}$ Moreover, as detailed in the diagnostics section, this was also required due to a violation of the independence of irrelevant alternatives (IIA) assumption for the complete model. To overcome the IIA, I group close substitutes.

${ }^{12}$ Coercive targeting is further subdivided into hard and soft targets; attention-seeking is subdivided into economic and political targets.
} 
types. $^{13}$

What follows in the next section is a detailed overview of the different categories. Following that, a multinomial logit for the target categories is discussed, followed by an estimation of the complete model that contains all 22 target types. The chapter is organized in this way so that a broad interpretation is possible from the estimation of the categories while the complete model is discussed only where there is deviation from the general results. A brief case study concludes the chapter.

\subsubsection{Coercive Target Selection}

One way to explain why a group chooses a particular target is to examine the coercive power one target may have over another. Libicki et al. (2007) posit that coercive targets are those that result in higher casualties. In this way, a group chooses a target that will guarantee a high casualty rate in the hopes that it will coerce the public to push the government to give in to the group's demands. To some extent, while all terrorist attacks are coercive, in this chapter coercive targeting is more precisely defined and refers to those groups that choose a target with the intent of forcing a change through higher casualty attacks. This change can be policy-related, political, or religious. These attacks are coercive in that they are designed to be of such power and fury that the intended audience will demand the government appease, or acquiesce, to the terrorist's demands.

\footnotetext{
${ }^{13}$ The basic idea behind grouping attack targeting comes from Libicki et. al (2007) however they use different categories and apply it only to one case study.
} 
The coercive category is subdivided into hard and soft targets. Hard targets are defined as military outposts and police stations where it is clear that if attacked, these sites will respond in force. Moreover, a hard target has likely been fortified in advance to protect against the possibility of attack, thus making the terrorist's job significantly more difficult and fraught with risk. The decision to attack a hard target therefore signals that the group believes that the coercive message the attack will send is worth the risk of death or imprisonment of its members. ${ }^{14}$ It is expected that centralized groups such as hub-spoke and bureaucracies will be more likely to attack hard targets because these groups are more capable than less centralized groups. Moreover, it is expected that loosely organized groups, especially market groups, will be incapable or unwilling to attack hard targets.

Soft targets are, from a terrorist point of view, easier to attack than hard targets. ${ }^{15}$ Soft targets include educational institutions, NGOs, journalists (and the media), and private citizens and private property. Soft targets are chosen for their convenience, their low security and, of course, for ideological reasons.

Figure 7 shows the proportion of coercive targets of all four organizational structures. There is an increase in coercive attacks as group structure becomes more centralized. This increase is most pronounced when moving from market to all-channel structures

\footnotetext{
${ }^{14}$ Hard targets can also include - especially post $9 / 11$ - high value targets such as legislatures, iconic tourist destinations or certain conspicuous government buildings. However for analytical clarity, the hard target category was kept to only those that pose a definite risk to the group: police and military outposts.

${ }^{15}$ From the state's point of view it is sometimes not possible to 'harden' a soft target, even if it may be under threat. This difficulty could be due to the inherently open nature of a soft target such as a school.
} 


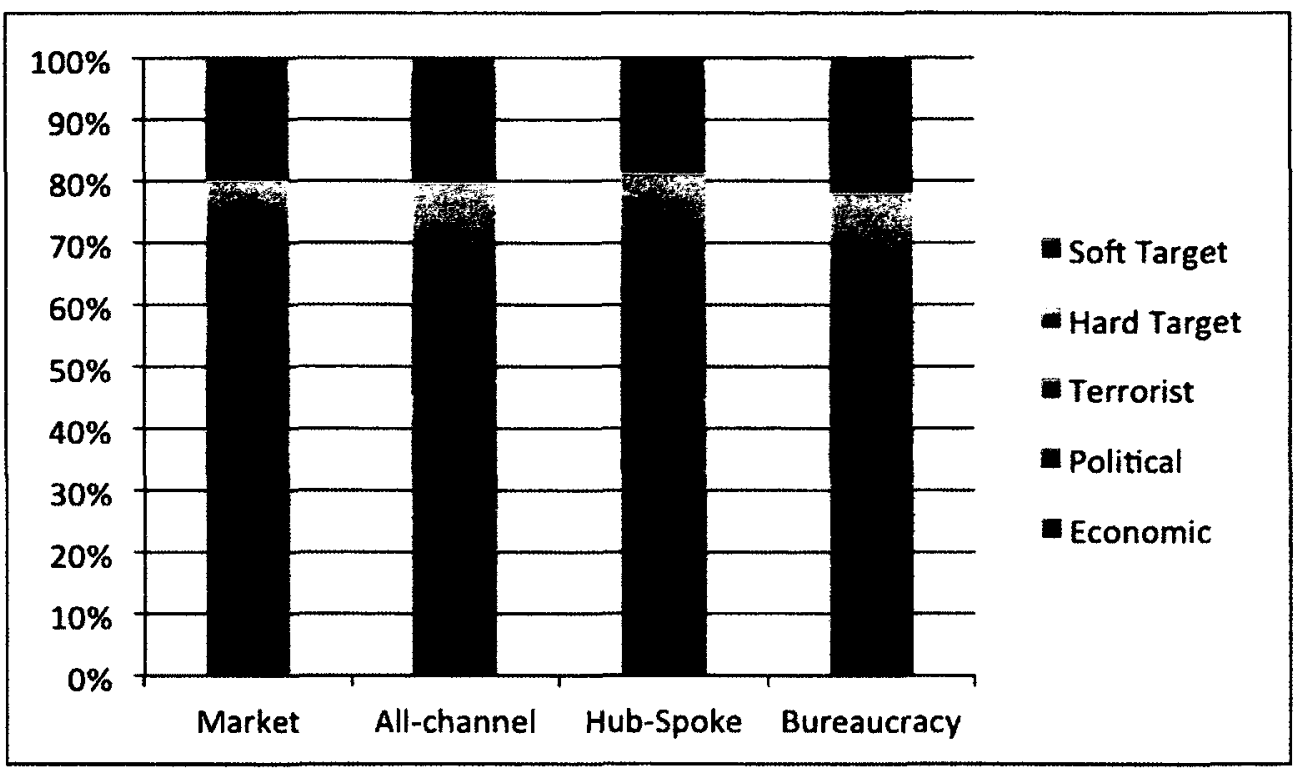

Figure 7: Target selection (\% of total)

where the proportion of coercive attacks goes from 38 to $53 \%$ of all attacks but then the proportion increases only slightly - less than 1 percent - as centralization increases to hub-spoke and bureaucracies.

\subsubsection{Attention-seeking Target Selection}

Often, a group will choose a target not with the primary goal of coercion but simply to raise awareness of their issue and to heighten the group's profile. For some groups, their goals are incompatible with high casualty attacks. Nationalist groups are one such type. An infamous example of the hazards of nationalist groups employing high fatality attacks is the 1998 Omagh bombing by the Real Irish Republican Army. The attack killed 29 and injured over 200. It was perceived as a massive error and resulted in a great deal of damage to the republican cause. In fact, the backlash against the 
republican efforts for independence following the attack was so severe that many argue it precipitated the Good Friday agreement in 1999 (see, among others, Cox et al., 2006; Dingley, 2001; Hayes and McAllister, 2001). When a group is interested in little more than "a lot of people watching, not a lot of people dead," it turns to attention-seeking targets (Jenkins, 1975, p. 4). It is posited that when a group attacks an attention-seeking target the focus is more on the symbolism of the target, and not inflicting maximal casualties. ${ }^{16}$ It is a strategic choice to destroy property but spare lives. There are two subtypes of attention-seeking targets, economic and political.

Economic targets include businesses, airports, food and water supplies, maritime operations (non-military), telecommunications, tourist attractions, transportation hubs and utilities. ${ }^{17}$ Economic targets are attractive to terrorist groups because they often represent a lower risk compared to hardened targets and offer an opportunity to disrupt economic activity within a state. Economic targets can affect a broad spectrum of the public since disrupting the flow of goods and services can have a large impact on the economy (see Chen and Siems, 2004; Karolyi and Martell, 2005). Generally

\footnotetext{
${ }^{16} \mathrm{As}$ with all of these categorizations I make here, there are exceptions. Most notably, the attacks on the Twin Towers in New York in 2001. This attack, while coded as an attention-seeking, economic target, had more than 2,600 fatalities. It is important to note, therefore, that while my method of categorizing the 22 target types provides a chance to examine basic trends, it is by no means perfect.

${ }^{17}$ While creating distinct categories of target types suits the purposes of this chapter, it is important to note that the actual decision-making by a terrorist group of which type of target is considerably more nuanced. For example, some tourist attractions are hardened targets due to the high potential of an attack against them, such as the CN Tower in Toronto. A tourist attraction can also be used as a site for a high casualty attack, such as the Luxor massacre in Egypt in 1997. One advantage of the current dataset is that since it is incident-based, it can capture the overall trends of separate organizational types.
} 
speaking, economic attacks impose a financial cost, not necessarily a high human cost. As the cross-tabulation presented in Table 8 shows, attention-seeking attacks have a much lower casualty rate than coercive attacks. ${ }^{18}$

Political targets are often chosen due to their symbolic value. While attacking economic targets is a strategy aimed at the broader public, I argue that attacking political targets are often more narrowly focused on a particular issue or symbol. Political targets are not just defined as the apparatus of government and political actors, but also include abortion-related sites, diplomatic persons or buildings, and religious targets. For groups attacking political targets, it is posited here that their constituency is often smaller. Therefore, I expect that groups selecting political targets will have a small membership that are either left or right-wing motivated. This result is expected because smaller groups without nationalist or religious aspirations have smaller constituencies which reflects their more narrow, and obscure, goals.

\subsubsection{Infighting target selection}

The final category is infighting targets, defined as attacks against terrorist groups or violent political parties. ${ }^{19}$ Infighting targets are distinct from other targets because they do not actually advance the goals of any group. ${ }^{20}$ Rather, infighting occurs as a result of competition from other groups. When these types of targets are chosen in

\footnotetext{
${ }^{18}$ The test indicates that target and lethality are statistically dependent.

${ }^{19}$ The GTD codes terrorist groups and violent political parties separately. Violent political parties are coded as distinct from normal political parties.

${ }^{20} \mathrm{I}$ know of no terrorist group that exists simply to compete with other terrorist groups for support.
} 
Table 8: Frequency Table: Target Category and Lethality

\begin{tabular}{lllll}
\hline Target Category & 0 Dead & 1-5 Dead & 6+ Dead & Total \\
\hline Economic & 16,547 & 3,208 & 843 & 20,628 \\
& $(11,422)^{a}$ & $(7,141.6)$ & $(2,064.4)$ & \\
Political & 8,736 & 4,171 & 525 & 13,432 \\
& $(7,437.5)$ & $(4,650.3)$ & $(1,344.3)$ & \\
Hard Target & 6,715 & 9,327 & 3,033 & 19,075 \\
& $(10,562.1)$ & $(6,603.9)$ & $(1,909)$ & \\
Soft Target & 8,321 & 7,921 & 2,783 & 19,025 \\
& $(10,534.4)$ & $(6,586.6)$ & $(1,904)$ & \\
Infighting & 463 & 872 & 157 & 1,492 \\
& $(826.1)$ & $(516.5)$ & $(149.3)$ & \\
\hline Total & & & & \\
\hline
\end{tabular}

${ }^{a}$ expected frequency in brackets.

$($ Pearson $\operatorname{chi} 2(8)=1100$, Pr. $=0.000)$

a state or region, it is a good indicator that a constituency is shared between several terrorist groups.

Since bureaucratic groups are most often quite large, it is posited that these groups will also have a larger constituency to support them. That there is a larger constituency means that there may be a greater 'market' of potential support within which groups may compete. Moreover, as established in Chapter 2, bureaucratic groups are more likely to occur in states with low GDP per capita and therefore low counter-terrorism capacity. In these states, terrorist groups are able to proliferate and it is therefore expected that bureaucratic groups will be more likely to engage in infighting as groups try to consolidate their power and establish a monopoly of 


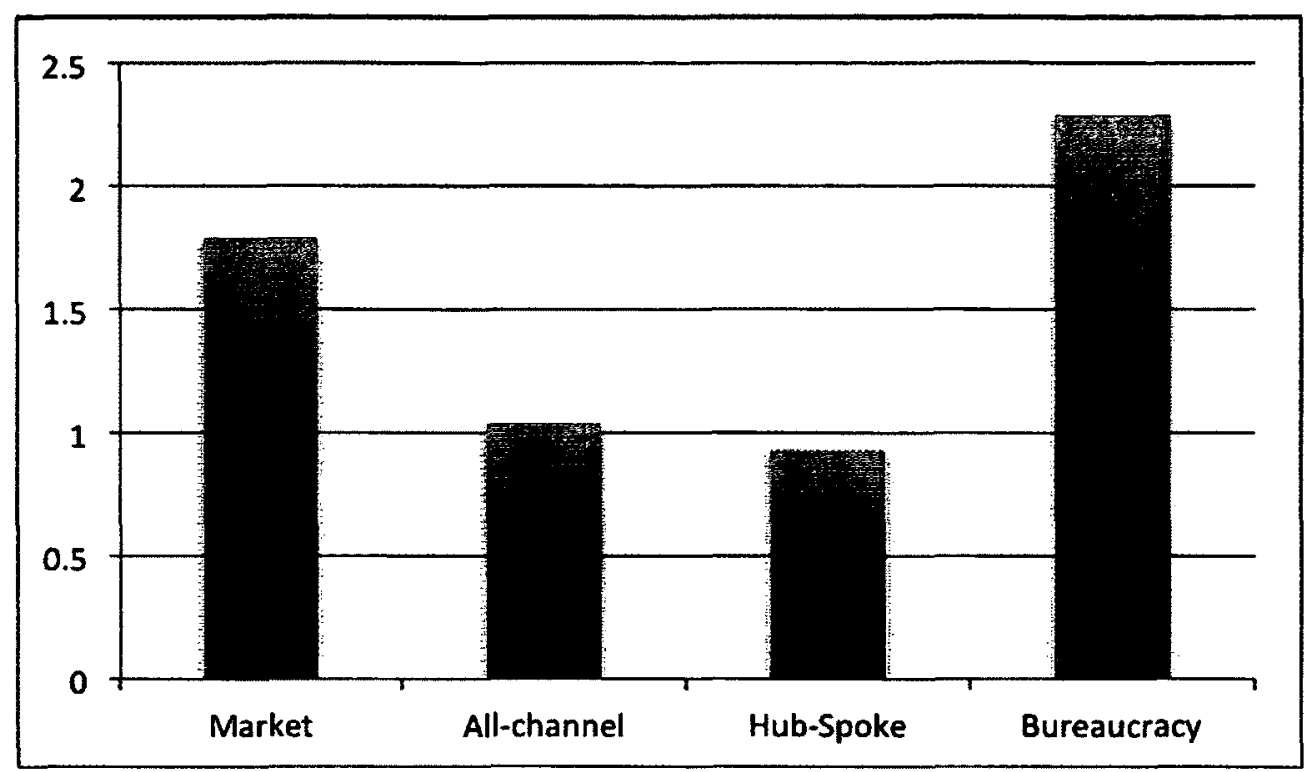

Figure 8: Infighting targets (\% of total attacks)

support. As Figure 8 suggests, the percentage total targets dedicated to infighting targets is highest for bureaucratic and market structures.

I also posit that market groups are more likely to engage in infighting attacks. Contrary to all-channel and hub-spoke groups, market groups have very little evidence of cooperation. A market structure is competing for support, with little or no internal or external cooperation.

\subsection{Results: Target Categories}

The first estimation, shown in Tables 9 to 11 , looks at the target categories: attentionseeking (economic or political), coercive (hard or soft targets), and infighting. The 
second estimation, shown in the Appendix across Tables 22 to 30 provides the complete model with all the constituent parts of each category presented. ${ }^{21}$

As is evident by the results of the multinomial logit for target categories, the results are highly complex. I make reference to the complete model, included in the Appendix, only when there is an exception to the general result of a target category. For example, the results of the economic target category accurately captures, for the most part, the constituent parts of all the economic target types. However, where differences exist between these two models, I make reference to the complete model; otherwise, I do not. The results are organized this way since the focus here is to provide an initial basic overview of these categories of targets. The next section is a first look at the affect of agency and context on terrorist group target selection. Below, I organize the results according to the independent variables in the following order:

1. Group ideology, ${ }^{22}$

2. GDP per capita (chain series) and Freedom House data

3. Calendar year, group age and peak size

\section{Organizational structure}

\footnotetext{
${ }^{21}$ Due to the extremely large size of these estimations, they are presented across several separate tables, even though there are only two estimations presented in this chapter.

${ }^{22}$ Religious, right-wing, left-wing and the base case, nationalist.
} 


\subsubsection{Group Ideology}

As shown in Table 9, compared to nationalist groups, left-wing groups are 2.65 times more likely to select economic targets and 1.74 times more likely to select political targets, holding all other variables constant. ${ }^{23}$ A similar relationship - but not a statistically significant one - is observed for right wing groups. Religious groups are (weakly) associated with a lower propensity for economic attacks, when compared to nationalist groups, holding all other variables constant.

For the economic target category there are two key differences when examining the disaggregated, complete model, as shown in the Appendix in Table 23. First is the results for maritime targets. Contrary to the economic target category, maritime targets by left-wing groups are only at $37 \%$ of the level of nationalist groups, holding all other variables constant. There are two plausible explanations for this variance observed in maritime targets compared to the economic category. First, while left-wing groups are positively associated with the overall economic category, this is not the case for maritime targets. One possible explanation is a constituency affect. Left-wing groups are most often motivated by socialist values, and these groups fight to support the worker. Maritime employment is often blue collar so attacking maritime targets could be bad for maintaining the group's constituency support. A second plausible explanation is that maritime targets, like other transportation targets, become more hardened in wealthy states. While economic targets are generally not hardened

\footnotetext{
${ }^{23}$ Attention-seeking targets consist of both economic and political targets
} 
targets, the maritime target set would be more so, especially in more wealthy states. ${ }^{24}$

The second difference is with tourist targets. As Table 23 shows, compared to nationalist groups, religious groups attack tourist targets 3.23 times more often. This result is in contrast to the economic category as a whole where religious groups are less likely to select economic targets than nationalist groups. One possible interpretation of this contradictory result is that nationalist groups, with their natural pool of support, do not want to negatively affect the tourist trade by attacking it (Post, 2005, p. 56). Religious groups, however, may see tourists as unworthy infidels unwelcome in a holy place. ${ }^{25}$

Turning to the coercive target category, as Table 10 shows, there is little in the way of statistically significant findings in terms of group ideology. The one key finding for ideology, relative to nationalist groups, is that right-wing groups attack soft targets 7.38 times more frequently. The relative risk ratios for both left-wing and religious groups, compared to nationalist groups, are also weakly positive for soft target attacks.

Left-wing groups are 3.93 times more likely, compared to nationalist groups, to attack

\footnotetext{
${ }^{24}$ To test this assertion I split the observations into two samples using the World Bank income group variable. This variable rates a state's economy from one to four, with four being high income and one being low income. I limited my sample to high income states and another sample to low and lower-middle income states. I re-ran the multinomial logit using each sample and found that for the lower income sample, the results remained consistent with the original result. However, for the sample that includes only the high income states, the results for the maritime target type closely resemble the hard target category listed above. This result seems to support the second hypothesis that maritime targets become hardened as state wealth rises.

${ }^{25}$ One illustrative example is the Luxor Massacre in Egypt in 1999 by the Muslim Brotherhood.
} 
journalists and media targets, holding all other variables constant. ${ }^{26}$ These results suggest that all ideologies are more likely to attack journalists or the media than nationalist groups; the implication of this is that, more than any other ideology, nationalism involves a populist, attention-seeking campaign with a strategy of winning over the press, not killing them.

Finally, Table 11 shows the results of the infighting target category. Relative to nationalist groups, right-wing groups are 18.7 times more likely while religious groups are 1.5 times more likely to select infighting targets, holding all other variables constant. ${ }^{27}$ Conversely, left-wing groups attack infighting targets far less - one quarter as often - as nationalist groups.

Putting this all together, it becomes clear that nationalist groups are less likely to attack attention-seeking targets than other ideologies. ${ }^{28}$ This result may have to do with the relatively high support nationalist groups receive. Many of the larger groups that have moved beyond the 'raising awareness' phase of a terror campaign towards an insurgency are nationalist groups (Jones and Libicki, 2008). These groups often enjoy broad-based support, more so than their contemporaries (Frey and Luechinger, 2003). It is for this reason that nationalist groups may shy away from attacking targets that would disrupt economic output.

However, this explanation does not explain why nationalist groups are less likely than

\footnotetext{
${ }^{26}$ These results are shown in Table 26.

${ }^{27}$ The results for religious groups are only statistically significant to a confidence interval of $85 \%$.

${ }^{28}$ Holding all other variables constant. The one exception here is economic targeting by religious groups which is negatively associated, to a confidence interval greater than $85 \%$.
} 
other groups to attack political targets. Indeed, it is political targets that are precisely at the centre to a nationalist campaign. Achieving independence, the stated goal for most nationalist groups, almost always comes by wresting autonomy away from the federal government and by putting pressure on the non-indigenous population to press for autonomy to be granted. However, upon closer examination of what constitutes the 'political' category (government, abortion clinics, diplomats and religious targets) it becomes more clear as to why this result is observed. Nationalist groups seek a homeland or autonomy. While their target is most often the state, their goal is not only winning over their constituency within the country but also often gaining the sympathy of the diaspora and the media alike. In playing to these constituencies, nationalist groups may be acutely aware of what is tolerated and what is not. While speculative, nationalist groups may limit attacks against general government buildings or even a legislature and instead choose to target the apparatus of government that is actually doing the oppressing: the police and the military, measured here as hard targets.

With the affects of group ideology on target selection sketched out, the next section turns to the independent variables for year, group age and peak size. 


\subsubsection{Calendar year, group age and peak size}

The incidence of all target categories in this estimation increases over time. ${ }^{29}$ The same cannot be said for the age of the group. With the exception of hard targets, as displayed in Table 10, for every year a group gets older, there is a decrease in the number of attacks targeting government, political, soft or infighting targets, holding all other variables constant. While not statistically significant, as a group ages it is weakly associated with an increase in hard target attacks. ${ }^{30}$

These findings suggest some general conclusions for the population of terrorist attacks since 1970. First, since 1970 there has been a rise in the overall frequency of terrorist attacks. ${ }^{31}$ Part of this rise can be explained by a possible underreporting bias in the early days of the GTD (see Drakos and Gofas, 2006; Drakos, 2007). One would also expect to see a sharp increase in attack monitoring capability with the widespread use of the Internet..$^{32}$ Beyond the 'numbers game,' however, is the fact that the age of a group has an general affect on targeting. With the exception of hard targets the most difficult and risky type - all other targeting categories decrease as the group ages. This result suggests that groups may have a vested interest to attack targets

\footnotetext{
${ }^{29}$ The relative rate ratio for the variable "year" is statistically significant and positive for every target category. This affect is seen in Tables 9 to 11 . This general result holds in most of the 22 target types detailed in the complete model found in the Appendix. There are a few exceptions: maritime, tourists, journalists \& the media, NGOs and terrorist group targets all decline over time, however only the result for NGOs is statistically significant.

${ }^{30}$ This finding is further investigated in Chapter 4.

${ }^{31}$ Not shown here but I have observed this trend in the GTD dataset.

${ }^{32}$ Indeed, there is a correlation that supports this. Following 1998 there are significantly more attacks per annum than prior to this date. While correlation does not imply causation, this finding is consistent with the under-reporting bias hypothesis.
} 
early on to establish themselves and stake a claim to a grievance. It also suggests that while coercive, infighting and attention-seeking targeting differ in what they say about the group, hard target attacks are more likely to be mounted only by those groups which demonstrate lasting power and therefore have had years to accumulate lessons learned from previous hard target attacks.

The results for peak size of a group are uniform across all target categories; as a group gets larger, the incidence of all targets increase, holding all variables constant. With the temporal variables and peak size covered, the next section looks at the affect of GDP per capita and Freedom House on terrorist group target selection.

\subsubsection{GDP per capita and Freedom House}

Examining GDP per capita as an indicator of counter-terror effectiveness provides further insight into the general trends surrounding targeting selection by groups. In terms of attention-seeking attacks, as seen in Table 8, there is a weakly positive relationship between an increase in GDP per capita and economic targets. ${ }^{33}$ For every increase in GDP per capita the rate of economic targets would be expected to increase by a factor of 1.02 .

For coercive targets the trend of GDP per capita is, overall, a negative relationship. As shown in Table 9, as GDP per capita increases, hard target attacks decrease by a

\footnotetext{
${ }^{33}$ To a $85 \%$ confidence interval, holding all other variables constant. For political targets, there is no relationship.
} 
Table 9: Multinomial Logit (Part I): Attention-seeking Category

\begin{tabular}{|c|c|c|c|}
\hline Term & RRR & Standard Error & p-value \\
\hline \multicolumn{4}{|l|}{ Economic targets } \\
\hline Market structure & 1.7379 & 1.0979 & $0.038 * *$ \\
\hline All-channel structure & 0.4343 & 0.0954 & $0.000 * * *$ \\
\hline Hub-spoke structure & 1.0674 & 0.1996 & 0.727 \\
\hline Is left-wing & 2.6586 & 0.5406 & $0.000 * * *$ \\
\hline Is right-wing & 3.9975 & 4.0573 & 0.172 \\
\hline Is religious & 0.6408 & 0.1752 & 0.104 \\
\hline Year & 1.0018 & 0.0002 & $0.000 * * *$ \\
\hline GDP per capita (chain) & 1.0221 & 0.0146 & 0.124 \\
\hline Freedom House & 1.0455 & 0.0569 & 0.233 \\
\hline Group age & 0.9844 & 0.0050 & $0.000 * * *$ \\
\hline Peak size & 1.6286 & 0.1926 & $0.000 * * *$ \\
\hline \multicolumn{4}{|l|}{ Political targets } \\
\hline Market structure & 2.2084 & 1.4001 & 0.212 \\
\hline All-channel structure & 0.6251 & 0.1386 & $0.034 * *$ \\
\hline Hub-spoke structure & 0.8447 & 0.1596 & 0.372 \\
\hline Is left-wing & 1.7429 & 0.3587 & $0.007 * * *$ \\
\hline Is right-wing & 3.8822 & 3.9559 & 0.183 \\
\hline Is religious & 1.2672 & 0.3479 & 0.388 \\
\hline Year & 1.0017 & 0.0002 & $0.000 * * *$ \\
\hline GDP per capita (chain) & 0.9992 & 0.0144 & 0.956 \\
\hline Freedom House & 0.9902 & 0.0546 & 0.857 \\
\hline Group age & 0.9761 & 0.0051 & $0.000 * * *$ \\
\hline Peak size & 1.5781 & 0.1885 & $0.000 * * *$ \\
\hline
\end{tabular}

Note: Pseudo R2 is $0.2350 . \mathrm{N}=34,811$. Base category is 'unknown'

$\dagger: p<.1 ;^{*}: p<.05 ;^{* *}: p<.01 ;^{* * *}: p<.005$ 
Table 10: Multinomial Logit (Part II): Coercive Category

\begin{tabular}{|c|c|c|c|}
\hline Term & RRR & Standard Error & p-value \\
\hline \multicolumn{4}{|l|}{ Hard Targets } \\
\hline Market structure & 1.8445 & 1.1696 & 0.334 \\
\hline All-channel structure & 0.7063 & 0.1547 & 0.112 \\
\hline Hub-spoke structure & 1.3881 & 0.2593 & $0.079 \dagger$ \\
\hline Is left-wing & 1.2183 & 0.2472 & 0.331 \\
\hline Is right-wing & 0.6363 & 0.6507 & 0.658 \\
\hline Is religious & 0.8210 & 0.2222 & 0.466 \\
\hline Year & 1.0022 & 0.0002 & $0.000 * * *$ \\
\hline GDP per capita (chain) & 0.9436 & 0.0135 & $0.000 * * *$ \\
\hline Freedom House & 0.9957 & 0.0541 & 0.937 \\
\hline Group age & 1.0029 & 0.0051 & 0.571 \\
\hline Peak size & 1.6781 & 0.1938 & $0.000 * * *$ \\
\hline \multicolumn{4}{|l|}{ Soft Targets } \\
\hline Market structure & 1.5448 & 0.9793 & 0.493 \\
\hline All-channel structure & 0.4518 & 0.0996 & $0.000 * * *$ \\
\hline Hub-spoke structure & 0.7813 & 0.1466 & 0.188 \\
\hline Is left-wing & 1.2873 & 0.2629 & 0.216 \\
\hline Is right-wing & 7.3847 & 7.4862 & $0.049 *$ \\
\hline Is religious & 1.5689 & 0.4260 & $0.097 \dagger$ \\
\hline Year & 1.0022 & 0.0001 & $0.000 * * *$ \\
\hline GDP per capita (chain) & 0.9798 & 0.0141 & 0.156 \\
\hline Freedom House & 0.9158 & 0.0500 & 0.108 \\
\hline Group age & 0.9805 & 0.0050 & $0.000 * * *$ \\
\hline Peak size & 1.5009 & 0.1781 & $0.001 * * *$ \\
\hline
\end{tabular}

Note: Pseudo $\mathrm{R} 2$ is $0.2350 . \mathrm{N}=34,811$. Base category is 'unknown'

$\dagger: p<.1 ;^{*}: p<.05 ;^{* *}: p<.01 ;^{* * *}: p<.005$ 
Table 11: Multinomial Logit (Part III): Infighting Category

\begin{tabular}{lccl}
\hline Term & RRR & Standard Error & p-value \\
\hline Market structure & 1.0792 & 0.7281 & 0.910 \\
All-channel structure & 0.1756 & 0.0494 & $0.000 * * *$ \\
Hub-spoke structure & 0.3294 & 0.0722 & $0.000 * * *$ \\
Is left-wing & 0.2524 & 0.0605 & $0.000 * * *$ \\
Is right-wing & 18.690 & 19.173 & $0.004 * * *$ \\
Is religious & 1.5365 & 0.4567 & 0.148 \\
Year & 1.0014 & 0.0002 & $0.000 * * *$ \\
GDP per capita (chain) & 0.9836 & 0.0156 & 0.298 \\
Freedom House & 0.9022 & 0.0563 & 0.100 \\
Group age & 0.9726 & 0.0056 & $0.000 * * *$ \\
Peak size & 1.7945 & 0.2414 & $0.000 * * *$ \\
\hline
\end{tabular}

Note: Pseudo $\mathrm{R} 2$ is $0.2350 . \mathrm{N}=34,811$. Base category is 'unknown'

$\dagger: p<.1 ;^{*}: p<.05 ;^{* *}: p<.01 ;^{* * *}: p<.005$

factor of 0.94 , holding all other variables constant. A similar relationship is observed for soft target attacks but the result is not statistically significant. ${ }^{34}$ The result for hard target attacks is of particular interest. If we accept that GDP per capita is a measure of counter-terror effectiveness, then these results suggest that the preference for hard targeting in lower income states is due to those states' lower counterterrorism capacity. There is therefore a greater likelihood of a successful hard target attack. The complete model has a few exceptions to this general trend. Attacks on both transportation and utilities targets decrease as GDP per capita increases, by 0.97 and 0.94 , respectively. These results are displayed in Table $24 .{ }^{35}$

\footnotetext{
${ }^{34}$ For infighting targeting, the relationship is also negative but not statistically significant.

${ }^{35}$ The GTD codes the transportation target type as attacks on public transportation systems (buses, minibuses, trains, metro/subways, highways (if the highway itself is the target of the attack), bridges and roads. Coding for the target type 'utilities' is defined as attacks on power lines, oil pipelines, electrical transformers, high tension lines, gas and electric substations (see GTD Codebook, 2009).
} 
Results from the variable Freedom House suggest that political rights and civil liberties variable is (weakly) negative for all target categories. The strongest results, as seen in Tables 10 and 11, are for soft and infighting targets. ${ }^{36}$ In other words, as political rights and civil liberties decrease, there is a decrease in soft and infighting targets selected, by a factor of 0.92 or 0.9 , respectively, holding all other variables constant. This result can be interpreted that for states that are less democratic, soft targets and infighting target selections decrease.

There is only one discrepancy between the target categories discussed here and the complete model displayed in the Appendix. For the political category, the results for the Freedom House variable are not significant, the results for the target type 'government (diplomatic)' are quite robust. Table 29 shows that as political rights and civil liberties decrease, targeting diplomats increases by $22 \%$, holding all other variables constant. This, of course, implies that attacks on diplomats occur more often in less democratic states. This result does not, however, suggest the nationality of the diplomatic target attacked so it is impossible to assess what states the attacked diplomats represent. ${ }^{37}$

\footnotetext{
${ }^{36}$ Both of these are statistically significant to a confidence interval of only $85 \%$.

${ }^{37}$ This would be an interesting topic for future research from a comparative case study perspective. The GTD codes the location of each attack and, often, notes on who the intended target is. Examining the relationship between the type and structure of group and the diplomats they attack could yield some interesting results.
} 


\subsubsection{Organizational Structure}

For the economic target category, all-channel groups have the strongest results. As Table 9 indicates, compared to bureaucracies, economic attacks by all-channel groups are $57 \%$ lower. Compared to bureaucracies, market structures are expected to select economic targets 1.74 times more often, holding all other variables constant. The results for hub-spoke groups are positively signed but not statistically significant. When examining the complete model in the Appendix, two target types differ from the economic category: tourist targets and airports and airlines.

For tourist targets, as seen in Table 23, there are three key differences when compared to the economic category. Compared to bureaucracies, the rate of tourist targeting by market structures increases in magnitude by 3.57 but becomes less significant in a statistical sense. For the economic category, the finding is that all-channel groups attack economic targets less often than bureaucracies. However, for tourist targets specifically, all-channel structures are just as likely as bureaucracies to attack tourist targets.

For the airport and airlines target, Table 22 in the Appendix reveals that, contrary to the general economic target category, hub-spoke structures attack airports and airlines at only $38 \%$ of the rate of bureaucratic groups. This result is rather stark. Market groups continue to be positively, but not significantly in a statistical sense, associated with attacks on airports and airlines. Both networked structures, however, are less likely to attack airports and airlines than bureaucracies, holding all other 
variables equal. This result is interesting since it implies that while groups at opposite ends of the centralization spectrum are somewhat similar, networked groups abstain from attacks on airlines and airports. The explanation cannot simply be a matter of organizational capability, conceived as a measure of centralization, since market groups are loosely coordinated without real leadership or centralization. It is possible that necessary details of each attack are missing from this analysis, namely if market groups attack the 'soft parts' of the airline industry such as offsite ticketing counters while bureaucratic groups focus more on the 'hard parts' such as the airport and aircraft. When comparing the lethality between market and bureaucratic groups attacking the airline and airport target there is a difference. Attacks by market groups have zero fatalities more than $92 \%$ of the time while bureaucratic groups have zero fatalities less than $78 \%$ of the time.

Table 9 shows that there is a similar relationship in organizational structures for both economic and political targets. Political targeting by all-channel groups is $37 \%$ lower than bureaucratic groups, holding all other variables constant. ${ }^{38}$

Turning to the coercive target category - both hard and soft targets - compared to bureaucratic groups, all-channel groups are less likely to select either of these targets, by a factor of 0.70 or 0.45 , respectively. ${ }^{39}$ Hub-spoke groups, compared to bureaucracies, are $40 \%$ more likely to select hard targets, holding all variables constant. For

\footnotetext{
${ }^{38}$ While not statistically significant, market groups are more likely to attack attention-seeking targets than bureaucratic groups and hub-spoke groups are more likely to attack economic but less likely to attack political targets than bureaucratic groups.

${ }^{39}$ The hard target result is not statistically significant.
} 
soft target attacks, compared to bureaucratic groups, hub-spoke groups are (weakly) expected to increase, holding all other variables constant. (See Table 10). For both the hard and soft target categories, market groups have a higher expected rate but the results are not statistically significant. Finally, compared to bureaucratic groups, all-channel groups attack soft targets $55 \%$ less often, holding all other variables equal. This trend is seen across all category types suggesting that all-channel groups are the least capable structure type.

When examining the disaggregated model, as shown in Table 25, I find no statistically significantly different results for either police or military targets. This suggests therefore that the hard target category accurately captures the results from both police and military targets on their own. However, it must be noted that while not statistically significant, compared to bureaucratic groups, market structures are expected to have a higher rate of both police and military targeting by a relatively large magnitude of 2.97 and 2.59 , compared to bureaucratic structures, respectively. These are unexpected results and are statistically significant to almost the 90 and $85 \%$ levels, respectively. ${ }^{40}$

\footnotetext{
${ }^{40}$ To help explain this finding, I investigated the market groups responsible for the most hard target attacks. One of these groups, while it meets the coding requirements of a market structure, is an umbrella group for several groups. This group is the Simon Bolivar Guerilla Coordinating Board (CGSB), which was an umbrella organization for various Colombian left-wing groups including FARC, M-19 and ELA, among others. The CGSB is coded as a market group because the umbrella group lacks discernible leadership, centralized command and control of the sub-groups and was not functionally differentiated (Jane's, 2005; START). The GTD attributes a number of attacks to this group and and not one of its subgroups.; this is the reason for its inclusion. This one group is responsible for more than $26 \%$ of all hard target attacks by market groups, and more than $44 \%$ of all attacks with greater than five fatalities. When the CGSB is excluded from the estimation, the unexpected result of market structures with high hard target attacks disappears. To push this result a little further $I$ also re-ran the estimation with only attacks with more than 5 casualties and the strength of the RRR for market structures gets stronger. When re-running the estimation with
} 
There are a few differences between the category 'soft target' and the complete model as shown in in the Appendix in Table 26. For educational institutions, the affects of all the structure types are more pronounced. As in the soft target category, compared to bureaucracies, market structures target educational institutions 4.05 times more often, holding all other variables constant. This result suggests that perhaps there is more of a link between market groups and students when compared to bureaucratic groups. For example, environmental and animal rights groups, many of which are market structures, were founded by students. It is possible, then that these groups would have a bias toward attacking education institutions, perhaps their own, since they are a part of that community and seek to influence other within the academic community. ${ }^{41}$

The result that market groups are at least as likely to attack coercive targets as bureaucracies is a surprise. It was expected that market groups would be least likely to employ coercive attacks. As Table 10 shows, this is not the case. Continuing this trend, Table 9 shows that market groups are also more likely to attack both political and economic targets than other groups.

Finally, for infighting targets, Table 11 shows that there are two statistically significant

a sample of high casualty attacks but excluding the CGSB, the RRR for market groups loses its statistical significance completely. These tests strongly suggest that the unusual results in the police and military targets are being driven by the CGSB, a group coded as a market structure but with a much higher sophistication than a typical market groups. To be sure that the group CGSB was not driving the results from the target categories, found in Tables 9 to 11, I excluded the CGSB and re-ran that model. There was no discernible difference. In sum, the CGSB seems to have a stronger affect on police and military targets on their own than it does on the hard target category.

${ }^{41}$ The other notable difference is for hub-spoke groups. The relative risk comparing hub-spoke groups to bureaucracies would be expected to decrease by a factor of 0.67 given the other variables in the model are held constant. 
results. The relative risk of hub-spoke groups, compared to bureaucracies, is $68 \%$ lower, holding all other variables constant.Compared to bureaucracies, all-channel groups are $84 \%$ less likely to target other violent groups, holding all other variables constant.

When I compare the results of infighting category to the complete model in the Appendix, a few differences arise. Table 28 illustrates, compared to bureaucratic groups, market groups are 3.47 times more likely to attack terrorist groups, holding all other variables constant and that hub-spoke groups are much less likely. These are strong results and suggest that bureaucratic groups are more likely to attack terrorist targets compared to either all-channel or hub-spoke groups but that market groups are even more likely than bureaucratic groups to fight other terrorist groups. There are several plausible explanations for this.

First, market structures, by nature, are disaggregated and small in numbers (Arquilla and Ronfeldt, 2001). The public support enjoyed by market groups is also generally quite small. By making the reasonable assumption that competition exists wherever terrorist groups are attacking each other, one can surmise that if a terrorist group is spending time and energy to attack competing groups in an environment of increased competition, it will have less time and energy to plan attacks in support of their cause. Second, bureaucratic groups generally operate in lower-income states where there is often a unstable or weak polity. Bureaucratic groups may fight with each other more often as the stakes are higher; they have the possibility of deposing the 


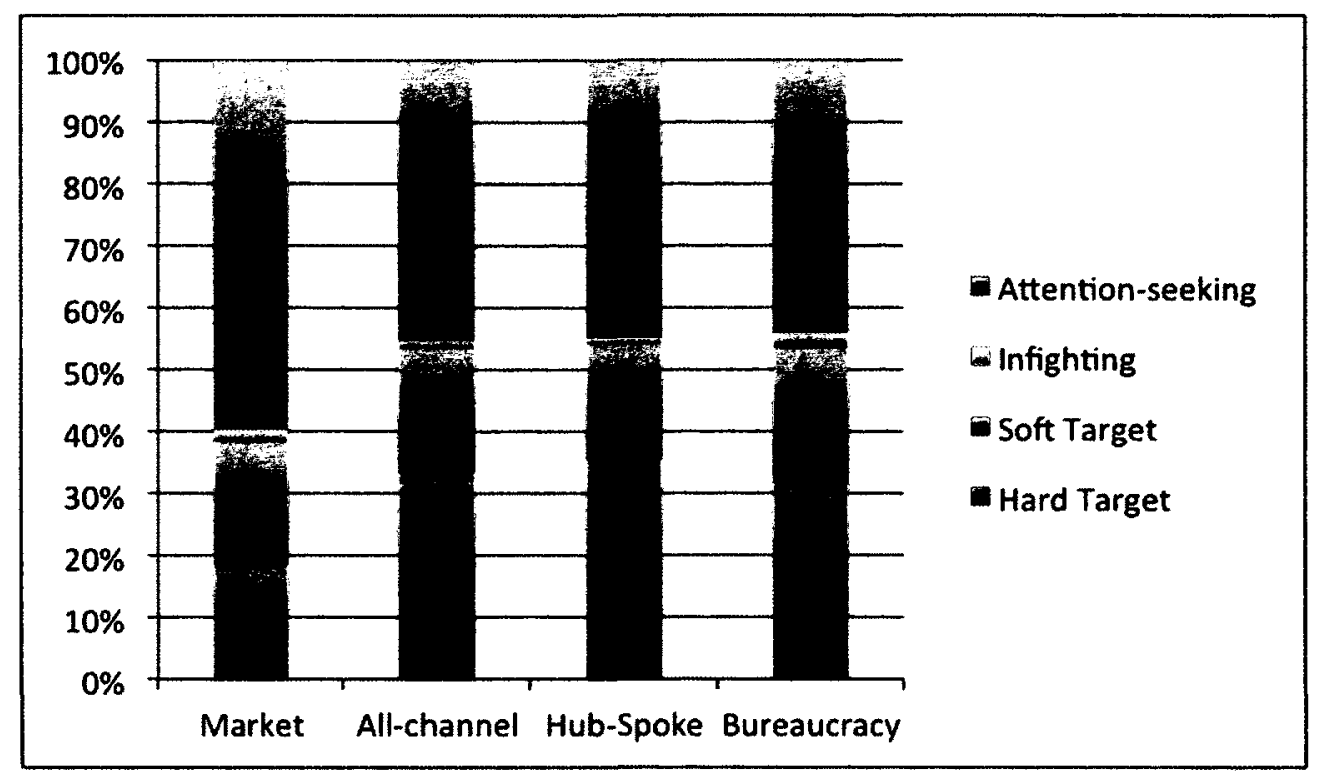

Figure 9: Target category by group structure

government and take over the government - a prize worth fighting for.

Putting all of these results together, a picture begins to emerge that is unexpected. Contrary to my hypothesis that bureaucratic groups will be more likely to select coercive targets than other structures, the results suggest that market groups are at least as likely - if not more likely - to select coercive targets as bureaucratic groups. Hub-spoke groups also select hard targets $38 \%$ more often than bureaucratic groups, holding all other variables constant. As Table 25 suggests, the unexpected market group result holds true when examining both police and military targets; market groups are 2.97 and 2.59 times more likely than bureaucratic groups to attack police or military targets. ${ }^{42}$ While the statistical significance may be slightly low, these results are unexpected and strongly suggest that bureaucratic groups are not the

\footnotetext{
${ }^{42}$ The statistical significance of these findings is almost 90 and $85 \%$, respectively.
} 
most likely structure to attack hard targets. In fact, the results suggest that allchannel groups are the least likely to attack coercive - hard or soft - targets followed by bureaucracies, then market groups and finally hub-spoke groups, as the most likely. This finding is explored below in the discussion.

\subsection{Diagnostics}

For the target category model testing for the Independence of Irrelevant Alternatives (IIA) assumption was done using a Small-Hsaio test for IIA assumption (Long and Freese, 2005). This test is done because a multinomial logistic regression assumes that odds for each specific pair of outcomes does not depend on other outcomes available (Sarkasian, 2011). The results of the test indicate that the IIA assumption is not violated with the current empirical model which means we can proceed to the other diagnostics.

Testing for multicollinearity was performed using an ordinary least squares (OLS) regression analysis and the variance inflation factors (VIFs) were inspected for each independent variable. ${ }^{43}$ The mean VIF is 1.42 . The VIF values for all independent variables were no higher than 2.14 , suggesting an almost total lack of multicollinearity ${ }^{44}$

There is in-built heteroscedasticity in logit models - the variance of the error term

\footnotetext{
${ }^{43}$ The VIF quantifies the severity of multicollinearity.

${ }^{44}$ As mentioned in Chapter 2, pairwise correlation was also performed, but not detailed here.
} 
is the greatest at the predicted probabilities around 0.5 and is smallest approaching either 0 or 1 (Sarkasian, 2011). The base model uses robust standard errors which further mitigates any affect of heteroskedasticity that may be present. When the base model with robustness was compared to the same model without robust standard errors, there was no change in the results indicating a lack of non-constant error term distribution (Cheng and Long, 2007).

Testing for linearity and additivity was performed visually using graphs using a locally weighted regression of structure on each separate independent variable (STATA, 2005 , p. 347). These plots compared the dependent variable with each independent variable and confirmed the presence of a linear relationship for each. To further push the test for linearity, bivariate relationships were examined by creating dichotomous dependent variables and these were subsequently plotted using locally weighted regressions.

Outliers were found in one independent variable, group age. ${ }^{45}$ When these outliers are removed there is no discernible affect in any of the comparator categories. The outliers are therefore included in the final analysis.

For the complete model testing for the IIA assumption was done using a HausmanMcFadden and Small-Hsaio test (Long and Freese, 2005). The results of the test

\footnotetext{
${ }^{45}$ The IRA is coded, in 2007, as 88 years old. Al Fatah and ETA are coded as 49 in 2007 while Italian Social Movement (MSI) is coded as 49 in 1995, the year of its demise. The mean of the variable 'group age' in this dataset is 17.99 and the standard deviation is 16.22 but it should be pointed out that this is an incident-based dataset. The actual mean age of the groups studied here is much lower.
} 
are that the IIA is not congruent with the empirical model. ${ }^{46}$ This is a relatively common problem to multinomial logit testing, particularly in the social sciences.(Long and Freese, 2005; Cheng and Long, 2007; Kropko, 2008). In particular, this IIA violation occurs in cases where there are a high number of categories in the dependent variable. Some, such as Kennedy (2003), argue that multinomial probit can be used to circumvent this problem as it does not carry the IIA assumption. However, others argue against this due to a greater chance of misspecification in the multinomial probit (Keane, 1992; Kropko, 2008). ${ }^{47}$

Moreover, employing a multinomial probit requires placing exclusion restrictions (i.e: some explanatory variables do not affect the utility of some options) which may further misspecify the model (Kennedy, 2003, p. 271). Finally, McFadden (1974) argues that multinomial logit be used only in cases where it can be assumed that the outcomes categories are "assumed to be distinct in the eyes of each decision maker." In other words, care in specifying the model is most important. In the current model, it is likely the result of a high number of categories in the independent variable and not a poorly specified model that is the cause of the IIA violation. ${ }^{48}$ However, for the current model, it was possible to theoretically simplify the number of targets into the five categories detailed in Tables 9 to 11. By re-specifying the model in this way, the

\footnotetext{
${ }^{46}$ In fact, some of these tests did not achieve convergence. However, both the Hausman-McFadden and Small-Hsaio test are known for giving contradictory and inconclusive results (see Long and Freese, 2005).

${ }^{47}$ In particular, Kropko (2008) goes so far as to claim that multinomial probit almost never gives as accurate results as a multinomial logit - even when the IIA assumption is severely violated.

${ }^{48}$ Moreover, there is strong evidence that the popular solution to this common problem, using a multinomial probit, may not provide any more precision.
} 
IIA violation is overcome. However, the complete model, shown here in Tables 22-30 is still included due to greater detail it provides. Readers should be aware that the interpretations of the complete model are done in spite of the IIA violation.

Testing for heteroskedasticity, linearity and additivity in the compete model was done in the same way as the category model discussed above. The results were within normal parameters.

In sum, the diagnostics for the complete model suggest that it does suffer from a violation of the IIA. There is evidence that this relatively common violation is not a problem of a mis-specification of the model but rather a result of a high number of categories of the dependent variable. Moreover, the fact that when comparing the results between the complete model, in Tables, 22 to 30 , and the categorized model, in Tables 9 to 11, the results are largely similar represents a theoretically derived re-ordering of the dependent variable and overcomes the IIA violation.

\subsection{Discussion}

As the above results suggest, as structure varies, so too does target selection. To restate a key result, all-channel groups are least likely to attack hard targets, followed by market and bureaucratic structures (statistically the same) while hub-spoke structures are the most likely. In effect, the results from this chapter are that, at least for target selection, market groups are more similar to bureaucracies than to either of 
the networked structures. In fact, it many ways, market groups look to be the most effective structure, but they operate under more difficult circumstances. Below, I discuss three considerations that may help clarify this result: leadership in the group and risk-taking by a group and competition from other groups.

Considering that these results are unexpected, one question to ask is: Why are allchannel groups, not market groups, the least likely to use coercive attacks? The only difference in structure between market and all-channel groups is leadership all-channel groups have nominal leadership; market groups do not. I argue that leadership should be the first place to look for answers to this unexpected result. Focusing on leadership leads me to posit that, if a leader exists, members turn to her or him for guidance or even inspiration. A leader of an all-channel group is really only nominally in control of the organization and this weak leadership may actually place constraints on the members of the group, disempowering them from being effective. Weak leadership may even translate as a drag on the capability of the organization. A market group, without any leadership at all can result in members who are fully empowered to act as they see fit to advance the organization. In this way, while a market group's members may not receive the benefits of any leadership, they are more empowered to act. It is possible that, in terms of the capability of an organization, no leadership is better than weak leadership. A similar argument can be made when comparing all-channel groups to hub-spoke groups. Here, hub-spoke groups have a much more clear delineation of role via functional differentiation and a 
more hierarchical structure. It can be argued that comparing all-channel to hub-spoke groups, capability flows in the direction of centralization.

Hard targets represent, I argue, the highest risk to a group since there will surely be armed opposition to their attack. A successful attack on a hard target requires careful planning and coordination; without it, the group will likely suffer large losses. ${ }^{49}$ For market structures, it was posited that these expected losses would serve as a disincentive for attacking these targets. Part of this expectation was that because market groups are typically the smallest-sized groups, they simply cannot afford to lose too many members. However, the size of the group ('peak size') is taken into account by the estimation. Therefore, while the results from this variable are that as a group gets larger their hard target attacks increase, the same cannot be said for market structures. These results suggest at least two explanations. First, perhaps hard targets, both police and military targets, are not as difficult to attack as expected. Second, the affect of structure is highly complex and does not translate into a linear relationship with respect to target selection. In any case, risk assessment of terrorist groups is a complex interaction fraught with multiple internal and external factors.

The competition facing any terrorist group will vary. However, based on two findings from this chapter, it is possible to argue that market and bureaucratic groups face more competition than their networked cousins. As Figure 8 shows, infighting targets as a percentage of total targets is higher for both market and bureaucracies. Market

\footnotetext{
${ }^{49}$ As Table 8 shows, hard targets are, by far, the most deadly target category.
} 
groups almost always operate in states with a high GDP per capita, a measure of counter-terror effectiveness. While this will likely act to limit the group's selection of targets and to keep the group relatively small, it may also mean that market groups enjoy more capable members. As an example, Sageman (2004) found that many Al Qaeda operatives who were successful in their attacks were raised in Western countries and had a high level of education. Bureaucracies are capable organizations that may seek to achieve a monopoly and will therefore vigorously defend their turf from other terrorist groups.

By contrast, the two network structures, all-channel and hub-spoke, may have builtin cooperation with other groups by virtue of their structure. These groups possess leadership but they are not capable enough to try to seek a monopoly like bureaucratic groups nor are they necessarily operating in a harsh environment like a market group. .50

The target package a group selects is one of the most important ways for a terrorist group to generate a narrative and push their agenda. The findings in this chapter suggest a complex interaction with both organizational structure and group ideology on target selection. While the large- $\mathrm{N}$ study provides a very good way to examine the overall affects of structure on targeting, it necessarily leaves out some detail in favour of generalizability; detail can only be achieved with a more focused methodology. Further research is required to further clarify and push the findings in this chapter.

\footnotetext{
${ }^{50} \mathrm{~A}$ future study could examine the level of cooperation between all structures to see which one is most competitive and which is most cooperative.
} 
One way to examine these findings is through a case study analysis. The next section examines in greater detail the question of structure on one group's targeting profile.

\subsection{Case Study: Euzkadi Ta Askatasuna (ETA)}

\subsubsection{Selection Criteria}

According to George and Bennett (2005) within-case analysis is a powerful tool for theory-building research, especially when it involves typological theory. Typological theory:

Specifies independent variables, delineates them into the categories for which the researcher will measure the cases and their outcomes, and provides [hypotheses] on how these variables operate individually but also contingent generalizations on how and under what conditions they behave in specified conjunctions (types) (George and Bennett, 2005, p. 235).

In other words, typological theory specifies generalized pathways. In contrast to a historical case study, typological theory may explain a phenomenon as one example of a general type of phenomena. As the current study represents the organizational theory of terrorist groups at its infancy (a building-block approach) selecting withincase studies as a means of cumulation of findings is appropriate (George and Bennett, 2005, p. 242). 
In terms of case study selection I identified 31 terrorist groups that had a documented change in structure within the analysis period of the GTD. ${ }^{51}$ Since structure is the object of study, these were the best candidates for study as a within-case study to control for most, if not all, variability and to isolate structure. ${ }^{52}$ Of these 31 groups, many were ruled out due to language barriers and a paucity of data. Others were ruled out as a result of low observations. ${ }^{53}$. The selection criteria for this study was ten or more attacks so while this low level of attacks benefits a large- $\mathrm{N}$ study, it excludes those groups from a case study that involves some simple statistical analysis. ETA has a relatively high number of attacks before and after their structure change. Given this change in structure, ETA provides a good example for a within-case study (George and Bennett, 2005; Eckstein, 1975).

\subsubsection{Background}

ETA is a Basque separatist group that aims to establish an independent socialist state in their homeland in northern Spain and southwest France (Jane's, 2009b). It was founded in 1959 in reaction to policies set in place by Spain's dictator General Francisco Franco, in particular banning the Basque language, suppressing its culture and

\footnotetext{
${ }^{51}$ These 31 groups are listed in the Appendix.

${ }^{52}$ This is preferable above two cases because controlling for the myriad of unique factors for each group and the CT environment is extremely difficult.

${ }^{53}$ While selecting for case studies in a systematic way is important, the information deficit that arises from studying secret organizations such as terrorist groups also matters. Moreover, a structured-focused comparison of two terrorist groups, controlling for issues of group motivation, counter-terrorism environment, group age, target strategy, among others, represents a daunting, if not impossible task. See Eckstein (1975)
} 
imprisoning Basque intellectuals (Alexander et al., 2001). ETA has claimed responsibility for more than $80 \%$ of the 1,000 people killed in Spain as a result of terrorist attacks between 1968 and 2001 (Civil, 2003). Yet, throughout this bloody campaign, ETA has sustained its support through effective public information campaigns reinforcing the notion that ETA's goals are Basque goals (Dishman, 2001).

From its humble beginning, ETA has proven itself to be a highly resilient and capable force. According to the GTD, ETA is responsible for 1,984 attacks between 1970 and 2007. However, beginning in late 2001, as part of a global push to combat terrorism, ETA has undergone some big changes. First, its popular support has declined. This is in part due to political concessions by the Spanish government granting the Basques more rights and more autonomy to the region. Second, following the March 2004 bombings in Madrid - that were originally blamed on ETA but were later proven to be the work of Abu Hafs al Masri Brigades - the country's appetite for terrorism waned, and with it, ETA fortunes. ${ }^{54}$ Finally and most crucially is the concerted, coordinated counter-terror campaign since 2001 that has proven highly successful in disrupting ETA's organization (Jane's, 2009b).

\subsubsection{Command and Control}

Prior to 2003, ETA's structure was hub-spoke and formed around commando groups. Each of these groups was supplied information from ETA's intelligence units and

\footnotetext{
${ }^{54}$ This is still a point of contention with some scholars. See De la Calle (2006).
} 
received training from other dedicated units (Jane's, 2009b). For many years, the hub-spoke structure provided ETA with enough security - they largely avoided leadership arrests until the early 2000s - and a functionally differentiated structure that provided the organization with enviable efficiencies. Indeed, arrests of key leadership figures were relatively rare until 2001 - a remarkable achievement for such a long-lived organization. With one exception, the March 1992 arrest of its three main leaders in Bidard, France, ETA's leadership had remained hidden and viable until about 2002-03. However, since 2003 there has been a spate of arrests of the upper echelon including the 2003 arrest of three more leaders in Spain (Henley, 2003).

Previously, ETA was able to rapidly adapt to its counter-terrorism environment with help from its youth organization, the Haika. There is no question that any terrorist group will suffer personnel losses through death, arrest or exile; the question is how readily the organization can fill the vacated positions with quality members. For ETA these recruits would come from the Haika - themselves veterans of violence as the active participants in what is called the kale borroka, the campaign of civil disorder and urban violence perpetrated by the Haika in Basque country (Ward et al., 2010). The increased police and intelligence effectiveness in Basque country has meant that these recruits are fewer and, increasingly, poorly trained. Infiltration has also been a problem. It is for these reasons that in November 2002 ETA made a change to its command and control structure from hub-spoke to all-channel (Jane's, 2009b).

Under this new all-channel structure, ETA operates in small cells that are largely 
autonomous in planning and carrying out attacks. While these cells may each have a leader, the central executive of ETA has little to no control over attack planning. This new structure involves these small cells travelling to France to receive instructions from the ETA executive on how to identify and collect intelligence on a possible attack but beyond this, they are on their own (Jane's, 2009b).

\subsubsection{Targeting Preferences}

As shown in Figure 10, ETA's attacks per year have declined since the $1980 \mathrm{~s}^{55}$ However, since 2003 ETA's operational pace is the lowest it has been since under the Franco regime in 1973. In the years between 1970 and 2002, ETA was responsible for an average of 59.7 attacks per year. This average drop to 15 attacks per year in the years between 2003 and 2007. The operational pace of a group, however, is only one way to measure its behaviour. The subject of inquiry of this chapter is target selection by a group.

ETA's targeting preferences have also changed quite a bit following the organizational restructuring in 2003. As Table 12 shows, the key difference is the decrease in hard target attacks, as a percentage of total targets. Prior to 2003, ETA attacked hard targets $35 \%$ of the time. Following their reorganization to a hub-spoke structure, that percentage drops to just 8 percent. ${ }^{56}$ This drop in hard target attacks is made up

\footnotetext{
${ }^{55}$ As mentioned in Chapter 2, the GTD is missing data from 1993 so this should be kept in mind when interpreting the figure.

${ }^{56}$ See Table 12. A similar comparison was performed examining ETA targeting profile for the previous five years leading up to the change in structure in 2003 and the results were consistent with
} 


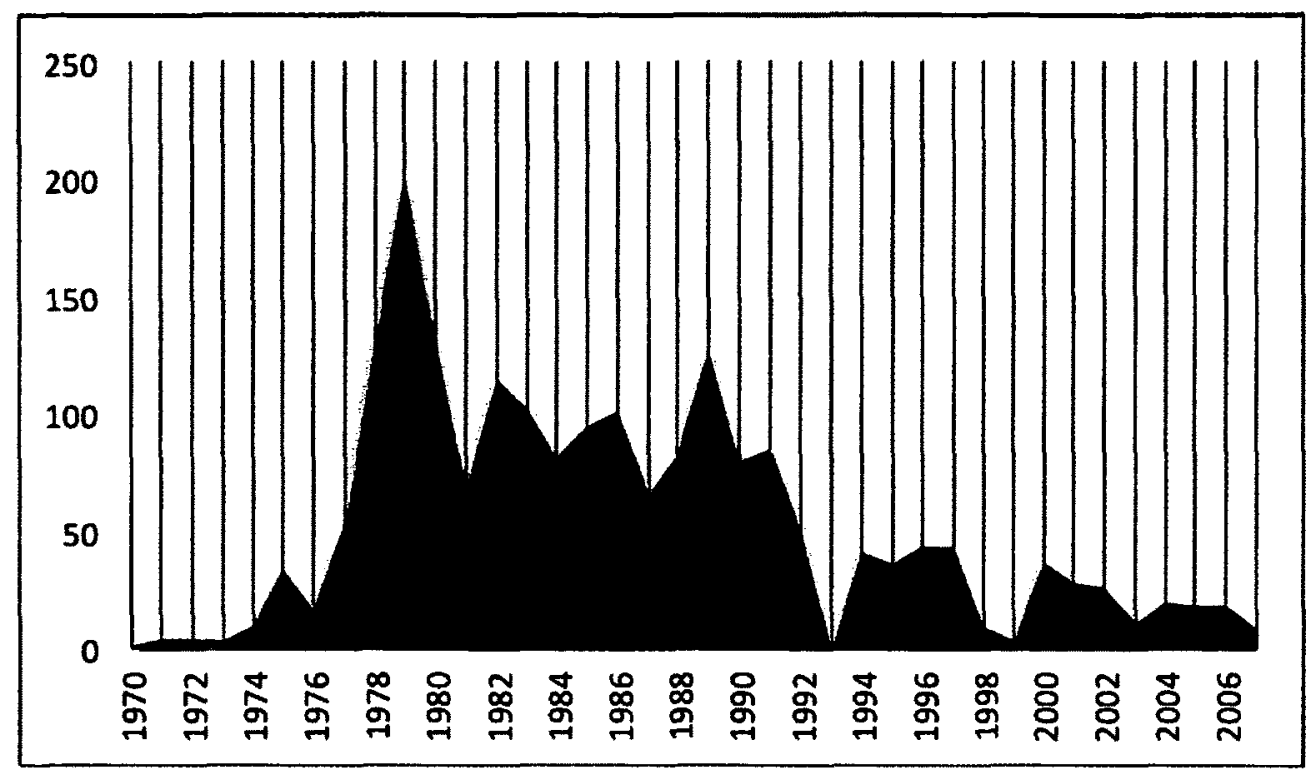

Figure 10: ETA Attacks Per Year (1986 obs.)

almost exclusively by the increase of soft target attacks, from $11 \%$ to $26 \%$. ETA's attention-seeking attacks remain relatively stable, with a small increase in political targeting. ${ }^{57}$

ETA has experienced an overall decline of attacks for several decades so it is difficult to attribute this to any measure of structure. Indeed, the more likely answer is that the political concessions by the Spanish have placated much of the grievance felt by the Basque population. Like the IRA's slow progression to a permanent ceasefire, ETA seems to be on its way to this end. As Neumann (2007) asserts, there are always some hard-core holdouts in a group that refuse to give up their struggle, even in the face of dwindling support and effective counter-terrorism efforts. While there have this table.

${ }^{57}$ While there is a correlation between the group's change in structure and the change in targeting selection profile, it is ultimately difficult to assess the direction of causality. In other words, has the target selection changed as a result of the change in structure or did the change in structure force a change in target selection. 
Table 12: Target Selection by ETA in 5-Year Periods (\% of total)

\begin{tabular}{lll}
\hline Target Type & $\begin{array}{l}\text { Hub \& spoke } \\
(\mathbf{1 9 9 8} \text { to 2002) }\end{array}$ & $\begin{array}{l}\text { All-channel } \\
\mathbf{( 2 0 0 3} \text { to 2007) }\end{array}$ \\
\hline Business & $21(20 \%)$ & $22(33 \%)$ \\
Government & $35(34 \%)$ & $8(12 \%)$ \\
Police & $10(10 \%)$ & $5(7 \%)$ \\
Military & $11(11 \%)$ & $1(1 \%)$ \\
Journalists & $\mathbf{9 ( 9 \% )}$ & 0 \\
Private citizens & $\mathbf{1 1}(11 \%)$ & $19(28 \%)$ \\
Tourists & $5(5 \%)$ & $0(0 \%)$ \\
Transportation & $\mathbf{1}(1 \%)$ & $7(10 \%)$ \\
Other & 0 & $5(7 \%)$ \\
Total & $\mathbf{1 0 3}$ & $\mathbf{6 7}$ \\
\hline
\end{tabular}

been several ceasefire declarations by ETA, one in 1998 and another in March, 2006 - both were subsequently broken. This behaviour suggests a high level of internal struggle wherein moderates are battling with hard core elements. This is often a generational battle between older, wiser moderates and hot-headed youth.

However, along with the outward indications of internal turmoil, there has also been a significant decline in fatal attacks since the change in structure indicating a shift in either strategy or, more likely, capability. In the five years prior to the change in structure, ETA completed 101 successful attacks. In the five years since the change, they have completed 73 attacks - a $28 \%$ decline. In terms of lethality, in the five years before the structure change, $32 \%$ of ETA's attacks had at least one fatality. In the subsequent five year period following their change in structure, the percentage of fatal attacks dropped to just $6 \%$. 
Looking deeper into target selection there is also a considerable change in the mix of targets selected between the five year periods leading up to ETA's change in structure. As Table 12 shows the greatest change is attacks on government. As a hub and spoke group, ETA attacked government targets $34 \%$ of the time. As an all-channel group this percentage decreased to just $12 \%$. Conversely, attacks on private citizens went from 11 to $28 \%$ of total attacks.

In terms of targeting the government, it is not just the number of attacks that has changed but also the nature of the attacks. Examining the individual attacks reveals that as a hub-spoke group from 1998-2002, ETA targeted individual government officials or political figures $86 \%$ of the time when targeting government. ${ }^{58}$ This is in contrast to ETA's targeting profile as an all-channel group from 2003-2007 where out of eight attacks on government targets, none were directed at an individual.

These results suggest that a significant change has occurred in the organization. If target selection says as much about a group as any kind of behaviour then this result suggests that following its structural change, ETA has become less focused as an organization. Instead of going after individual politicians that are directly responsible for policies against the group, ETA seems to have shifted to attacking symbols instead. This change also implies a loss of capability. In Spain, particularly in the north, politicians are often protected by personal bodyguards so attacking them represents a more difficult challenge. All of the eight attacks on government

\footnotetext{
${ }^{58} \mathrm{O}$ the 35 attacks on government, 30 were directed at an individual, not a building.
} 
Table 13: Target Selection by ETA (\% of total)

\begin{tabular}{lcc}
\hline Target Category & $\mathbf{1 9 7 0}$ to $\mathbf{2 0 0 2}$ & $\mathbf{2 0 0 3}$ to $\mathbf{2 0 0 7}$ \\
\hline Political & $794(42 \%)$ & $34(47 \%)$ \\
Economic & $204(11 \%)$ & $8(11 \%)$ \\
Hard target & $663(35 \%)$ & $6(8 \%)$ \\
Soft target & $215(11 \%)$ & $19(26 \%)$ \\
Infighting & $12(1 \%)$ & $6(8 \%)$ \\
Total & 1891 & 73 \\
\hline
\end{tabular}

since 2003 , by contrast, were bombs planted outside of government buildings - a much easier task to accomplish.

\subsubsection{Conclusion}

While it is difficult to assess the causality of a change in structure, there is little doubt that there has been a significant change in ETA's targeting priorities and in the organization's capabilities. As a hub and spoke group ETA was a much more deadly and prolific organization. It was able to target politicians - many of whom received constant police protection and it focused more of its attacks on hard targets. As an all-channel organization, not only has the number of attacks declined, but the target profile of the group has changed to one where easier targets are the preferred option. As Drake (1998b) argues: "with terrorist target selection...the motives are known, the means can usually be estimated, and the opportunities are fairly plentiful. What one has to determine is who or what is likely to be the victim."

For ETA, the motives of the organization did not change - it still seeks a Basque 
homeland. In an open democratic society such as Spain, there are plenty of opportunities. All that remains are the means, the way in which to attack a target. How organizational structure affects a group's attack type profile is the subject of the next chapter. 


\section{Chapter 4}

\section{Structure and Effectiveness}

\subsection{Introduction and Motivation}

As violent organizations, terrorist groups communicate by attacking. A key measure of any violent attack is the scale of the destruction. This chapter examines the effects a group's structure has on effectiveness which is measured here by lethality per attack. The literature review in this chapter focuses on measuring effectiveness, group learning and terrorist group lethality. There is no single agreed upon way to measure effectiveness; below I detail the contributions others have made to the discussion. Like other organizations, learning in terrorist groups is crucial if the group is going to effectively adapt to challenges. Examining the affect of structure on a group's effectiveness is the first step in answering to broader question of what structure is best for a terrorist group. 


\subsubsection{Lethality as a measure of effectiveness}

Group effectiveness is difficult to quantify. ${ }^{1}$ Does one measure the effectiveness of a group in terms of accomplishing its goals? If so, most terrorist groups would prove to be ineffective (Abrahms, 2006). As Jones and Libicki (2008) point out, only 10 percent of all terrorist groups actually achieve their goals. However, this is not the only reason why groups employ violence. For many groups, the act of violence itself and the drive to remain viable, become the goal. Without the continued viability of the group, the goal it seeks cannot be achieved. Outside of the group, members lose their identity as it is often tied up in the act of using violence (Horgan, 2008).

Others have attempted to measure effectiveness in terrorist groups and their results are instructive. Dugan et al. (2007) and LaFree et al. (2009) posit that a trajectorybased model of analysis is best. This analytical approach examines the long-term trends of terrorist activity, such as boom and bust behaviour. The trends measured are usually a combination of number of attacks and lethality. Others argue, similarly, that terrorism is contagious and once an upswing in total number of attacks begins, it tends to accelerate (Cronin, 2008; Rapoport, 2004). Clarke and Newman (2006) argue that the permissive factor for terrorist attacks is access to the target. In other words, the geography of the group's home base is the most important factor in a group's effectiveness. Blomberg et al. (2010) argue that rather than examine a trajectory, survival analysis is the approach to take when examining terrorist group effectiveness.

\footnotetext{
${ }^{1}$ In Chapter 1 the literature review discusses the difficulty in measuring success by any scale that allows for cross-comparison between groups.
} 
All of these methods build models based on change over time either attack counts or casualties. ${ }^{2}$ The models attempt to capture effectiveness by measuring factors that may influence it over time. My analysis differs from these studies in two ways. First, the current study is focused on terrorist organizational structure. Second, this chapter examines the lethality per attack of all groups with greater than ten attacks, with no geographic exclusions. Most of the above studies substitute generalizability for specificity, opting to use more sophisticated analytic techniques for subsets of the population rather than trying to examine the entire population.

While effectiveness cannot be measured by any one variable - no matter how complex a metric it may be - from a policymaking point of view, those groups that kill are more serious than those groups that do not. Measuring lethality as a measure of effectiveness is therefore a simple yet important way to compare one group against others. It also has immediate policy implications.

\subsubsection{Previous research on terrorist group learning}

Organizational learning is the process where a group uses new knowledge to make better decisions - both strategic and tactical - and increase the chances of success (Miller and Damask, 1996). Learning occurs whenever a group internalizes mistakes

\footnotetext{
${ }^{2}$ Hitzeman and Mabrey (2010) argue that analyzing operational effectiveness of terrorist groups is ideologically based and introduce new metrics to better measure ideology. While a promising idea, it is a work in progress and there have been few applications of their new analytical metrics, not to mention a lack of available data.
} 
and uses them to improve its performance. ${ }^{3}$ How a terrorist group learns has an impact on its success or failure. The ability for an organization to effectively adapt their behaviour and tactics to their environment reflects that organization's ability to learn (Jackson and Baker, 2005; Jackson, 2006). Successful groups will learn to become more effective by incorporating the lessons of failure and success and applying this learned knowledge to future tactics, targets and weapons choices. Terrorist groups must continually learn in order to "fend off attempts to infiltrate, undermine and destroy them" (Jackson and Baker, 2005, p. 2).

Of particular interest to the task of measuring success or effectiveness is the focus on how an organization develops capacity and maintains it (Jackson, 2004, 2006; Jones, 2006; Jackson and Baker, 2005; Jackson et al., 2005). Crucial to a terrorist group's capacity to acquire, interpret and store information is the structure of authority and communication. Trujillo and Jackson (2006) discuss competing theories on the affect of organizational structure on terrorist groups. On the one hand is the notion that hierarchical organizations learn less effectively. This ineffectiveness is due to a degradation of information as it is transmitted through the various levels of hierarchy (see Trujillo and Jackson, 2006; Arquilla and Ronfeldt, 2001). Previous studies suggest that hierarchical organizations learn less effectively because information is lost and distorted as it is passed along all the organizational levels (Schweiger et al., 2003). The implication is that less hierarchical groups are better suited to adapting quickly

\footnotetext{
${ }^{3}$ Organizational learning does not apply to individual, lone-wolf, terrorists but since none of these are included in the present study, this is less of a concern.
} 
to internal pressures or changes in the environment.

On the other hand, the competing explanation posits that hierarchical organizations and their "formally defined communications paths" are less susceptible to a degradation of information. This theory also suggests that hierarchical groups contain multiple redundancies that help protect them when under threat and make them more resilient to deterioration of knowledge (Trujillo and Jackson, 2006, p. 60). The Tamil Tigers, for instance, have formally defined command structures and, therefore, they are less likely to experience information distribution failures.

Jackson and Baker (2005, p. 12) observe that, to make up for deficiencies in their organizational capabilities, small organizations will seek outside assistance in the learning process including: learning from copying groups, cooperating with other groups or obtaining expertise from outside sources or technologies. ${ }^{4}$

Podolny and Page (1998) suggest that while there are differing views on the affect of structure on terrorist group learning, both hierarchies and decentralized groups can adopt some features of each other and thus it is possible that a hierarchy can take on some network features, and vice-versa. ${ }^{5}$ Trujillo and Jackson (2006, p. 60) cite

\footnotetext{
${ }^{4}$ While not aimed at examining terrorist group learning, Asal and Rethemeyer (2010) is one example of a study that attempts to look at the cooperation between groups. While outside the purview of this chapter, this is a very promising area of research. With the powerful social network analysis tools available, it is possible to better understand the level and type of cooperation that may occur between groups. At a case study level, it may be possible to map out enough of an organization that what may be generally described as a market group is in fact an all-channel structure. This, of course, requires good information about the group, something that is not often possible with terrorist groups.

${ }^{5}$ This is true of all organizational structures. That an idealized form of any structure type is rarely found; rather groups tend to take on features of several structure types. It is important, therefore, to emphasize that structures coded in this study, while illustrative, are not perfect.
} 
Al Qaeda as the best-known example of a group that has, at times, taken advantage of "both centralization and hierarchy in accumulating and diffusing knowledge while also promoting rapid experimentation by local cells".

Since terrorism is almost never met with anything but harsh reprisal, the groups perpetrating these attacks know full well that they often face very harsh consequences. This literature is important because it urges a dynamic view of a group in order to capture the learning and adaptability that goes on. Finally, it also brings to mind the fact that groups, like individuals, internalize failure and learn to cope with challenges in order to be successful. Part of this process is maintaining effectiveness - more specifically, lethality - to remain a potent force.

\subsubsection{Previous Research on Terrorist Group Lethality}

Within the literature is the expectation that religiously motivated groups are more deadly than other types (see Benjamin et al., 2002; Li, 2005; Stern, 2004). More specifically, Juergensmeyer (2003) argues that, for religious groups, there is no reason to discriminate when killing. As an example, the justification for Al Qaeda's killing has always been based on the concept of two enemies, the near and the far. The near enemy are apostate Muslims for not following the Salafi interpretation of the Koran. The far enemy are the infidels, in particular the United States, for being unbelievers. For the religious terrorist, violence is first and foremost a "sacramental act or or divine 
duty executed in direct response to some theological demand or imperative" (Hoffman, 1995, p. 2). In other words, secular terrorists generally consider indiscriminate violence counterproductive; religious terrorists consider it to be morally justified and even a necessary act for achieving their goals (Jenkins, 1985).

Beyond the dichotomy between religious terrorism and all other motivations for terrorism, lethality can be informed by the types of attacks used. Chemical, biological, radiological and nuclear (CBRN) weapons pose the greatest risk for mass casualties. However, while the GTD lists a total of only 246 CBRN attacks out of a total of more than 80,000 attacks - more than 83 percent of which are non-lethal. In fact there are only six CBRN attacks with more than 10 deaths. ${ }^{6}$ So, while CBRN attacks represent the greatest potential risk, the historical record demonstrates that these attack types are not the main driver of terrorist lethality.

Heger et al. (2008) argue that nationalist groups tend to carry out more lethal attacks than non-nationalist groups. Others find this prediction to be counter-intuitive because nationalist groups are dependent on their constituency for support and a high degree of violence can have blowback effects (Jenkins, 1975; Wilkinson, 1977). ${ }^{7}$ Using a negative binomial regression to test for lethality, Heger et al. (2008) posit

\footnotetext{
${ }^{6}$ According to the GTD there are a total of 558 deaths associated with the 246 CBRN attacks. Most of these deaths come from two attacks: the first by an unknown perpetrator in Uganda who poisoned the tea, with a chemical agent, of the followers of the cult Movement for the Restoration of the Ten Commandments of God with a chemical agent. This attack killed 200 people. The second is the 1998 attack by the Oromo Liberation Front in Kenya. Using a chemical bomb, the attack killed 142 Kenyan soldiers at a base in Wajir, Kenya. The rest of the lethal attacks led to much fewer casualties.

${ }^{7}$ This assertion is tested below.
} 
that nationalist groups that are also public goods providers (such as Hamas) are more lethal ceteris paribus than nationalist groups that do not provide public goods. ${ }^{8}$ They find that the coefficient for nationalist groups providing public goods is statistically significant to a $90 \%$ confidence interval, suggesting that these groups are more lethal than groups that do not provide public goods. This study represents an important step toward examining the effects of structure on lethality. Indeed, the conclude their study by writing:

With a universal variable like group structure, we can better understand the nature and affect of non-state politics and how this changes our understanding of global politics and governance. (Heger et al., 2008, p. 31) The work of Asal and Rethemeyer (2008) is probably the closest in content to the current study. They examine lethality in 398 groups from the GTD between 1998 and 2005, of which only 68 have killed 10 or more and only 28 have 100 or more. They find that "organizational size, ideology, territorial control, and connectedness are important predictors of lethality while state sponsorship, organizational age, and host country characteristics are not" (Asal and Rethemeyer, 2008, p. 437). The core of their argument is that organizational lethality is linked to either audience, 'othering' or the capabilities of the group

Asal and Rethemeyer (2008) conclude that large organizations, religious and nationalist organizations, groups that maintain good connections with their peers, and

\footnotetext{
${ }^{8}$ Nationalist groups are used as a proxy for hierarchical groups in this study. Non-nationalist groups such as left and right-wing groups are considered to be horizontally organized.
} 
organizations that control territory are the five main factors that contribute to high lethality. They also conclude that group age, democracy (measured by Polity IV), energy consumption per capita and state sponsorship has no affect on lethality (Asal and Rethemeyer, 2008, p. 444). The work of Asal and Rethemeyer (2008) differs from the current study in that it employs a shorter time period, from 1998-2005 using different data taken from the Terrorism Knowledge Base (TKB). The TKB data is a summary of the total number of incidents and fatalities per group between 1998 and 2005. As such, Asal and Rethemeyer's study includes 395 observations compared to the more than 35,000 observations used in the current study. ${ }^{9}$ This chapter should be seen as complementary to the findings of Asal and Rethemeyer (2008) and as a contribution to the literature because organizational structure is studied here.

\subsection{Data and Methodology}

This chapter employs the main dataset used in previous chapters. In order to assess the lethality and characteristics of each individual attack, a disaggregated dataset is used, where each individual attack is one observation. The basic information on each incident comes from the GTD project (START, 2010). The rest of the variables are either coded by the author or their sources are listed in Table 14.

The dependent variable number killed is coded by researchers at START for the GTD.

\footnotetext{
${ }^{9}$ However, the TKB has detailed information about group motivation which can provide more nuanced results about group ideology such as religious-nationalist groups. The current study makes a coding decision if a group is either religious or nationalist.
} 
Table 14: Variables, operationalization and sources

\begin{tabular}{|c|c|c|}
\hline Variable & Operationalization & Source \\
\hline Number Killed & For each incident, the total reported fatalities. & START. Global Terrorism Database \\
\hline GDP per capita & $\begin{array}{l}\text { Chain series data for year terrorist group is } \\
\text { believed to have begun }\end{array}$ & $\begin{array}{l}\text { Summers R. et. al. Penn world table } \\
\text { version } 6.3\end{array}$ \\
\hline Freedom House & $\begin{array}{l}\text { Political rights and civil liberties indices, each } \\
\text { out of } 7 \text {, averaged together. Lower score indi- } \\
\text { cates more rights/liberties }\end{array}$ & $\begin{array}{l}\text { Freedom House. 2004. Annual Free- } \\
\text { dom in the World Country Scores }\end{array}$ \\
\hline Seeks Regime Change & Coded for group goal & $\begin{array}{l}\text { Jones S. G. and Libicki M. } 2008 . \\
\text { How Terrorist Groups End. RAND } \\
\text { Corporation. (With supplemental } \\
\text { coding by the author) }\end{array}$ \\
\hline Seeks Territorial Change & Coded for type of group & Ibid. \\
\hline Seeks Status Quo & Coded for type of group & Ibid. \\
\hline Seeks Policy Change & Coded for type of group & Ibid. \\
\hline Is Nationalist & Coded for primary motivation type of group & Ibid. \\
\hline Is Religious & Ibid. & Ibid. \\
\hline Is Right-wing & Ibid. & Ibid. \\
\hline Peak Size & $10 \mathrm{~s}, 100 \mathrm{~s}, 1000 \mathrm{~s}, 10000 \mathrm{~s}$ & Ibid. \\
\hline Age of group & Count (in years) & Coded by the author \\
\hline Structure & $\begin{array}{l}\text { Market (base case), all-channel, hub/spoke } \\
\text { and bureaucratic }\end{array}$ & Ibid. \\
\hline State Sponsor & Evidence of assistance from a state. & Ibid. \\
\hline
\end{tabular}


The variable GDP per capita (chain series) is used here as a lagged indicator of a state's counter-terrorism effectiveness. Building on the results of chapter three, it is expected that a high GDP per capita will result in lower casualties, due to the effective counter-terror apparatus of high income states.

The variable Freedom House measures political rights and civil liberties. Asal and Rethemeyer (2008) find no conclusive evidence that democracy, measured by Polity IV, has an affect on lethality. The Freedom House variable is included to test if it has an affect where Polity IV does not. It is expected that states with high political rights and civil liberties will experience fewer fatalities than states with a deficit of rights and liberties due to a greater opportunity for non-violent dissent in these types of states.

For the variables that capture a group's goals, seeks policy change, social revolution, territorial change, regime change or status quo, ${ }^{10}$ the expectation is that groups seeking the narrow goals of territorial and policy change or maintaining status quo will employ more deadly attacks. Since these groups have goals that are more likely to be achieved than those with broad goals, they are more likely to employ violence as a tool of coercion as opposed to attention-seeking. ${ }^{11}$

For the variables for group ideology nationalist, religious, left-wing and right-wing I expect that religious groups will have the highest lethality rate due to their lack of

\footnotetext{
${ }^{10}$ See Jones and Libicki, 2007

${ }^{11}$ It can be argued that a group's goals are related to its ideology. Nationalist groups, for example will often have a goal of territorial change. When I omit either goals or ideology from the sample, the results do not change; consequently, both sets of variables are included.
} 
aversion to indiscriminate violence that other group ideologies have.

As Asal and Rethemeyer (2008) find, it is also expected here that larger groups will be more lethal. Size of a group is measured by the variable peak size. ${ }^{12}$ Similarly, the variable group age is expected to be positively related to lethality; as a group gets older it will become more deadly through the process of learning detailed above. For the variable occupied or colonized it is expected that attacks in occupied or colonized attacks will be more deadly (see Pape, 2003).

The structure of the group is coded, in order of increasing centralization, as: market, all-channel, hub-spoke and bureaucracy. I expect that bureaucratic groups will be the most lethal, due to their high capabilities. Conversely, I also expect that market structures will be the least lethal.

\subsection{Estimating the Lethality of Attacks}

\subsubsection{Estimating lethality - Main Model}

The main model is displayed in Table 15. For every year a group gets older, the rate of lethality decreases by a factor of 0.98 . This result is not consistent with the expected outcome. Rather, this result implies that in the beginning, the group must try to make a name for itself and spectacular, bloody attacks can have this effect. As

\footnotetext{
${ }^{12}$ This variable measures the maximum number of members in a group during its existence. It is measured in magnitudes (see Jones and Libicki, 2007).
} 
the group gets older, the survival of the group becomes more important and lethal attacks can disturb the support a group enjoys. These risk factors may become an important part in mitigating attack lethality.

When GDP per capita increases, lethality declines by a factor of 0.98 , holding all other variables constant. Upon further investigation this result can be further refined to state that high casualty attacks are much less likely to occur in wealthy states than in poor states. ${ }^{13}$ There are several possible findings from this result. First, this result reinforces the strength of using GDP per capita as a proxy for measuring counter-terror effectiveness. In states with a high GDP per capita, the likelihood of perpetrating a successful high casualty attack is lower. Moreover, this finding implies that while counter-terrorism capacity effects the behaviour of a group, it does not mean that it can stop terrorism altogether.

Connected with state wealth is the level of political rights and civil liberties in a state. Richer countries tend to also afford more rights and liberties to its citizens (see Helliwell, 1994). As political rights and civil liberties decline by one point on the Freedom House scale, the rate of lethality increases by a factor of 1.28 , holding all other variables equal. ${ }^{14}$

For groups that are state-sponsored compared to groups that are not, the rate of

\footnotetext{
${ }^{13} \mathrm{~A}$ basic range of lethality per attack (zero, 1-4, and over 5 ) was compared in a cross-tabulation against the income group category of the World Bank. While non-lethal attacks and attacks with less than five attacks are relatively well distributed between all states, attacks with five or more kills are under-represented in high income states and over-represented in low-income states.

${ }^{14}$ The Freedom House score is for the state in which the attack occurred which is not necessarily the group's home country. Using the results of the location of the attack provides more dynamic results than using the group's home country.
} 
Table 15: Lethality of attacks - Main Model

\begin{tabular}{lccl}
\hline Term & IRR $^{a}$ & Standard Error & p-value \\
\hline Market structure & 0.7768 & 0.2588 & 0.448 \\
All-channel structure & 0.8016 & 0.0615 & $0.004 * * *$ \\
Hub/spoke structure & 0.7138 & 0.0489 & $0.000 * * *$ \\
Is religious & 1.9676 & 0.3459 & $0.000 * * *$ \\
Is right-wing & 2.0927 & 0.4198 & $0.000 * * *$ \\
Is left-wing & 1.1101 & 0.2174 & 0.594 \\
Seeks policy change & 0.7565 & 0.1706 & 0.216 \\
Seeks social revolution & 1.6031 & 0.4245 & $0.075 \dagger$ \\
Seeks territorial change & 2.0131 & 0.2732 & $0.000 * * *$ \\
Seeks regime change & 1.5175 & 0.2870 & $0.027^{*}$ \\
Group age & 0.9837 & 0.0025 & $0.000 * * *$ \\
Peak size & 0.9425 & 0.0477 & 0.242 \\
GDP per capita & 0.9819 & 0.0106 & $0.090 \dagger$ \\
Freedom House & 1.2769 & 0.0355 & $0.000 * * *$ \\
State sponsor & 2.3709 & 0.2340 & $0.000 * * *$ \\
\hline
\end{tabular}

${ }^{a}$ Incident rate ratio (IRR). Number of observations is 28,942 .

$\dagger p<.1 ;^{*}: p<.05 ;^{* *}: p<.01 ;^{* * *}: p<.005$ 
lethality is 2.37 times higher, holding all other variables equal. This suggests that groups with state support are more deadly than states without. Part of this affect may be due to the increased proportion of hard and soft targets state-sponsored groups attack compared to non state-sponsored groups. ${ }^{15}$ It could also occur because state-sponsored groups have better equipment and training.

In terms of group type, compared to nationalist, both religious and right-wing groups have a higher rate of lethality, by a factor 1.97 and 2.09 , respectively, holding all other variables constant. ${ }^{16}$ This result seems to confirm the hypothesis by Juergensmeyer (2003) that religious groups are more deadly than most other group ideologies. That right-wing groups employ higher lethality attacks than nationalist groups goes against the findings by Asal and Rethemeyer (2008, p. 439) that nationalist and religious groups - groups with a strong sense of other $^{17}$ - will be most deadly. It is possible that right-wing groups do in fact have a strong sense of other, especially since rightwing groups are often reactionary, turning to violence when their core constituency loses rights. ${ }^{18}$ In cases of reactionary violence, there is a clear sense of the other. Figure 11 illustrates the differences between group motivation and lethality.

\footnotetext{
${ }^{15}$ This was examined using cross-tabulations so while the causality is not clear, the relationship exists.

${ }^{16}$ Left-wing groups have a similar relationship when compared to nationalist groups but this affect is not statistically significant.

${ }^{17}$ Asal and Rethemeyer (2008, p. 437) defines 'othering' as: "the process of clearly articulating groups and individuals that have a lesser moral or ethical status than members of the terrorist organization and the racial, ethnic, geographic, or language group they purport to represent".

${ }^{18} \mathrm{This}$ idea is advanced by Gurr (1970). An anecdotal example of this type of group is the Ku Klux Klan, a group dedicated to maintaining the rights of whites over blacks and opposed to any move for equality. During the period of civil rights reform in the United States, whenever blacks were granted new rights, the KKK would react with a wave of violence.
} 


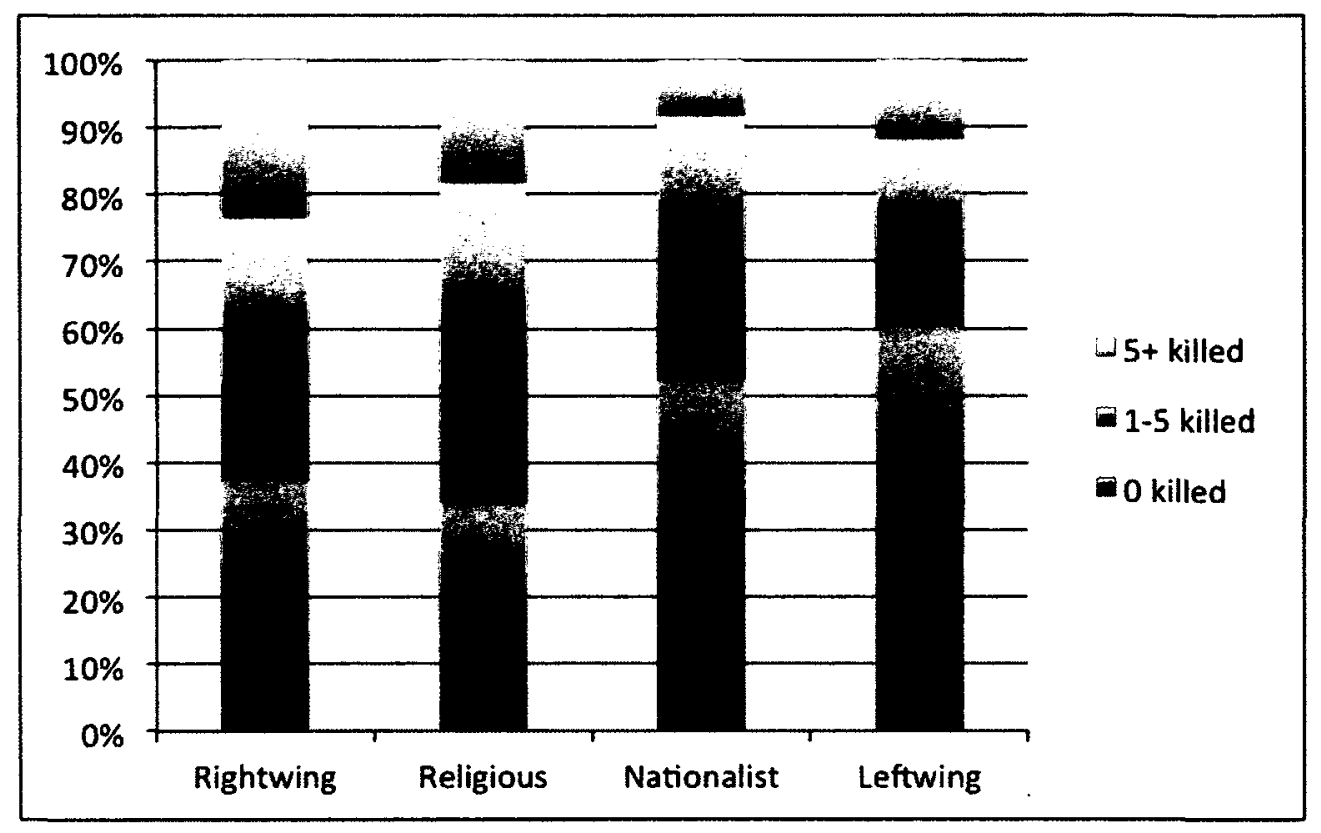

Figure 11: Attack Lethality Range by Group Ideology

For group goals, compared to maintaining the status quo, lethality is higher for groups seeking policy change, social revolution or territorial change by a factor of $1.60,2.01$ or 1.52 , respectively. ${ }^{19}$ These results are somewhat difficult to interpret.

A possible explanation for this result is that deposing an unwanted regime most likely means that the regime respects neither political rights nor civil liberties. Opposition groups in this case have no other recourse to change other than violence and the use of violence here is not for attention-seeking purposes, but rather to force a concrete change.

Compared to bureaucratic structures, the lethality of both all-channel and hub-spoke

\footnotetext{
${ }^{19}$ While not shown here, a cross-tabulation was performed correlating group goals against lethality and the results show that groups seeking regime change are much more likely to employ attacks with greater than five fatalities than any other goal type. This result suggests, at least for groups seeking regime change, that high fatality attacks are perceived as a good way to force the regime out.
} 
structures are lower by $20 \%$ and $29 \%$, respectively. The lethality of market structures, while not statistically distinct compared to bureaucratic structures, follows this same pattern. This means that, compared to any other structure, bureaucracies are most likely to have high lethality attacks. ${ }^{20}$ This result is consistent with the hypothesis that bureaucracies will be most lethal. To push this result further a breakdown of target type selection was performed for all structures. Bureaucracies are more likely to attack hard targets and use multiple attacks, both measures of sophistication. ${ }^{21}$

\subsubsection{Diagnostics}

As the dependent variable is count data with indications of over-dispersion, a negative binomial regression is used..$^{22}$ This was verified by performing a likelihood ratio test for the over-dispersion parameter alpha which confirmed that a Poisson distribution is not appropriate (UCLA: Academic Technology Services, 2011).

Testing for multicollinearity was done by examining variance inflation factors (VIFs) (Ender, 2004). No individual variable had a VIF higher then 5.50 and the mean VIF is 2.15. These results suggest that multicollinearity is not a concern. ${ }^{23}$

\footnotetext{
${ }^{20}$ Holding all other variables constant. This result is supported by examining the same model but with different base cases for structure.

${ }^{21}$ However, not all groups seek maximum destruction; in fact, for many groups it is counterproductive. This finding is important but it requires further investigation. Examining some models of different types of bureaucracies such as religious bureaucracies versus nationalist bureaucracies could be helpful.

${ }^{22}$ Negative binomial is preferred over Poisson in cases like this when the conditional variance does not equal the conditional mean.

${ }^{23}$ Pairwise correlations were also examined but are not shown here.
} 
Table 16: Descriptive Statistics - Base Model

\begin{tabular}{lccccl}
\hline Variable & Obs & Mean & Std. Dev. & Min & Max \\
\hline \# killed $^{a}$ & 75832 & 2.510 & 12.822 & 0 & 1380.5 \\
Structure & 37368 & 0.0396 & 0.842 & 1 & 4 \\
GDP Per Capita & 36215 & 8.198 & 6.693 & 0.160 & 96.149 \\
Group type & 37368 & 1.979 & 1.114 & 1 & 4 \\
Group age & 37004 & 17.999 & 1.114 & 1 & 87 \\
Freedom House & 35629 & 3.325 & 1.504 & 1 & 7 \\
State sponsor & 33992 & 0.151 & 0.358 & 0 & 1 \\
Group goals & 37355 & 2.366 & 1.489 & 1 & 5 \\
\hline
\end{tabular}

${ }^{a}$ Dependent variable

Testing for linearity and additivity was performed visually using graphs of a locally weighted regression of structure on each independent variable, separately (Royston, 2005). These plots compare the dependent variable against each independent variable and confirmed the presence of a linear relationship for each. To further push the test for linearity, bivariate relationships were examined by creating dichotomous dependent variables and these were subsequently plotted using locally weighted regressions (Sarkasian, 2011).

Outliers exist in the dependent variable. The attacks of $9 / 11$, using GTD methodology, are divided into two separate attacks, each totalling 1380.5 fatalities. These two attacks are, by far, the most lethal attacks in the dataset. When I exclude these attacks from the estimation, the results do not differ significantly. These two attacks are subsequently left in the analysis. Another outlier is Kuwait in 1972 with a GDP per capita (chain series) lever of over $\$ 96,000$. However, this high value has no affect 
on the results and therefore is included. The descriptive statistics can be found in Table 16.

\subsubsection{Alternate Models: By Organizational Structure}

In this section I examine the differences in lethality between organizational structures. The main model compares structure as separate independent variables. In the four models below, the sample is limited to one structure only. The purpose of this is primarily to check if any of the effects observed in the main model differ when examining the attacks of just one structure. The estimation tables for each of these structures are presented in the Appendix in Tables 31 to 34 .

Table 31 shows the main model model but with only market structures included in the sample. The results reveal a few differences compared to the main estimation. As shown in Table 31, compared to nationalist groups, both right-wing and left-wing market groups are less lethal by a factor of 0.25 or 0.29 , respectively, holding all other variables constant. In the main model these results are the opposite. This difference suggests that there is something different about market-based left and right-wing groups than the general population of these types of groups.

One possible explanation is that in market groups, a leaderless, decentralized organizational structure may mean something different for one motivation type versus another. For example, left and right-wing groups may prefer this structure due to the 
advantages offered by leaderless resistance (see Beam, 1992; Garfinkel, 2003). Leaderless resistance has its roots in right-wing groups, and left-wing market groups may adopt this structure due to a lower level of support in the public as a result of more specialized grievances. ${ }^{24}$ The low level of support for these groups is in contrast to nationalist and religious groups which have a natural well of support (Post, 2005). For those groups, a market structure may mean the group has failed to connect to its constituency.

Market groups also differ in terms of their goals. Compared to maintaining the status quo, the attack lethality of groups seeking social revolution or regime change are lower, by a factor of 0.18 or 0.12 , respectively, while holding all other variables equal constant.

A one magnitude increase in the variable peak size for a market group would result in a 1.82 times rise in lethality, holding all other variables constant. Market groups will never have strength in the tens of thousands, however, those groups which have membership in the hundreds, compared to small groups with less than 100 members, lethality per attack is higher.

The results of the model for all-channel groups is shown in Table 32. There are two ways that this model is differentiated from the main model. First, for every magnitude increase in an all-channel group's peak size the rate of lethality is expected to be 2.2

\footnotetext{
${ }^{24}$ Examples of specialized grievances include advocating for a radical Marxist-Leninist government or advocating for animal rights, among others. Della Porta (1995) observes this trend in her study of left-wing groups in Italy.
} 
times higher, holding all other variables constant. This result differs from the main model in that it is positively signed and statistically significant to a confidence interval greater than 99 percent.

The other difference with the all-channel subset is that for an increase in GDP per capita, lethality increases by a factor of 1.02 . For both of these results the differences may be explained by the fact that this trend exists for all-channel groups and is picked up in a disaggregated model but it disappears in the main model. One reason why this is the case could be that all-channel groups are better suited to the harsh environment of a high-income state that has a strong counter-terrorism capacity. While an initial finding, the suggestion here is that all-channel groups may be the most suited to the challenges of operating in higher income states.

As Table 33 shows, for hub and spoke groups, lethality is negatively and statistically significantly associated with several goal types when compared to the main model. Compared to the base case of maintaining the status quo, the rate of lethality for groups seeking social revolution and regime change would be expected to decrease by a factor of 0.32 or 0.38 , respectively, holding all other variables constant.

Moreover, for every magnitude increase in the peak size of hub-spoke groups, the rate of lethality would be expected to increase by a factor of 1.53 , holding all other variables constant.

As seen in Table 34, compared to maintaining the status quo, the rate of lethality of bureaucratic groups seeking social revolution would be expected to decrease by a 
factor of 0.53 , holding all other variables constant.

\subsubsection{Diagnostics}

Testing for multicollinearity was done by examining variance inflation factors (VIFs) (Ender, 2004). No individual variable in the estimations for market, all-channel or bureaucratic structures have a VIF higher then 5.96 and the mean VIF's are 3.77 , 4.29 and 2.35 , respectively.

However, there is some evidence of multicollinearity for the hub-spoke model. The VIF for the variables left-wing and seeks regime change are 13.08 and 11.79, respectively. While there are different interpretations of what VIF level constitutes multicollinearity, these values exceed the general threshold I observe with this dataset. ${ }^{25}$ To make interpretation more difficult, as O'Brien (2007) warns, removing a variable due to its high VIF factor means re-specifying the model with no theoretical reason do to so. However, when I drop the variables showing multicollinearity, there is no change to the results. Moreover, when I re-specifying group goals into a dummy variable of broad versus narrow categories, the VIF values drop to an acceptable level. For the purposes of comparison between all group structures, and keeping in mind the various views in the literature, I include the goal variables with the caveat that there is some evidence of multicollinearity in the hub-spoke estimation.

\footnotetext{
${ }^{25}$ The literature is unsettled with VIF scores in that there is no agreed upon level of what constitutes multicollinearity; some argue any value above 5 , other any value above 10 , still others argue that multicollinearity exists only when VIF scores are above 20 (see Sarkasian, 2011; Long and Freese, 2005).
} 
As discussed above, outliers exist in the dependent variable. In each case, when these outliers were excluded the results did not differ significantly and were subsequently left in the analysis.

\subsubsection{Alternate Models: Lethality of armed assaults versus bombings}

The two most popular attack types used by terrorist groups are armed assaults and bombings. ${ }^{26}$ It is therefore important to compare lethality between these two attack types since they are the most popular type of attack. As in the previous section, the main model is re-run twice with a sample of either armed assaults or bombings. The results are displayed in Tables 17 and 18.

The differences that emerge when comparing armed assaults against bombings are, in many ways, stark. In terms of similarities, for both attack types, the lethality rate of a group with state sponsorship is 1.42 times higher for armed assaults and 2.03 time higher for bombings, compared to groups without state sponsorship. Another similarity is with GDP per capita. For both attack types, a $\$ 1000$ increase in GDP per capita means an expected 6 percent decrease in armed assaults and a 9 percent decrease for bombings, holding all other variables constant. This is where the similarities end. The results for the rest of the independent variables are vastly different between these two attack types. A different story emerges from both.

\footnotetext{
${ }^{26}$ In the GTD data, these two attack types account for more than 67 percent of all attacks.
} 
For armed assaults, as seen in Table 17, a one magnitude increase in peak size would mean a rise in lethality by a factor of 1.23 , holding all other variables constant. In other words, as group size increases, lethality increases for armed assaults. This makes sense since larger groups will have more people - and therefore a higher threshold for risk - to deploy for an armed assault. However, this result is in contrast to the results for bombings, shown in Table 18. For bombings, lethality is two-thirds lower for every magnitude increase in peak size. For example, this result suggests that if a group had an initial size of less than 100 members and its membership grew to the hundreds - a one magnitude increase in size - the lethality of this group's bombing attacks would decline by 33 percent than when it was a smaller size.

One possible reason for why small groups seem to be more lethal in their bombing than larger groups could have to do with the decision-making of a group. It is possible that when groups are small, they prefer other attack types over armed assaults. Small groups may weigh the risks of an armed assault and conclude that the risk of losing many members is too high since armed assaults are often result in high casualty rates of both terrorists and their targets. Moreover, larger groups do not face extinction with the loss of a dozen members, as is the case for small groups, so for larger groups, armed assaults may represent a more effective high profile method than a bomb, with an acceptable level of risk. As groups grow in size, bombings may begin to seem like too blunt an instrument, incapable of distinguishing between friend or foe - something that a group with a larger constituency must be very careful of. 
In a similar result, for every year a group gets older its lethality during armed assaults decreases by a factor of 0.98 , holding all other variables equal. By contrast, for every year a group gets older the lethality of its bomb attacks increases by a factor of 1.0059 , holding all other variables constant. ${ }^{27}$

In terms of the goals a group seeks, compared to the base case of territorial change, the lethality of armed assaults by groups seeking policy change, social revolution, maintaining the status quo and regime change are all lower, by factors of $0.35,0.38$, 0.63 and 0.68 , respectively, holding all other variables constant. The result that groups seeking territorial change are more likely to employ deadly armed assault attacks suggests, yet again, that there is a link with lethality and group size, (or group support).

For bombings, compared to the base case of territorial change, lethality is lower for groups seeking policy change, social revolution and regime change, by $47 \%, 48 \%$ and $47 \%$, respectively, holding all other variables constant. In contrast, the bombing lethality of groups that seek to maintain the status quo is 1.98 times higher, compared to territorial change, holding all other variables constant.

The differences between group motivations are also quite clear. For armed assaults,

\footnotetext{
${ }^{27}$ This is an interesting finding requiring further investigation. One possible mechanism that is at work here is that as a group gets older, it becomes more capable through internalizing the lessons of prior attacks. This could be tested by performing a negative binomial estimation using the variable 'terrorists killed' as the dependent variable. While the GTD does have a variable for the number of terrorists killed, it is a rare event in the data when a terrorist is coded as killed; less than 4 percent of all attacks coded for this variable have one or more terrorists killed. Future work could perform a zero-inflated negative binomial for this variable.
} 
compared to nationalist groups, lethality rate increases for both right-wing or leftwing, by factors of 1.72 and 1.74, respectively. By contrast, for armed assaults, lethality of both right-wing and left-wing groups decline by 72 and 31 percent, respectively, holding all other variables constant. This result implies that nationalist groups choose bombings over armed assaults, when compared to left or right-wing groups.

Finally is the difference in organizational structures. For armed assaults, compared to the base case of bureaucratic groups, the lethality of both market and all-channel structures decreases by 41 and 26 percent, respectively, holding all other variables constant. This result is in contrast to the results for bombings where compared to bureaucratic groups, the lethality of market and all-channel structures both increase by 1.28 and 1.27 times, respectively. ${ }^{28}$

\subsection{Discussion}

While the interesting findings from the current chapter are myriad, there are three main topics of discussion that I address here. First is evaluating lethality as a measurement of terrorist group effectiveness. Second is the affect of group age and why the findings above differ from other studies. Finally the focus turns to the affect of group structure on lethality.

\footnotetext{
${ }^{28}$ The market structure result is only a weak association and is not statistically significant.
} 
Table 17: Lethality of armed assaults

\begin{tabular}{lccl}
\hline Term & IRR & Standard Error & p-value \\
\hline Market structure & 0.5936 & 0.0896 & $0.001 * * *$ \\
All-channel structure & 0.7463 & 0.0509 & $0.000 * * *$ \\
Hub/spoke structure & 0.7181 & 0.0388 & $0.000 * * *$ \\
Is religious & 1.0149 & 0.0874 & 0.864 \\
Is right-wing & 1.7236 & 0.2459 & $0.000 * * *$ \\
Is left-wing & 1.7429 & 0.1519 & $0.000 * * *$ \\
Seeks policy change & 0.3588 & 0.0554 & $0.000 * * *$ \\
Seeks social revolution & 0.3847 & 0.0530 & $0.000 * * *$ \\
Seeks status quo & 0.6338 & 0.0853 & $0.001 * * *$ \\
Seeks regime change & 0.6847 & 0.0574 & $0.000 * * *$ \\
Group age & 0.9797 & 0.0021 & $0.000 * * *$ \\
Peak size & 1.2325 & 0.0506 & $0.000 * * *$ \\
Occupied/Colonized & 1.0046 & 0.1157 & 0.968 \\
GDP per capita & 0.9480 & 0.0066 & $0.000 * * *$ \\
Freedom House & 1.2918 & 0.0283 & $0.000 * * *$ \\
State sponsor & 1.4242 & 0.0927 & $0.000 * * *$ \\
\hline
\end{tabular}

NOTE: Number of observations is 8,364 .

$\dagger p<.1 ;^{*}: p<.05 ;^{* *}: p<.01 ;^{* * *}: p<.005$ 
Table 18: Lethality of bombing/explosions

\begin{tabular}{lccl}
\hline Term & IRR & Standard Error & p-value \\
\hline Market structure & 1.2871 & 0.4465 & 0.467 \\
All-channel structure & 1.2719 & 0.1814 & $0.092 \dagger$ \\
Hub/spoke structure & 0.7564 & 0.0814 & $0.010 *$ \\
Is religious & 4.0084 & 0.7215 & $0.000 * * *$ \\
Is right-wing & 0.2868 & 0.0848 & $0.000 * * *$ \\
Is left-wing & 0.6949 & 0.1159 & $0.029 *$ \\
Seeks policy change & 0.5281 & 0.1166 & $0.004 * * *$ \\
Seeks social revolution & 0.5237 & 0.1207 & $0.005 * *$ \\
Seeks status quo & 1.9816 & 0.4291 & $0.002 * * *$ \\
Seeks regime change & 0.5265 & 0.0835 & $0.000 * * *$ \\
Group age & 1.0059 & 0.0032 & $0.070 \dagger$ \\
Peak size & 0.6657 & 0.0537 & $0.000 * * *$ \\
Occupied/Colonized & 2.0968 & 0.3623 & $0.000 * * *$ \\
GDP per capita & 0.9132 & 0.0113 & $0.000 * * *$ \\
Freedom House & 1.1582 & 0.0552 & $0.002 * * *$ \\
State sponsor & 2.0342 & 0.2468 & $0.000 * * *$ \\
\hline
\end{tabular}

NOTE: Number of observations is 12,039 .

$\dagger p<.1 ;^{*}: p<.05 ;^{* *}: p<.01 ;^{* * *}: p<.005$ 
In addressing the question of attack lethality as a measure of effectiveness the above results bring up several key considerations. First, while attack lethality helps untangle part of the story of group behaviour, it is limited by the fact that some groups, while perfectly capable of mass casualty attacks, eschew fatalities for strategic reasons. These groups choose to use violence as a means of communication and raising awareness yet they do not perceive violence as a coercive tool. ${ }^{29}$ Indeed, for many groups, a high fatality attack can spell a precipitous drop in support. As an example, the Omagh bombing disaster by the Real Irish Republican Army (RIRA) is one such example. It killed 29 people - a massive number of casualties for the group that included Protestants, Catholics and seven children - and forced the RIRA to apologize and some argue, it even hastened the final Good Friday peace agreement (Hayes and McAllister, 2001). While this one anecdote may serve as a counterpoint to using lethality as a measure, based on other attempts to measure effectiveness discussed in the literature review, lethality is - on balance - a powerful and simple tool that works well in most cases.

Indeed, measuring terrorist group effectiveness is very hard to do. While not discussed in the present chapter in detail, perhaps a complementary measure could be the number of attacks by a group. Lethality and number of attacks together may provide a good way to compare one group against another. Terrorism is most often defined

\footnotetext{
${ }^{29}$ Chapter 3 defines coercive targeting as: targets chosen by a group with the intent of forcing a change through higher casualty attacks. This change can be policy-related, political, or religious. These attacks are coercive in that they are designed to be of such power and fury that the intended audience will demand the government appease, or acquiesce, to the terrorist's demands.
} 
as having a communicative role; it is intended to coerce a target audience. This coercion is done through violence. The level of that violence, measured by lethality - and perhaps, in future work, the number of attacks - provide an outside observer with two crucial measurements of a group's output.

Another interesting finding is that the age of a group negatively affects lethality. This finding is in contrast to the findings of Asal and Rethemeyer (2008) who find no connection between lethality and group age. With the exception of market groups, lethality per attack decreases as all groups get older. While only statistically significant to a confidence interval of 85 percent, this study found that as market groups age they become more deadly.

One possible reason why market groups become more lethal as they get older could be that they experience very little pressure from counter-terror efforts. Since there is no leadership to target and very little to no communication between individuals or cells there is little to disrupt. Provided group members stick with the cause and are successful in some attacks, they can learn from these experiences and increase their lethality with little pressure from the authorities. So, while market groups may achieve a higher level of security than other structures, this may occur at the expense of efficiency.

The affect of group age with respect to market groups must be viewed in the context that market groups are the least prolific of all the structures. This result may come down to a problem of collective action. The formation of market groups may be less 
frequent because it requires a certain set of circumstances of like-minded, independent individuals who are willing to work alone or in small groups with no outside help or leadership beyond some training manuals. ${ }^{30}$ Because of the incentive to expand in size, and the consequent need for coordinating mechanisms, it is highly unlikely that a market structure would arise from a group with mass popular appeal. This supposition is supported by the data; most market groups have a peak size well below what is observed in other organizations. ${ }^{31}$ Market groups' issues tend to be narrow; its supporters few. This result suggests that other structure types may learn better from their experiences better than market structures.

In terms of structure, bureaucratic groups are more lethal than their counterparts. Bureaucratic groups are rarely seen in a high capability counter-terrorism environment because they are more often than not large organizations and therefore more susceptible to effective policing and intelligence. ${ }^{32}$ The reasons why bureaucratic

\footnotetext{
${ }^{30}$ The Earth Liberation Front is an ideal example of this type of group. Their publication, available online, Ecodefence: A Field Guide to Monkeywrenching is a manual in terrorist techniques designed to be widely distributed and reads like a manual of doctrine with the hope of inspiring others to join the cause (see Foreman and Haywood, 1993).

${ }^{31} 100 \%$ of market groups have a peak size of less than 100 members. By contrast, for all-channel groups that percentage drops to $15 \%$, for hub-spoke it is $24 \%$ and only $3 \%$ of all bureaucratic groups have a peak size of less than 100 members.

${ }^{32}$ While not shown here, a negative binomial test was also performed using the number of attacks per year as the dependent variable. The results of this estimation suggest that hub-spoke groups are most prolific in terms of operational pace, followed by bureaucratic groups. Market structures are the least prolific. This result is interesting since the expectation that operational pace would be directly correlated with organizational complexity does not ring true. Instead, hub-spoke groups maintain the highest operational pace. This finding suggests that hub-spoke groups, ceteris paribus, have a greater appetite for attacks and that they may be more adaptable to varying counter-terrorism environments than bureaucratic groups.
} 
groups are most deadly could include: the greater sophistication found in hierarchical groups, they face less capable policing and intelligence service, or that bureaucratic structures tends to be adopted by more militaristic, insurgency-oriented groups engaged in higher intensity conflict than other structure types. ${ }^{33}$ This finding is consistent with the peak size variable finding that suggests that as a group gets larger, it becomes more deadly.

The story from the results in this chapter is that lethality is an issue of both capability and will. Generally speaking, hierarchical groups are more lethal than decentralized groups. However, this relationship varies depending on a group's strengths and its environment and is best demonstrated by comparing the results between armed assaults and bombings. Here there is a clear difference between bureaucratic groups and both market and all-channel groups. When examining armed assaults, bureaucratic groups, true to form, are the most lethal. For bombings, this relationship is reversed; bureaucratic groups are less lethal than either market or all-channel structures. The findings in this chapter suggest that bureaucratic groups are the most lethal type of organization. If the hierarchical structure in a bureaucracy enables the group to be more effective and more willing to use armed assaults then there is no reason to believe that bureaucratic groups would not also be effective at bombings. But this is not the case. Bureaucratic groups are less lethal than most other structures. These results suggest that it is a matter of choice, not necessarily capability for bureaucratic

\footnotetext{
${ }^{33}$ When re-running the estimation only for those groups larger than 10,000 members bureaucratic groups remain the most deadly structure, but the z-scores and incidence rate ratio values become more pronounced, lending support to this hypothesis.
} 
groups. These groups choose to use one attack type over another.

In sum, it is suggested here that the groups with the most lethal attacks tend to be centralized in structure, larger in size, religious or right-wing motivated, and in some cases, they will be older, more established groups. With the basics sketched out of the affect of structure on a group's lethality, the focus now turns to a case study to help illustrate these conclusions.

\subsection{Case Study: Al Qaeda in Iraq (AQI)}

Selecting a within case study is appropriate for cases of taxonomic, theory building work (George and Bennett, 2005). ${ }^{34}$ The case selected for this chapter is Al Qaeda in Iraq. AQI makes an ideal case for a categorical theory-building exercise. This group has a clear point where it abruptly changed its organizational structure due to internal and external pressures. It therefore provides a good illustration of the affect on lethality when a group undergoes structural change. ${ }^{35}$ Finally, as a result of the attention in the media to the war in Iraq in general and, to AQI in particular, there is ample evidence and analysis available.

As with the study of any terrorist group, information is incomplete and often rife with competing explanations and facts. This fact is especially true with AQI since it

\footnotetext{
${ }^{34}$ See Chapter 3 for a longer discussion of the justifications for this type of case study.

${ }^{35}$ The time frame of the analysis below begins in 2003 and ends in 2008. While there is more to the story of AQI since it is an active organization, the GTD data at present ends in 2008 and therefore limits the analytical precision in more recent times.
} 
is still very much an active organization in Iraq, under increasing pressure from U.S. forces. What follows is a description of the organizational evolution of AQI using the best available open sources. Where there is credible evidence, attacks under AQI's previous names are subsumed. ${ }^{36}$

\subsubsection{Background}

Also known as Al Qaeda in Mesopotamia, Al Qaeda in Iraq is the dominant force of the umbrella movement, Khalf al-Mutayibeen that includes the self-proclaimed caliphate, the Islamic State of Iraq (ISI).$^{37}$ Like the bin Laden cadre of Al Qaeda, AQI subscribes to a radical interpretation of Salafism, itself a extreme view of Islam that justifies violence through takfir - a concept used by extremists to justify others as apostate - and jihad, the more common holy war justification employed widely by Islamic terrorists (Jane's, 2010).

The roots of AQI date as far back as 1999. At that time, the Jordanian Abu Musab al-Zarqawi was released from prison following a general amnesty in Jordan. Zarqawi is then thought to have travelled to Afghanistan where he commanded a group of volunteers under the name Al-Tawhid. Zarqawi was wounded following the invasion

\footnotetext{
${ }^{36}$ Ansar al Sunnah post-2004 is considered to be a separate organization while Tawid and Jihad is considered to be an alias for AQI during the transition in 2004 from one name to the other.

${ }^{37}$ The group referred to here as AQI, was originally associated with Ansar al-Islam, then it adopted the name, Tawid (Monotheism) and Jihad Group, both of which were designated as a Foreign Terrorist Group by the U.S. Department of State on March 15, 2004 and October 15, 2004, respectively. Perhaps in response to this designation, the group again changed its name in October 2004 to $\mathrm{Al}$ Qaeda in Iraq. The proceeding analysis takes these group name changes into account. See Katzman (2008).
} 
of Afghanistan by U.S. forces in 2001 and he went to Baghdad for respite (Bruno, 2011). After his convalescence he travelled to northern Iraq and joined a Kurdish Islamic group Ansar al-Islam, itself founded in late 1998 (Katzman, 2008). At its peak, Ansar al-Islam had more than 600 fighters located in a compound near the town of Kurmal in an area near the border with Iran and outside of the sphere of influence of both Baghdad and the autonomous Kurdish government (Chivers, 2002). It is believed that Zarqawi took command of the Arab faction of this group and set up a training camp at the Ansar al-Islam compound. By 2004, the Zarqawi faction had overshadowed the rest of Ansar al-Islam through a bloody campaign of violence aimed not just at the invading American forces, but against the large Iraqi Shia Muslim population - a sect of Islam Zarqawi labels as apostates (Jane's, 2010) ${ }^{38}$ While small, Zarqawi's group was seen, by mid-2003, as having a large impact on sectarian violence in Iraq. From the beginning of the insurgency, AQI had a large foreign-fighter component, including veterans from other theatres of jihad

While the U.S. government, in the lead up to the invasion of Iraq in 2003, pushed a narrative that Zarqawi was the link between the Iraqi regime under Saddam Hussein and Al Qaeda, it was not until October 2004 that Zarqawi published a letter pledging fealty to Bin Laden and the Al Qaeda network (Jane's, 2010). Moreover, there are further reports that the relationship between Bin Laden, Zawahiri and Zarqawi broke

\footnotetext{
${ }^{38}$ There is some question as to whether or not AQI has its roots through the broader al-Qaeda movement - a theory advanced in 2003 by the U.S. government. Most analysts, however, contend that Ansar al-Islam is the precursor since al-Zarqawi had initially joined this group prior to the U.S. invasion in 2003.
} 


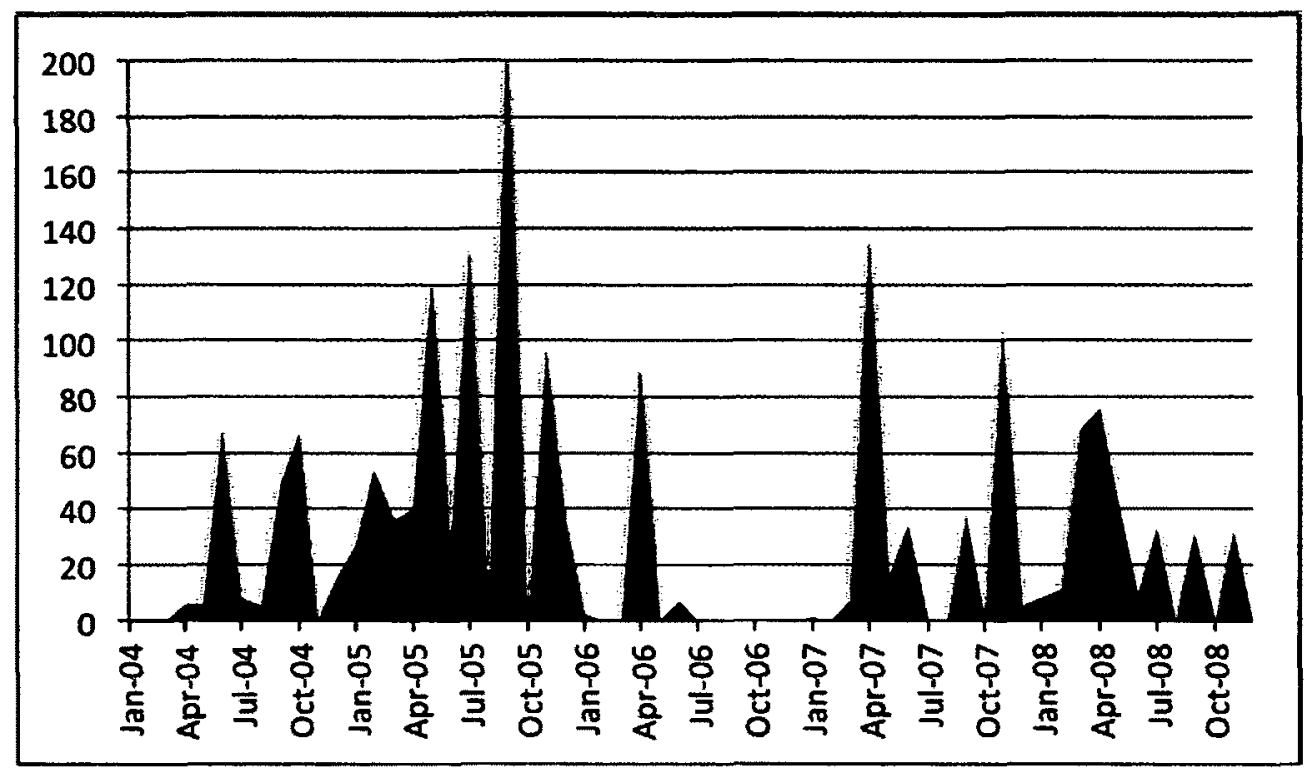

Figure 12: Al Qaeda in Iraq monthly lethality (2004-2008)

down by 2005 as a result of disagreements of AQI's strategy of targeting other Muslims $(\mathrm{Ulph}, 2005) .{ }^{39}$

\subsubsection{Command and Control}

Al Qaeda in Iraq has an interesting organizational structure, made more complicated by its sister organization, the Islamic State of Iraq, and by its past iterations under different names. Prior to June 2006, AQI operated in what was effectively a hub-spoke structure whereby the leader provides strategic direction to the group and there is evidence of functional differentiation. ${ }^{40}$ In mid-2006, this structure had changed to all-channel with less centralized control.

\footnotetext{
${ }^{39}$ This information is based on a letter released by U.S. intelligence from Ayman al-Zawahiri to Zarqawi in which he urges a stop to the practice of filming beheadings and attacking Shia targets.

${ }^{40}$ Most notably is the AQI rather elaborate Al-Furqan Institute of Media Production, a part of the organization that produced videos depicting martyrs as a means of recruitment and fundraising (see Jane's, 2010).
} 


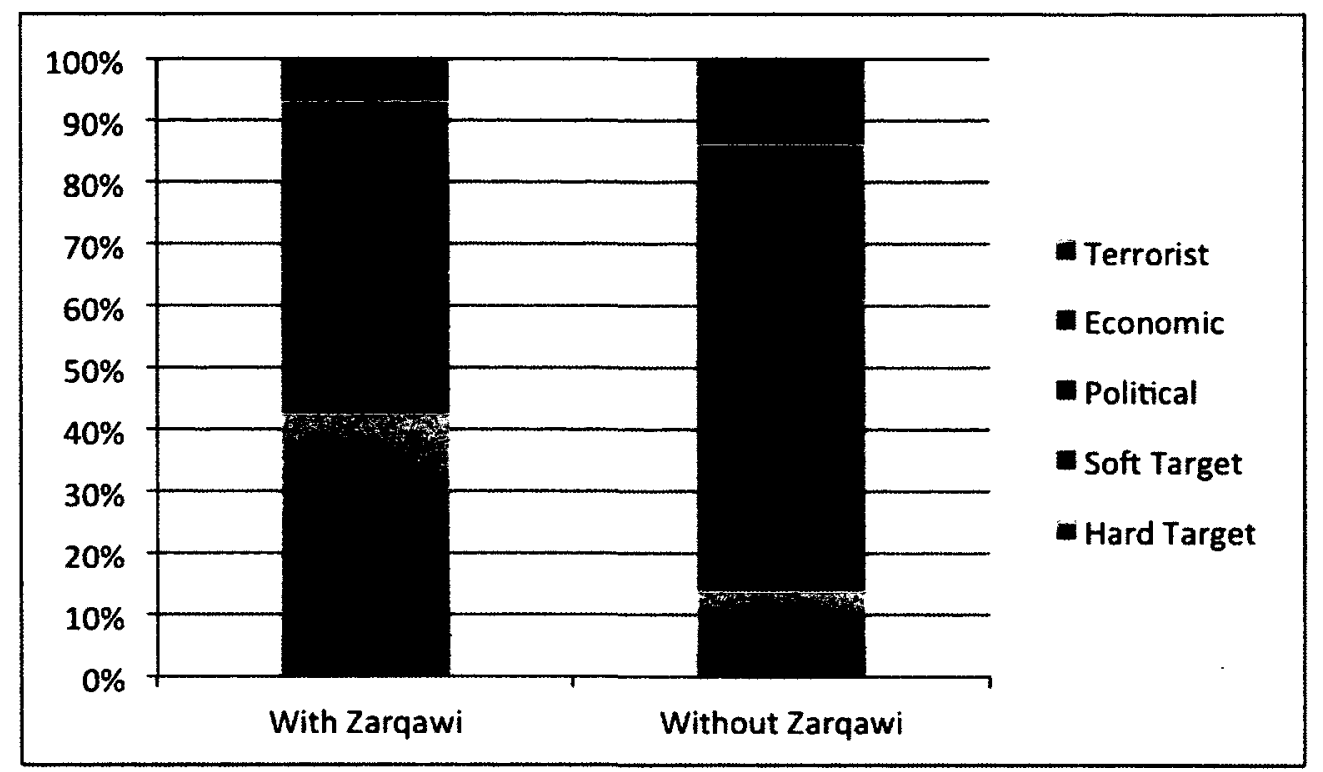

Figure 13: Change in Attack Profile for Al Qaeda Iraq

Explaining the changes to the command and control of AQI begins with the assassination of the group's founder, Abu Musab al-Zarqawi by an American bomb on 7 June 2006. Following Zarqawi's death, there is a lull in operations until the beginning of 2007 as depicted in Figure 12. The organization took some time to reorganize and appoint a new leader. It is alleged by U.S. intelligence sources that Bin Laden's second in command, Ayman al-Zawahiri pushed for and was successful in having appointed Abu Ayyub al-Masri, a fellow Egyptian and former Egyptian Islamic Jihad member, as military emir for AQI (Jane's, 2010). ${ }^{41}$

It was not just the death of Zarqawi that precipitated a structural change to the

\footnotetext{
${ }^{41}$ In fact, it is alleged that al-Masri created a fictitious character called Abu Omar al-Baghdadi and appointed him a overall emir to put an Iraqi face to the leadership of the organization so that it would gain more legitimacy amongst the Iraqi population. This alleged ruse also appears to add a layer of command to the group when it does not actually exist. American intelligence sources have repeatedly claimed that the organizational structure post-Zarqawi is much more streamlined than it appears to be (see Jane's, 2010; Bruno, 2011; Katzman, 2008).
} 
organization; the more effective counter-terrorism strategy employed by the U.S. and Iraqi forces also affected AQI's operations. This shift in structure is also reflected in Figure 13 which shows the difference in targeting selection pre and post-Zarqawi. In particular the groups ability, or willingness, to attack hard targets was significantly diminished. ${ }^{42}$

In October 2006, during the lull in attacks following Zarqawi's June death, AQI announced the formation of the Islamic State of Iraq (ISI), a new virtual government designed, along with the group's strategy of impeding the Iraq government, to overthrow the state. The ISI reportedly has a virtual cabinet with a leader - the alleged Sheikh Abu Omar al-Baghdadi - and ministers for the many portfolios found in a normal, functioning state. This new organization seems to have an elaborate chain of command resembling a bureaucracy (Bruno, 2011). However, slides presented by U.S. Brigadier General Kevin Bergner on 18 July 2007 show a much more compact command structure in which al-Masri is both the Emir and the military Emir (Jane's, 2010). In practice, the operational side of AQI became much more decentralized by the end of 2006. That the group is decentralized is supported by the fact that while determining an estimate of the group's size is very difficult - made even more so by the U.S. government's habit of ascribing any Sunni violence in Iraq to AQI members. The maximum size of the group by any assessment is not generally thought to exceed 50 members on the operational side and 150 on the communication and ISI side (Bruno,

\footnotetext{
${ }^{42} \mathrm{~A}$ similar pattern is seen in Chapter 3 ; as a group moves to an all-channel structure, hard target attacks decline.
} 
2011). There is recent evidence from captured members of AQI that, beginning in 2010, the group has become even more decentralized and is possibly moving toward a market structure of leaderless resistance (Bruno, 2011; Jane's, 2010).

\subsubsection{Attack Lethality}

In terms of its output, AQI is blamed for 102 attacks between 2004 and the end of $2007,{ }^{43}$ and in 2008 , a further 36 attacks. As Figure 12 shows, there is a sharp drop in attacks in 2006. The drop is notable because AQI founding leader, Abu Musab al-Zarqawi was killed on 7 June, 2006. Of the five attacks by AQI in 2006, all of them occur in the first half of the year. Four days following the death of al-Zarqawi, AQI detonated a bomb in a central market in Baghdad, killing 6 and injuring 59. Given the close proximity to the date of their leader's death, this attack can be seen as a form of retribution, a pattern in keeping to a general trend of an increase in fatalities immediately following the death of a terrorist leader (Kilberg and Rowlands, 2011). Most notable, however is the break in any attacks by this group for a period of seven months following al-Zarqawi's death.

In the group's early period, before the death of Zarqawi their attack profile can be described as high casualty and high profile (Katzman, 2008). In sum, Al Qaeda in Iraq, following its transition to an all-channel group is significantly diminished.

\footnotetext{
${ }^{43} 2007$ is the limit of main database for this study. Attacks for 2008 are included in this case study since these have recently been released by the GTD (START, 2011).
} 
Table 19: Different Measures of AQI Lethality

\begin{tabular}{|c|c|c|}
\hline Target Category & $\begin{array}{c}\text { Zarqawi } \\
\text { (Hub-Spoke) }\end{array}$ & $\begin{array}{l}\text { Post-Zarqawi } \\
\text { (All-Channel) }\end{array}$ \\
\hline Total killed & 1112 & 650 \\
\hline Total attacks & 88 & 68 \\
\hline Avg. \# killed per month & 37.06 & 21.66 \\
\hline Avg. \# attacks per month & 11.53 & 6.54 \\
\hline Avg. \# killed per attack & 12.63 & 9.56 \\
\hline \# terrorists killed & 56 & 80 \\
\hline \# suicide attacks ${ }^{a}$ & 40 & 11 \\
\hline
\end{tabular}

As shown in Table 19, in the 30-month period under the command of Zarqawi, AQI killed on average 37.06 people per month. Following Zarqawi's death and the subsequent reorganization of the group, that monthly fatality average falls to 21.66. Moreover, the number of casualties inflicted on the group itself rises dramatically in the second half of the period of analysis. While there may seem to be little difference between the 56 terrorists killed in the first half and 80 killed in the second what makes this difference so striking is that in the first half there were 40 suicide attacks which account for at least 71 percent of these casualties. In the second half of the analysis, there are only 11 suicide attacks which accounts for only 14 percent of the terrorist casualties.

Put together these results show a clear decline in lethality between hub-spoke and all-channel structures. Not only has group targeting changed from predominantly hard targets to softer, easier targets, but the operational pace has diminished. 


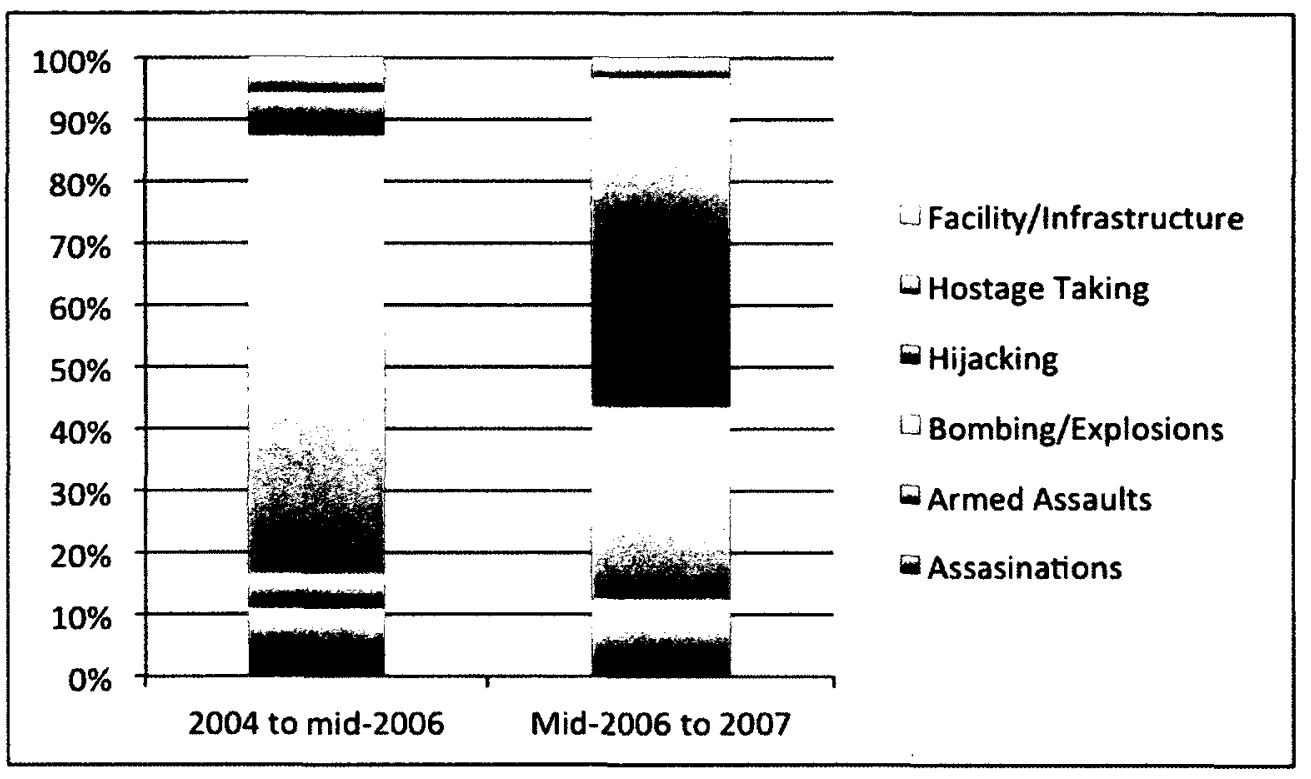

Figure 14: Attack type: Al-Qaeda in Iraq

\subsubsection{Conclusion}

The change experienced by AQI in 2006 resulted in a less deadly organization. While it is difficult to separate the affect of Zarqawi's death and the ever-improving counterterror campaign by U.S. forces during the period where the group reorganized, there is a clear difference between AQI as a hub-spoke group and as an all-channel group in terms of not only its lethality but also its target selection as depicted in Figure 14.

From a policymaking point of view there are some clear lessons here. On the one hand, as a mitigation strategy, pushing a group away from a centralized structure could help reduce a groups lethality and hard target attacks. Following the invasion of Iraq in 2003, U.S. forces, while somewhat ineffective at first, gradually increased external pressure on AQI to the point where they are now largely marginalized and represent little risk of overthrowing the national government (Jane's, 2010). 
On the other hand, AQI serves as a potent reminder that it is virtually impossible to thwart a determined terrorist group completely. Selecting AQI as a within-case study allows for a recent case study of organizational structure but it is also difficult to make conclusions since the group is still very much actively protesting the occupation of Iraq. Only with the benefit of time will it be possible to evaluate the sum total of output by Al Qaeda in Iraq and its effectiveness in the face of an ever improving and formidable foe. 


\section{Chapter 5}

\section{Conclusions and Implications for the}

\section{Future}

This study is the first attempt to systematically categorize and describe terrorist group organizational structures. Through my analysis of 254 groups, some clear results emerge.

As Coase (1937) describes, the way an organization adapts its information and communication flows to best suit the production of goods or services is at least as important as the product itself. A dualistic notion of either market or hierarchy persists in the literature until others, in particular Granovetter (1973) and Powell (1990), make the case that some organizations are neither market nor hierarchy but, rather, something in between. In an important study, Baker and Faulkner (1993) examine the implications of organizational structure in an illegal price-fixing enterprise and 
lay the groundwork for investigating the differences between one group's need for secrecy and another's need for efficiency. Finally, Arquilla and Ronfeldt describe four organizational structures that best encompass violent groups (Arquilla and Ronfeldt, 1993, 1996, 2001).

The struggle to balance efficiency with the need for security is the key finding in this thesis. As the results suggest, a terrorist group's organizational structure represents an attempt to balance their security concerns with their need for efficiency. The balance between security and efficiency lies at the centre of the explanation for why groups choose the structures that they do.

Chapter 2 identifies the internal and external factors that shape a group's structure. There is no easy answer to this; each group faces a unique situation and adapts accordingly. While preliminary, the results from Chapter 2 show that rich, free, durable democratic states push groups to adopt a decentralized structure. These qualities typify so-called Western states and the implication of this result is that while an open, democratic regime does not guarantee the absence of terrorism, it does suggest that terrorist groups in these states will be mostly decentralized. If in its first year a group lacks the ability or willingness to attack hard targets, it likely has a decentralized structure. If in its first year a group has a low operational pace, it likely has a decentralized structure. Finally, when a group has broad goals - which are less likely to be achieved than narrow goals - it likely has a decentralized structure. Below, I sketch out some features of each structure that emerge from Chapter 2. 
A market structure represents those groups that have chosen a leaderless resistance format. Market groups do not have any discernible leadership, functional differentiation or centralized command and control. These types of groups are, more often than not, left or right-wing motivated; in their first year, they are the least deadly and least prolific structure type that a terrorist group can take. In their first year, market groups are less likely to employ sophisticated types of attacks including attacking hard targets. If the home state of a group has a high GDP per capita - and therefore a high counter-terror capability - then it is more likely that the group is either a market or all-channel structure.

All-channel structures are inter-netted, networked groups that differ from market groups in that they do have some type of leadership. Like market groups, however, they are neither centrally-controlled nor do they possess functional differentiation. What this structure does have is the possibility of dense connections between individuals or nodes that allow for some coordination, often in a non-hierarchical way. The leadership in these groups is more often inspirational than anything else, leaving most of the decision-making to node commanders. Religious groups are more likely to take an all-channel structure than any other ideology. In states with a stable polity and high political rights and civil liberties terrorist groups are also more likely to take on an all-channel or market structure. Groups with broad goals such as seeking social revolution are also more likely to adopt a market or all-channel structure.

Hub-spoke structures - or as Kenney (2007) calls them, wheel networks - have more 
hierarchy in their structure than all-channel groups. Hub-spoke structures have leadership and exhibit functional differentiation; some or all parts will have a specialized function. This specialization is the crucial difference between all-channel and hubspoke groups. Hub-spoke groups are also more likely to operate in states where high political rights and civil liberties exist. This organizational structure is also favoured by religious groups, more than any other motivation type. In terms of internal factors, there are few statistically significant differences between hub-spoke groups and bureaucracies; one such difference is that hub-spoke groups are more likely to seek broad goals than bureaucratic groups. ${ }^{1}$

Bureaucratic structures are centrally-run organizations. These structures also have a high degree of functional differentiation. It is not uncommon for these types of terrorist groups to have a propaganda wing, a media production team, communication liaisons around the globe, specialized weapon and bomb-making groups, regional brigades of fighters ready to be deployed when needed and a political wing. At their most extreme, bureaucratic groups operate in a similar manner to the governments that they are fighting. In fact, they can be a more effective organization than the state itself. $^{2}$ Bureaucratic structures, as a result of their hierarchy are often found

\footnotetext{
${ }^{1}$ As illustrated in the ETA case study in Chapter 3, the specialization offered by hub-spoke groups can also mean a higher capability for the group. For ETA, the specialized intelligence groups that operated within the group were crucial to contributing to the group's ability to plan and execute sophisticated attacks on precise targets such as a police inspector or a politician. The loss of these specialized groups following reorganization to a all-channel structure resulted in a drop in ETA's output and a sharp decline in focused, sophisticated attacks. Instead, the group chose simpler targets of opportunity that were less menacing to the population.

${ }^{2}$ One example of this is the group Hezbollah. Following the 2006 war with Israel, it was Hezbollah that led the reconstruction efforts - and made the Lebanese government look ill-prepared and incapable of supporting its citizens (see Fisk, 2006; Hamieh and MacGinty, 2010).
} 
in groups where membership is greater than a thousand; this structure is well-suited to large organizations. It is also the most effective organizational form for dealing with high information flows and complex tasks in large groups (Weber, 1952). For terrorist groups this effectiveness manifests in maintaining a high operational pace, planning and executing complex attacks and in selecting hard targets to attack. The downside of a terrorist bureaucracy, however, is that as a result of the many layers of management that exist and the centralized decision-making, the group does not adequately insulate itself against infiltration or disruption by an effective counterterrorist campaign. This is why it is extremely rare for a bureaucratic group to exist in wealthy states. Whatever a bureaucratic terrorist group gains in efficiency, it loses in security.

The goal of Chapter 2 was to identify distinct characteristics about terrorist group structure. While Heger et al. (2008) have previously examined the role of structure in terrorist groups, this chapter represents the first time a large-scale quantitative study has been done examining the organizational structures of individual terrorist groups. Terrorist groups use their attacks to communicate. How a terrorist group chooses its targets says a lot about the group. In Chapter 3, I investigate how structure affects target selection. The GTD logs 22 possible target types so, in order to simplify things, I sort these into three distinct categories according to what the group is trying to communicate with an attack: coerce, seek attention or fight other violent groups.

The results from the multinomial logit in Chapter 3 are surprising. Contrary to my 
hypothesis, market groups are as likely to attack hard targets as bureaucratic groups. ${ }^{3}$ Hard targets represent the highest risk to a group since the opposition they face will definitely be armed and ready to respond to an attack. For market structures it was expected that incurring high losses in personnel can be particularly devastating since they are typically the smallest-sized groups and cannot afford to lose many members. However, what the results suggest is that all-channel groups are the least likely to attack any coercive target - hard or soft.

The ETA case study in Chapter 3 illustrates well the effect a devolution in structure can have on a group's targeting preferences. As a hub-spoke group - a relatively hierarchical structure - ETA had the capability and the will to target individual police and government officials. In Spain, public figures often have a security detail; targeting these individuals represents a formidable task. As a hub-spoke structure, ETA was able to consistently target public figures using sophisticated attack methods. When ETA was forced to reorganize into an all-channel structure, the sophistication in the group's targeting dropped dramatically; difficult targets that were previously chosen were replaced by less risky, less sophisticated attacks.

The results of the case study serve to illustrate anecdotally what is suggested in the population of incidents included in the statistical analysis in Chapter 3 - that structure affects the targeting choices a group makes.

Chapter 4 uses lethality per attack to measure group effectiveness. By no means

\footnotetext{
${ }^{3}$ In fact, there is evidence that market groups may be even more likely to attack hard targets than bureaucratic groups (see Tables 10 and 25).
} 
should lethality per attack be used as the sine qua non of terrorist group effectiveness. However, it does offer a simple analytic measurement from which to compare all groups. The results suggest that as most groups get older, they become less lethal. The only exception to this are market structure groups which gain lethality as they age.

The results from Chapter 4 are plentiful. Bureaucratic groups are the most lethal structures. In terms of ideology, religious and right-wing groups are more lethal than left-wing and nationalist groups. If a group is state sponsored its lethality is 2.3 times higher. States with low political rights and civil liberties have more lethal terrorist groups.

The case study of Al Qaeda in Iraq (AQI) provides a good illustration of what happens to the effectiveness of a group when it is forced to change its organizational structure. Putting aside the difficult task of separating the causality between improved counterterrorism by US and Iraqi forces, the death of Zarqawi and the change in structure - all factors in precipitating the decline of violence - AQI serves as a reminder that effective counter-terrorism strategy often results in the disruption and restructuring of a terrorist group, diminishing its lethality. 


\subsubsection{Implications for the Future}

Given the paucity of research in this field, this thesis is primarily a theory-building exercise. One should be cautious when deriving policy prescriptions from this work as much more needs to be done. Future research is necessary to fully understand the implications of terrorist group structure. That said, the potential policy implications of this study are vast.

One prescription that emerges is that counter-terror policy in low and middle income states should differ from policies in high income states. In low and middle income states, capacity is low; the ability of the government to fend off threats and maintain public safety may not always be possible in the face of a concerted wave of protest. Counter-terrorism capability is therefore limited and these states should focus their resources on mitigating risk by targeting bureaucratic terrorist groups first. For lower income states, mitigating the risk means focusing its meagre resources on combating hierarchical groups with the intention of atomizing the group to a less centralized structure, preferably all-channel. While this may seem like a tall order, the results suggest that this could be an effective strategy. Consider that of the 254 groups surveyed, I identified 32 that changed structure at some point. Of these 32 groups, none change to a market structure. Groups become more or less centralized, but the evidence suggests that moving to a leaderless resistance is rare indeed. ${ }^{4}$ The results

\footnotetext{
${ }^{4}$ That is not to say that this cannot happen; one possible exception is Al Qaeda in Iraq which is believed to have moving towards a market structure beginning in 2010 (see Bruno 2011; Jane's, 2011).
} 
of this study, ceteris paribus, suggest that the greatest threat - at least in terms of a body count - comes from highly centralized organizations.

Hierarchical terrorist groups form in poor countries because they can. These groups are able to enjoy the efficiencies of a bureaucracy without suffering the security disadvantages that come with this structure. The states' challenge is to keep focused on the few really dangerous groups. Most of the time governments respond in a highly reactive way to terrorist attacks. The results here suggest, for lower income states, this may not be the most effective way forward.

For high income countries the counter-terrorism prescription is even less forgiving. In these states, nothing less than total success is considered acceptable. Unfortunately, due to the capable counter-terror environment in rich countries, terrorist groups almost never have a centralized structure, which would be relatively easy for a wealthy state to disrupt. Rather, the government faces groups that, aware of the huge asymmetric imbalance, have adopted an organizational structure to suited to this environment. By this I mean that in rich countries, terrorist groups are more likely to be all-channel and market structures. While market groups are the least prolific, in many ways they seem to be the most capable; they seem to attack hard targets with impunity. That market groups often operate in the harshest conditions is a testament to their adaptability and resilience. Market groups, at their most marginalized, can represent an almost lone wolf threat that can be extremely difficult to stop, even for high capacity states. 
The variables I coded over the course of this project complement the GTD dataset and provide a future research agenda with many possibilities. The 'problem' I faced from the beginning of this project was an abundance of riches; so much data and so many avenues to explore. This is a new area of exploration. In the end, what was needed was a basic model for understanding terrorist group structures, what affects these structures and how structure, in turn, affects a group's behaviour. 


\section{Bibliography}

Abadie, A. (2006), Poverty, political freedom, and the roots of terrorism, The American Economic Review 96(2), 50

Abrahms, M. (2006), Why terrorism does not work, International Security 31(2), 42

Abrahms, M. (2007), Why democracies make superior counterterrorists, Security Studies 16(2), 223

Alexander, Y., Swetnam, M., and Levine, H. (2001), ETA: profile of a terrorist group, Transnational Publishers Incorporated

Allison, G. (1971), Essence of decision, Harvard University Press

Alonso, R. and Reinares, F. (2006), A case study on religious radicalization processes in Spain, Root causes of suicide terrorism: the globalization of martyrdom $\mathrm{pp}$ 179-202

Alterman, J. (1999), How Terrorism Ends, USIP Special Report pp 8-15

Arquilla, J. and Ronfeldt, D. (1993), Cyberwar is Coming, RAND Corporation 
Arquilla, J. and Ronfeldt, D. (1996), The Advent of Netwar, RAND Corporation

Arquilla, J. and Ronfeldt, D. (2001), Networks and netwars: The future of terror, crime, and militancy, RAND Corporation

Arquilla, J., Ronfeldt, D., and Zanini, M. (1999), Networks, Netwar, and InformationAge Terrorism, RAND Publications pp 75-112

Asal, V., Nussbaum, B., and Harrington, D. W. (2007), Terrorism as Transnational Advocacy: An Organizational and Tactical Examination, Studies in Conflict E Terrorism 30(1), 15

Asal, V. and Rethemeyer, R. (2008), The nature of the beast: Organizational structures and the lethality of terrorist attacks, The Journal of Politics 70(02), 437

Asal, V., Rethemeyer, R., Anderson, I., Stein, A., Rizzo, J., and Rozea, M. (2009), The softest of targets: a study on terrorist target selection, Journal of Applied Security Research 4(3), 258

Atran, S. (2006), The Moral Logic and Growth of Suicide Terrorism, The Washington Quarterly 29(2), 127

Atran, S. (2010), Who Becomes a Terrorist Today?, Perspectives on Terrorism 2(5)

Baker, W. and Faulkner, R. (1993), The social organization of conspiracy: Illegal networks in the heavy electrical equipment industry, American Sociological Review $58(6), 837$ 
Beam, L. (1992), Leaderless Resistance, The Seditionist 12

Benjamin, D., Simon, S., Gunaratna, R., Laqueur, W., Rubin, B., and Rubin, J. (2002), The age of sacred terror, New York

Berrebi, C. (2003), in Working Paper - Princeton University Industrial Relations Section

Blomberg, S., Engel, R., and Sawyer, R. (2010), On the duration and sustainability of transnational terrorist organizations, Journal of Conflict Resolution 54(2), 303

Bloom, M. (2004), Dying to kill, Columbia University Press

Bloom, M. (2007), Female suicide bombers: a global trend, Daedalus 136(1), 94

Boyns, D. and Ballard, J. (2004), Developing a sociological theory for the empirical understanding of terrorism, The American Sociologist 35(2), 5

Bruno, G \& Jeffrey, J. (2011), Profile: Al-Qaeda in Iraq (aka al-Qaeda in Mesopotamia)

Byman, D. (2003), Should Hezbollah Be Next?, Foreign Affairs 82, 54

Chen, A. and Siems, T. (2004), The effects of terrorism on global capital markets, European Journal of Political Economy 20(2), 349

Cheng, S. and Long, J. (2007), Testing for IIA in the multinomial logit model, Sociological methods 6 research $35(4), 583$ 
Child, J. (1972), Organizational structure, environment and performance: The role of strategic choice, Sociology $6(1), 1$

Chivers, C. (2002), Repulsing Attack by Islamic Militants, "Iraqi Kurds Tell of Atrocities", New York Times

Civil, G. (2003), Guardia Civil Report

Clarke, R. and Newman, G. (2006), Outsmarting the terrorists, Praeger Publishers

Clauset, A., Young, M., and Gleditsch, K. (2006), Scale Invariance in the Severity of Terrorism, Arxiv preprint physics/0606007

Coase, R. H. (1937), The nature of the firm, Economica pp 386-405

Collins, N. and Preston, L. (1969), Price-cost margins and industry structure, The Review of Economics and Statistics 51(3), 271

Cox, M., Guelke, A., and Stephen, F. (2006), A farewell to arms?: beyond the Good Friday Agreement, Manchester University Press

Crenshaw, M. (1985), An Organizational Approach to the Study of Terrorism, Orbis $29(3), 465$

Crenshaw, M. (1991)a, How terrorism declines, Terrorism and Political Violence $\mathbf{3}(\mathbf{1}), 69$

Crenshaw, M. (1991)b, How Terrorism Declines, in C. McCauley (ed.), Terrorism Research \& Public Policy, pp 69-87, Frank Cass 
Crenshaw, M. (1995), Terrorism in Context, Pennsylvania State University Press

Crenshaw, M. (1996), Why violence is rejected or renounced: A case study of oppositional terrorism, The Natural History of Peace

Crenshaw, M. (1999), How Terrorism Ends, in J. Alterman (ed.), How Terorism Ends, p. 8, United State Institute for Peace

Crenshaw, M. (2000), The psychology of terrorism: An agenda for the 21st century, Political Psychology 21(2), 405

Crenshaw, M. (2007), The organization of terrorism, National Memorial Institute for the Prevention of Terrorism, Wesleyan University

Cronin, A. (2008), Ending terrorism: lessons for defeating al-Qaeda, Routledge for the International Institute for Strategic Studies

Cronin, A. (2009), How terrorism ends: understanding the decline and demise of terrorist campaigns, Princeton University Press

Cronin, A. K. (2006), How al-Qaida Ends: The Decline and Demise of Terrorist Groups, International Security 31(1), 7

Davies, J. (1962), Toward a Theory of Revolution, American Sociological Review $\mathbf{2 7 ( 1 )}, 5$

De la Calle, L., Sánchez-Cuenca, I., de Estudios e Investigaciones, I. J. M., and 
de Estudios Avanzados en Ciencias Sociales, C. (2006), The Production of Terrorist Violence: Analyzing Target Selection within the IRA and ETA, Centro de Estudios Avanzados en Ciencias Sociales, Instituto Juan March de Estudios e Investigaciones

Della Porta, D. (1995), Social Movements, Political Violence, and the State, Cambridge University Press, 1st. edition

Della Porta, D. (2006), Social movements, political violence, and the state: $A$ comparative analysis of Italy and Germany, Cambridge University Press, 2nd edition

DeNardo, J. (1985), Power in numbers: The political strategy of protest and rebellion, Princeton University Press

DeSanctis, G. and Fulk, J. (1999), Shaping organization form: Communication, connection, and community, Sage Publications, Inc

Dingley, J. (2001), The bombing of Omagh, 15 August 1998: the bombers, their tactics, strategy, and purpose behind the incident, Studies in Conflict $\mathcal{E}$ Terrorism 24(6), 451

Dishman, C. (2001), Terrorism, crime, and transformation, Studies in Conflict $\mathcal{E}$ Terrorism 24(1), 43

Drake, C. (1998)a, The role of ideology in terrorists target selection, Terrorism and Political Violence 10(2), 53

Drake, C. (1998)b, Terrorists' target selection, Palgrave Macmillan 
Drakos, K. (2007), The size of under-reporting bias in recorded transnational terrorist activity, Journal of the Royal Statistical Society: Series A (Statistics in Society) $\mathbf{1 7 0}(4), 909$

Drakos, K. and Gofas, A. (2006), The devil you know but are afraid to face, Journal of Conflict Resolution 50(5), 714

Dugan, L., Huang, J., LaFree, G., and McCauley, C. (2008), Sudden desistance from terrorism: The Armenian Secret Army for the Liberation of Armenia and the justice commandos of the Armenian Genocide, Dynamics of Asymmetric Conflict $\mathbf{1 ( 3 )}, 231$

Dugan, L., LaFree, G., and Miller, E. (2007), in Presentation at the American Society of Criminology Annual Meeting, Atlanta, GA

Eckstein, H. (1975), Case study and theory in political science, Handbook of political science 7,79

Eilstrup-Sangiovanni, M. and Jones, C. (2008), Assessing the Dangers of Illicit Networks: Why al-Qaida May Be Less Threatening Than Many Think, International Security 33(2), 7

Ender, P. (2004), Collin diagnostic tool for Stata, UCLA Department of Education

Enders, W. and Sandler, T. (1993), The effectiveness of antiterrorism policies: A vector-autoregression-intervention analysis, The American Political Science Review $87(4), 829$ 
Erickson, B. (1981), Secret societies and social structure, Social Forces $60(1), 188$

Eubank, W. L. and Weinberg, L. (1994), Does democracy encourage terrorism?, Terrorism and Political Violence 6(4), 417

Eubank, W. L. and Weinberg, L. (2001), Terrorism and democracy: Perpetrators and victims, Terrorism and Political Violence 13(1), 155

Fisk, R. (2006), Hizbollah's reconstruction of Lebanon is winning the loyalty of disaffected Shia

Foreman, D. and Haywood, B. (1993), Ecodefense: A field guide to monkeywrenching

Frey, B. and Luechinger, S. (2003), Measuring terrorism

Garfinkel, S. L. (2003), Leaderless resistance today, First Monday 8(3)

George, A. and Bennett, A. (2005), Case studies and theory development in the social sciences, The MIT Press

Gerlach, L. (2001), The structure of social movements: Environmental activism and its opponents, in J. Arquilla and D. Ronfeldt (eds.), Networks and netwars: The future of terror, crime, and militancy, pp 289-310, RAND Corporation

Gerlach, L. and Hine, V. (1970), People, power, change: Movements of social transformation, MacMillan Publishing Company

Gerlach, L. and Hine, V. (1973), Lifeway Leap: The Dynamics of Change in America. Minneapolis: Univ, Minnesota Press 
Goffman, E. (1969), Strategic interaction, U. Pennsylvania Press

Granovetter, M. (1973), The strength of weak ties, American journal of sociology 78(6), 1360

Gunaratna, R. and Ali, M. (2009), De-Radicalization Initiatives in Egypt: A Preliminary Insight, Studies in Conflict $\mathcal{B}$ Terrorism 32(4), 277

Gupta, D. (2008), Understanding terrorism and political violence: the life cycle of birth, growth, transformation, and demise, Psychology Press

GWU (2011), The National Security Archive, online

Hamieh, C. and MacGinty, R. (2010), A very political reconstruction: governance and reconstruction in Lebanon after the 2006 war, Disasters 34, S103

Hayes, B. and McAllister, I. (2001), Who voted for peace? Public support for the 1998 Northern Ireland Agreement, Irish Political Studies 16(1), 73

Heger, L., Jung, D., and Wong, W. (2008), Organizing for resistance: How group structure impacts the character of violence, Annual Meeting of the International

Helliwell, J. (1994), Empirical linkages between democracy and economic growth, British journal of political science 24(02), 225

Henley, J. Walker, J. (2003), French anti-terror squad arrests key Eta leaders

Heston, A., Summers, R., and Aten, B. (2006), Penn world table version 6.2, Center 
for International Comparisons of Production, Income and Prices at the University of Pennsylvania 10

Heston, A., Summers, R., and Aten, B. (2009), Penn World Table Version 6.3, Center for International Comparisons of Production, Income and Prices at the University of Pennsylvania

Hitzeman, J. and Mabrey, D. (2010), Moving Beyond Counts: An Event-Based Analytical Paradigm for Measuring Changes in Terrorist Operational Effectiveness in Time 8 Space* John Hitzeman jhitzeman@isvg. org Institute for the Study of Violent Groups, unpublished

Hoffman, B. (1995), Holy terror: the implications of terrorism motivated by a religious imperative, Studies in Conflict $\mathcal{E}$ Terrorism 18(4), 271

Hoffman, B. (2006), Inside terrorism, Columbia University Press

Horgan, J. (2005), The Psychology of Terrorism, Routledge Press

Horgan, J. (2008), From Profiles to Pathways and Roots to Routes: Perspectives from Psychology on Radicalization into Terrorism, The Annals of the American Academy of Political and Social Science 618(1), 80

Horgan, J. and Braddock, K. (2010), Rehabilitating the Terrorists?: Challenges in Assessing the Effectiveness of De-radicalization Programs, Terrorism and Political Violence 22(2), 267 
House, F. (2009), Freedom in the world: The annual survey of political rights and civil liberties

Hudson, R. and Majeska, M. (1999), The Sociology and Psychology of Terrorism: Who Becomes a Terrorist and Why?, Library of Congress: Federal Research Division

Hutchinson, P. O. . S. (2007), How terrorist groups decline, Canadian Centre for Intelligence and Security Studies $\mathcal{G}$ ITAC Presents 5(1)

Jackson, B. and Baker, J. (2005), Aptitude for destruction: Organizational learning in terrorist groups and its implications for combating terrorism, Rand Corp

Jackson, B., Baker, J., Chalk, P., Cragin, K., Parachini, J., and Trujillo, H. (2005), Aptitude for Destruction, Volume 2: Case Studies of Organizational Learning in Five Terrorist Groups, RAND

Jackson, B. A. (2004), Organizational learning and terrorist groups, RAND

Jackson, B. A. (2006), Groups, Networks, or Movements: A Command-and-ControlDriven Approach to Classifying Terrorist Organizations and Its Application to Al Qaeda, Studies in Conflict \& Terrorism 29(3), 241

Jane's (2009)a, Earth Liberation Front

Jane's (2009)b, Profile: Euzkadi Ta Askatasuna (ETA)

Jane's (2010), Profile: Al-Tawid E Al Qaeda in Iraq 
Janis, I. (1972), Victims of groupthink, Houghton Mifflin

Jenkins, B. (1975), Will terrorists go nuclear?, Rand Corporation

Jenkins, B. (1985), The Likelihood of Nuclear Terrorism, RAND Corporation

Jenkins, B. (2010), Would-be warriors: incidents of jihadist terrorist radicalization in the United States since September 11, 2001, Rand Corp

Jones, C. (2006), Al-Qaeda's Innovative Improvisers: Learning in a Diffuse Transnational Network, Cambridge Review of International Affairs 19(4), 555

Jones, S. G. and Libicki, M. C. (2008), How terrorist groups end: lessons for countering Al Qa'ida, Rand Corp

Juergensmeyer, M. (2003), Terror in the mind of God: The global rise of religious violence, University of California Press

Karolyi, G. and Martell, R. (2005), Terrorism and the stock market

Katzman, K. (2008), Al Qaeda in Iraq: Assessment and Outside Links, Congressional Research Service Report for Congress

Keane, M. (1992), A note on identification in the multinomial probit model, Journal of Business \& Economic Statistics 10(2), 193

Keck, M. E. and Sikkink, K. (1998), Activists Beyond Borders: Advocacy Networks in International Politics, Cornell University Press

Kennedy, P. (2003), A guide to econometrics, The MIT Press 
Kenney, M. (2003), From Pablo to Osama: Counter-terrorism lessons from the war on drugs, Survival 45(3), 187

Kenney, M. (2007), From Pablo to Osama: Trafficking and terrorist networks, government bureaucracies, and competitive adaptation, Pennsylvania State University Press

Kilberg, J. and Rowlands, D. (2011), Targeting Leadership of Terrorist Groups: the organizational dimension, in progress

Krebs, V. (2002), Mapping networks of terrorist cells, Connections 24(3), 43

Kropko, J. (ed.) (2008), Choosing Between Multinomial Logit and Multinomial Probit Models for Analysis of Unordered Choice, Palmer House Hotel, Hilton, Chicago, IL, Paper presented at the annual meeting of the MPSA Annual National Conference

Krueger, A. and Maleckova, J. (2003), Education, poverty and terrorism: Is there a causal connection?, The Journal of Economic Perspectives 17(4), 119

Krueger, A. B. and Maleckova, J. (2002), Education, Poverty, Political Violence and Terrorism: Is There a Causal Connection?, unpublished manuscript

LaFree, G., Yang, S., and Crenshaw, M. (2009), Trajectories of terrorism, Criminology \& Public Policy 8(3), 445

Laqueur, W. (1987), The age of terrorism, Little, Brown Boston, MA 
Lawrence, B. (ed.) (2005), Messages to the world: The statements of Osama bin Laden, Verso Press, London, UK

Li, Q. (2005), Does democracy promote or reduce transnational terrorist incidents?, Journal of Conflict Resolution 49(2), 278

Libicki, M. C., Chalk, P., and Sisson, M. (2007), Exploring Terrorist Targeting Preferences, RAND Corporation

Lichbach, M. I. (1995), The Rebel's Dilemma, University of Michigan Press

Long, J. and Freese, J. (2005), Regression models for categorical dependent variables using Stata, Stata Press: College Station, TX, 2nd edition

Mannes, A. (2008), Testing the Snake Head Strategy: Does Killing or Capturing its Leaders Reduce a Terrorist Group's Activity?, The Journal of International Policy Solutions 9, 40

Marshall, M., Jaggers, K., and Gurr, T. (2003), Polity IV project: Political regime characteristics and transitions, 1800-2002, September 30, 2003

Mayntz, R. (2004), Hierarchy, Network, or a Type sui generis? Organizational Forms of Terrorism

McAdam, D., Tarrow, S., and Tilly, C. (2001), Dynamics of contention, Cambridge University Press

McCauley, C. (2008), Group desistance from terrorism: A dynamic perspective, 
Dynamics of Asymmetric Conflict 1(3), 269

McCauley, C. and Moskalenko, S. (2008)a, Mechanisms of political radicalization: Pathways toward terrorism, Terrorism and Political Violence 20(3), 415

McCauley, C. and Moskalenko, S. (2008)b, Mechanisms of political radicalization: Pathways toward terrorism, Terrorism and Political Violence 20(3), 415

McCormick, G. (2003), Terrorist decision making, Annual Review of Political Science 6(1), 473

McFadden, D. (1974), Conditional Logit Analysis of Qualitative Choice Behavior., in P. Zarembka (ed.), Frontiers of Econometrics, pp 105-142, Academic Press: New York

Miller, A. and Damask, N. (1996), The dual myths of 'narco-terrorism': How myths drive policy, Terrorism and Political Violence 8(1), 114

Nacos, B. (2005), The portrayal of female terrorists in the media: Similar framing patterns in the news coverage of women in politics and in terrorism, Studies in Conflict \& Terrorism 28(5), 435

Neumann, P. R. (2007), Negotiating with terrorists, Foreign Affairs 86, 128

Nohria, N. and Eccles, R. (1992), Networks and organizations: Structure, form, and action, Vol. 367, Harvard Business School Press Boston, MA

O'Brien, R. M. (2007), A Caution Regarding Rules of Thumb for Variance Inflation 
Factors, Quality $\mathcal{G}$ Quantity 41, 673

Pape, R. (2003), The strategic logic of suicide terrorism, American Political Science Review 97(03), 343

Pedahzur, A. and Perliger, A. (2005), The Changing Nature of Suicide Attacks: A Social Network Perspective, Social Forces 84, 1987

Pedahzur, A., Perliger, A., and Weinberg, L. (2003), Altruism and fatalism: The characteristics of Palestinian suicide terrorists, Deviant Behavior 24(4), 405

Piazza, J. (2006), Rooted in Poverty?: Terrorism, Poor Economic Development, and Social Cleavages, Terrorism and Political Violence 18(1), 159

Piazza, J. (2007), Draining the swamp: Democracy promotion, state failure, and terrorism in 19 Middle Eastern countries, Studies in Conflict $\mathcal{G}$ Terrorism 30(6), 521

Piazza, J. (2008), Do Democracy and Free Markets Protect Us From Terrorism?, International Politics 45(1), 72

Podolny, J. and Page, K. (1998), Network Forms of Organization., Annual Review of Sociology 24(1), 57

Pontecorvos, D. (1966), The Battle of Algiers, Film

Post, J. (1987), "It's us against them": The group dynamics of political terrorism., Terrorism 
Post, J. and George, A. (2004), Leaders and their followers in a dangerous world: The psychology of political behavior, Cornell Univ Pr

Post, J., Ruby, K., and Shaw, E. (2002), The radical group in context: 1. An integrated framework for the analysis of group risk for terrorism, Studies in Conflict $\mathcal{E}$ Terrorism 25(2), 73

Post, J. M. (1990), Terrorist psycho-logic: Terrorist behavior as a product of psychological forces, Origins of terrorism pp 25-40

Post, J. M. (2005), The socio-cultural underpinnings of terrorist psychology: 'When hatred is bred in the bone', in T. Bjorgo (ed.), Root Causes of Terrorsim: myths, reality and ways forward, pp $54-69$, Routledge Press

Powell, W. W. (1987), Hybrid organizational arrangements: new form or transitional development, California management review 30(1), 67

Powell, W. W. (1990), Neither market nor hierarchy: Network forms of organization, Research in Organizational Behavior 12, 295

Raab, J. and Milward, H. B. (2003), Dark Networks as Problems, Journal of Public Administration Research Theory 13(413)

Ranstorp, M. (1994), Hizbollah's command leadership: Its structure, decision-making and relationship with Iranian clergy and institution, Terrorism and Political Violence 6(3), 303 
Rapoport, D. C. (1992), Terrorism, in M. Hawkesworth and M. Kogan (eds.), Encyclopedia of government and politics, Vol. 2, Routledge

Rapoport, D. C. (2004), The four waves of modern terrorism, in A. K. Cronin and J. M. Ludes (eds.), Attacking terrorism: Elements of a grand strategy, pp 46-73, Georgetown University Press

Ross, J. I. (1996), A model of the psychological causes of oppositional political terrorism, Peace and Conflict: Journal of Peace Psychology 2(2), 129

Ross, J. I. (1999), Beyond the conceptualization of terrorism: a psychologicalstructural model of the causes of this activity, in C. Summers and E. Markusen (eds.), Collective Violence: Harmful Behaviour in Groups and Government, pp 169-192, New York: Rowman and Littlefield

Ross, J. I. and Gurr, T. R. (1989), Why Terrorism Subsides: A Comparative Study of Canada and the United States, Comparative Politics 21(4), 405

Royston, P. \& Cox, N. J. (2005), A Multivariable scatterplot smoother, Stata Journal $5(3)$

Sageman, M. (2004), Understanding Terror Networks, University of Pennsylvania Press

Sageman, M. (2008), Leaderless jihad, University of Pennsylvania Press

Sarkasian, N. (2011), Topics in Multivariate Statistics 
Schmid, A. (1992), Terrorism and democracy, Terrorism and Political Violence 4(4), 14

Schmid, A. and Jongman, A. J. (1988), Political terrorism: a new guide to actors, authors, concepts, data bases, theories literature, Transaction Publishers

Schweiger, D., Atamer, T., and Calori, R. (2003), Transnational project teams and networks: making the multinational organization more effective, Journal of World Business 38(2), 127

Shapiro, S. (1987), The social control of impersonal trust, The American Journal of Sociology 93(3), 623

Simmel, G. (1906), The sociology of secrecy and of secret societies, American Journal of Sociology 11(4), 441

START (2010), Global Terrorism Database

Stern, J. (2004), Terror in the name of God: Why religious militants kill, Harper Perennial

Stevens, T. \& Neumann, P. (2009), Countering Online Radicalisation: A Strategy for Action, International Centre for the Study of Radicalisation and Political Violence

Tarrow, S. (2011), Power in movement: Social movements and contentious politics, Cambridge University Press 
Thompson, G. F. (2003), Between hierarchies and markets: the logic and limits of network forms of organization, Oxford University Press, USA

Trujillo, H. and Jackson, B. A. (2006), Organizational Learning and Terrorist Groups, in J. Forest (ed.), Teaching Terror: Strategic and Tactical Learning in the Terrorist World, Chapt. Organizational Learning and Terrorist Groups, pp 52-68, Rowman \& Littlefield

Tse-Tung, M. and Griffith, S. (2000), On guerrilla warfare, Univ of Illinois Press

UCLA: Academic Technology Services, S. C. G. (2011), Introduction to STATA

Ulph, S. (2005), Is al-Zawahiri's Letter to al-Zarqawi a Fake?

Urwick, L. (1922), The Manager's Span of Control, Bulletin of the Taylor Society $7(2)$

Victoroff, J. (2005)a, The mind of the terrorist, Journal of Conflict resolution 49(1), 3

Victoroff, J. (2005)b, The Mind of the Terrorist: A Review and Critique of Psychological Approaches, Journal of Conflict Resolution 49(1), 3

Walsh, J. and Piazza, J. (2010), Why Respecting Physical Integrity Rights Reduces Terrorism, Comparative Political Studies 43(5), 551

Ward, L., Larramendy, D., Arbona, F., and Nivesjo, S. (2010), Basque Country Confict Map, Centre for Peace and Conflict Studie, University of St. Andrews 
Weber, M. (1952), The essentials of bureaucratic organization: An ideal-type construction, Reader in bureaucracy pp 18-27

Weimann, G. (2005), Cyberterrorism: The Sum of All Fears?, Studies in Conflict and Terrorism 28(2), 129

Weinberg, L. and Eubank, W. (1998), Terrorism and democracy: What recent events disclose, Terrorism and Political Violence 10(1), 108

Weinberg, L., Pedahzur, A., and Perliger, A. (2009), Political parties and terrorist groups, Taylor \& Francis

Wilkinson, P. (1977), Terrorism and the liberal state, Macmillan

Wilkinson, P. (2006), Terrorism versus democracy: The liberal state response, Taylor \& Francis

Williamson, O. E. (1975), Markets and hierarchies: analysis and antitrust implications: a study in the economics of internal organization, Free Press New York

World Bank, I. (2009), World development indicators, World Bank, Washington, D. C. 


\section{Appendix A}

Table 20: List of Group Names and Organizational Structure

\begin{tabular}{ll}
\hline Group Name & Structure \\
\hline 23rd of September Communist League & All-channel \\
2nd of June Movement & All-channel \\
31 January People's Front (FP-31) & Hub-spoke \\
Abu Hafs al-Masri Brigades & All-channel \\
Abu Nidal Organization (ANO) & Bureaucracy \\
Abu Sayyaf Group (ASG) & All-channel \\
Action Directe & Market \\
African National Congress (ANC) & Bureaucracy \\
Al-Aqsa Martyrs Brigade & All-channel \\
Al-Fatah & Bureaucracy \\
Al-Qaeda & Hub-spoke ${ }^{a}$ \\
Al-Qaeda in Iraq & All-channel \\
Al-Qaeda in the Lands of the Islamic Maghreb (AQLIM) & All-channel \\
Alex Boncayao Brigade (ABB) & Bureaucracy \\
Alfaro Vive, Carajo! (AVC) & Market \\
\hline$a$ Structure changes over time. &
\end{tabular}




\begin{tabular}{|c|c|}
\hline Group Name & Structure \\
\hline All Tripura Tiger Force (ATTF) & Bureaucracy \\
\hline Allied Democratic Forces (ADF) & Hub-spoke \\
\hline Amal & Bureaucracy \\
\hline Animal Liberation Front (ALF) & Market \\
\hline Ansar al-Islam & Hub-spoke \\
\hline Ansar al-Sunnah & Hub-spoke \\
\hline Anti-terrorist Liberation Group (GAL) & Bureaucracy \\
\hline April 6th Liberation Movement & All-channel ${ }^{a}$ \\
\hline \multicolumn{2}{|l|}{ Arab Communist Organization (ACO) } \\
\hline Argentine Anticommunist Alliance (AAA) & Bureaucracy \\
\hline Armed Forces of National Resistance (FARN) & Bureaucracy \\
\hline Armed Islamic Group (GIA) & Bureaucracy \\
\hline Armed Proletarian Nuclei (NAP) & Market \\
\hline Armed Revolutionary Independence Movement (MIRA) & All-channel \\
\hline Armed Revolutionary Nuclei (NAR) & Hub-spoke \\
\hline Armenian Secret Army for the Liberation of Armenia & Bureaucracy \\
\hline Autonomous Anti-Capitalist Commandos (CAA) & Market \\
\hline Autonomy (Italy) & Market \\
\hline Awami League & Bureaucracy \\
\hline Balochi Liberation Army (BLA) & All-channel \\
\hline Bangladesh Nationalist Party (BNP) & Bureaucracy \\
\hline Basque Fatherland and Freedom (ETA) & Hub-spoke ${ }^{a}$ \\
\hline Black Liberation Army & Market $^{a}$ \\
\hline Black Panther Group (Palestinian) & Market \\
\hline Black September & Bureaucracy \\
\hline Bougainville Revolutionary Army (BRA) & Bureaucracy \\
\hline Breton Liberation Front (FLB) & Hub-spoke \\
\hline Brunswijk Jungle Commando & Bureaucracy \\
\hline
\end{tabular}

${ }^{a}$ Structure changes over time. 


\begin{tabular}{ll}
\hline Group Name & Structure \\
\hline Canary Islands Independence Movement & Hub-spoke \\
Caribbean Revolutionary Alliance (ARC) & Hub-spoke \\
Catalan Liberation Front (FAC) & Bureaucracy \\
Che Guevara Brigade & Bureaucracy \\
Chukakuha (Middle Core Faction) & Market \\
Cinchoneros Popular Liberation Movement & Bureaucracy \\
Committee of Solidarity with Arab and Middle East Political Pris- & Bureaucracy \\
oners (CSPPA) & \\
Communist Combattant Cells (CCC) (Belgium) & All-channel \\
Communist Party of India - Maoist (CPI-M) & Bureaucracy \\
Communist Party of Nepal- Maoist (CPN-M) & Bureaucracy \\
Continuity Irish Republican Army (CIRA) & Market \\
Contra & Bureaucracy \\
Coordination of the United Revolutionary Organization (CORU) & Hub-spoke \\
Corsican National Liberation Front (FLNC) & Hub-spoke ${ }^{a}$ \\
Cuban Action Commandos & Market \\
Death Angels & All-channel \\
Death to Kidnappers (MAS) & Bureaucracy \\
Democratic Front for the Liberation of Palestine (DFLP) & Bureaucracy \\
Democratic Karen Buddhist Army (DKBA) & Hub-spoke \\
Democratic Revolutionary Alliance (ARDE) & Bureaucracy \\
Democratic Revolutionary Party & Bureaucracy \\
Devrimci Halk Kurtulus Cephesi (DHKP/C) & Bureaucracy \\
Devrimci Sol (Dev So) & Bureaucracy \\
Dishmish Regiment & Bureaucracy \\
Earth Liberation Front (ELF) & Market \\
Ejercito Revolucionaria del Pueblo (ERP) (Argentina) & Bureaucracy \\
Eritrean Liberation Front & Bureaucracy \\
\hline & \\
\hline
\end{tabular}

${ }^{a}$ Structure changes over time. 


\begin{tabular}{ll}
\hline Group Name & Structure \\
\hline Farabundo Marti National Liberation Front (FMLN) & Hub-spoke \\
February 28 Popular League (El Salvador) & Bureaucracy \\
Fighting Proletarian Squad & Market \\
First of October Antifascist Resistance Group (GRAPO) & Hub-spoke \\
Force-17 & Bureaucracy \\
Forqan Group & Market \\
Free Aceh Movement (GAM) & Hub-spoke \\
Free Galician People's Guerrilla Army & Market \\
Free Papua Movement (OPM) & Hub-spoke \\
Front for the Liberation of Lebanon from Foreigners (FLLF) & Hub-spoke \\
Front for the Liberation of the Enclave of Cabinda (FLEC) & Hub-spoke \\
Fuerzas Armadas de Liberacion Nacional (FALN) & Market \\
George Jackson Brigade & Market \\
Great Eastern Islamic Raiders Front (IBDA-C) & All-channel \\
Guatemalan Labor Party (PGT) & Bureaucracy \\
Guatemalan National Revolutionary Unity (URNG) & Bureaucracy \\
Guerrilla Army of the Poor (EGP) & Bureaucracy \\
Gurkha National Liberation Front (GNLF) & Bureaucracy \\
Hamas (Islamic Resistance Movement) & Hub-spoke \\
Harkat ul Ansar & unknown \\
Hezbollah & Bureaucracy \\
Hizb-I-Islami & All-channel \\
Hizbul Mujahideen (HM) & Bureaucracy \\
Iberian Liberation Movement (MIL) & Market \\
Independent Armed Revolutionary Commandos (CRIA) & All-channel \\
Inkatha Freedom Party (IFP) & Bureaucracy \\
Institutional Revolutionary Party (PRI) & Hub-spoke \\
International Revolutionary Action Group (GARI) & All-channel \\
\hline
\end{tabular}

\footnotetext{
${ }^{a}$ Structure changes over time.
} 


\begin{tabular}{|c|c|}
\hline Group Name & Structure \\
\hline Iparretarrak (IK) & Bureaucracy \\
\hline Irish National Liberation Army (INLA) & Market \\
\hline Irish People's Liberation Organization (IPLO) & All-channel \\
\hline Irish Republican Army (IRA) & Bureaucracy \\
\hline Islamic Salvation Front (FIS) & All-channel \\
\hline Islamic State of Iraq (ISI) & Hub-spoke \\
\hline Italian Social Movement (MSI) & Bureaucracy \\
\hline Jaish-e-Mohammad (JeM) & Hub-spoke \\
\hline Jama'atul Mujahideen Bangladesh (JMB) & Bureaucracy \\
\hline Jamaat-E-Islami (Bangladesh) & Bureaucracy \\
\hline Jammu and Kashmir Islamic Front & All-channel \\
\hline Janatantrik Terai Mukti Morcha (JTMM) & Bureaucracy \\
\hline Jemaah Islamiya (JI) & Market $^{a}$ \\
\hline Jewish Armed Resistance (JAR) & All-channel \\
\hline Jewish Defense League (JDL) & Hub-spoke \\
\hline Justice Commandos for the Armenian Genocide & Market \\
\hline Kach & All-channel \\
\hline Kachin Independence Army (KIA) & Bureaucracy \\
\hline Karen National Liberation Army (KNLA) & Bureaucracy \\
\hline Khalistan Commando Force & Market \\
\hline Khalistan Liberation Force & All-channel \\
\hline Khmer Rouge & Bureaucracy $^{a}$ \\
\hline Kosovo Liberation Army (KLA) & Bureaucracy $^{a}$ \\
\hline Kurdistan Freedom Hawks (TAK) & Market \\
\hline Kurdistan Workers' Party (PKK) & Bureaucracy $^{a}$ \\
\hline Lashkar-e-Jhangvi (LeJ) & All-channel \\
\hline Lashkar-e-Taiba (LET) & Hub-spoke \\
\hline Lebanese National Resistance Front & Bureaucracy \\
\hline
\end{tabular}

${ }^{a}$ Structure changes over time. 


\begin{tabular}{ll}
\hline Group Name & Structure \\
\hline Lesotho Liberation Army (LLA) & Bureaucracy \\
Liberation Tigers of Tamil Eelam (LTTE) & Bureaucracy \\
Lord's Resistance Army (LRA) & Bureaucracy \\
Lorenzo Zelaya Revolutionary Front (LZRF) & Market \\
Loyalist Volunteer Forces (LVF) & All-channel \\
M-19 (Movement of April 19) & All-channel \\
Macheteros & All-channel \\
Manuel Rodriguez Patriotic Front (FPMR) & Hub-spoke \\
Maoist Communist Center (MCC) & Bureaucracy \\
Maximiliano Gomez Revolutionary Brigade & All-channel \\
Meibion Glyndwr & Market \\
Misurasata Indian Organization & Bureaucracy \\
Mizo National Front (MNF) & Bureaucracy \\
Montoneros (Argentina) & Bureaucracy \\
Moro Islamic Liberation Front (MILF) & Hub-spoke \\
Moro National Liberation Front (MNLF) & Bureaucracy \\
Movement for Emancipation of Niger Delta (MEND) & Market \\
Movement of Democratic Forces of Casamance & Market \\
Movement of the Revolutionary Left (MIR) (Chile) & Bureaucracy \\
Mozambique National Resistance Movement (MNR) & Hub-spoke \\
Mujahideen Youth Movement (MYM) & All-channel \\
Mujahideen-e-Khalq (MEK) & Bureaucracy \\
Muslim Brotherhood & All-channel \\
Muttahida Qaumi Movement (MQM) & Bureaucracy \\
National Democratic Front of Bodoland (NDFB) & Bureaucracy \\
National Front for the Liberation of Cuba (FLNC) & All-channel \\
National Liberation Army (NLA) (Macedonia) & Hub-spoke \\
National Liberation Army of Colombia (ELN) & Hub-spoke \\
\hline
\end{tabular}

${ }^{a}$ Structure changes over time. 


\begin{tabular}{ll}
\hline Group Name & Structure \\
\hline National Liberation Front of Tripura (NLFT) & All-channel \\
National Patriotic Front of Liberia (NPFL) & Bureaucracy \\
National Socialist Council of Nagaland & Bureaucracy \\
National Union for the Total Independence of Angola (UNITA) & Bureaucracy \\
New Armenian Resistance & All-channel \\
New People's Army (NPA) & All-channel \\
New World Liberation Front (NWLF) & All-channel \\
Nicaraguan Democratic Force (FDN) & Hub-spoke \\
November 17 Revolutionary Organization (N17RO) & All-channel \\
Official Irish Republican Army (OIRA) & Hub-spoke \\
Omega-7 & All-channel \\
Palestine Liberation Organization (PLO) & Bureaucracy \\
Palestinian Islamic Jihad (PIJ) & Hub-spoke \\
Party for the Liberation of the Hutu People (PALIPEHUTU) & Hub-spoke \\
Patriotic Morazanista Front (FPM) & Bureaucracy \\
Pattani United Liberation Organization (PULO) & Hub-spoke \\
Peasant Self-Defense Group (ACCU) & All-channel \\
People's Liberation Army (India) & Hub-spoke \\
People's Liberation Forces (FPL) & Hub-spoke \\
People's Liberation Front (JVP) & Hub-spoke \\
People's Revolutionary Army (ERP) & Market \\
People's Revolutionary Organization & Bureaucracy \\
People's War Group (PWG) & Bureaucracy \\
Polisario Front & Bureaucracy \\
Popular Forces of April 25 & All-channel \\
Popular Front for the Liberation of Palestine (PFLP) & Hub-spoke \\
Popular Liberation Army (EPL) & All-channel \\
Popular Resistance Committees & Hub-spoke \\
\hline
\end{tabular}

${ }^{a}$ Structure changes over time. 


\begin{tabular}{|c|c|}
\hline Group Name & Structure \\
\hline Popular Revolutionary Army & Bureaucracy \\
\hline Popular Revolutionary Bloc (BPR) & Bureaucracy \\
\hline Prima Linea & Market \\
\hline Proletarian Patrols & All-channel \\
\hline Quintin Lame Armed Movement & Bureaucracy \\
\hline Real Irish Republican Army (RIRA) & Market $^{a}$ \\
\hline Rebel Armed Forces of Guatemala (FAR) & All-channel \\
\hline Recontras (Recontras 380) & Market $^{a}$ \\
\hline Red Army Faction (Baader-Meinhof Group) & All-channel \\
\hline Red Brigades & Bureaucracy \\
\hline Red Flag (Venezuela) & Bureaucracy \\
\hline Red Hand Commandos & All-channel \\
\hline Red Hand Defenders (RHD) & Market \\
\hline Resistenza Corsa (RC) & Market \\
\hline Revolutionary Armed Forces of Colombia (FARC) & Bureaucracy $^{a}$ \\
\hline Revolutionary Cell & Market \\
\hline Revolutionary Front for an Independent East Timor (FRETILIN) & All-channel \\
\hline Revolutionary Nuclei & Market \\
\hline Revolutionary Organization of People in Arms (ORPA) & All-channel \\
\hline Revolutionary Patriotic Anti-Fascist Front (FRAP) & Market \\
\hline Revolutionary People's Struggle (ELA) & Market \\
\hline Revolutionary United Front (RUF) & Market \\
\hline Revolutionary Workers Party & Bureaucracy \\
\hline Revolutionary Workers' Council (Kakurokyo) & Hub-spoke \\
\hline Ricardo Franco Front (Dissident FARC) & All-channel \\
\hline Rodrigo Franco Command & unknown \\
\hline Rwanda Patriotic Front (RPF) & Bureaucracy \\
\hline Sandinista National Liberation Front (FSLN) & Bureaucracy \\
\hline
\end{tabular}

${ }^{a}$ Structure changes over time. 


\begin{tabular}{|c|c|}
\hline Group Name & Structure \\
\hline Secret Anti-Communist Army (ESA) & All-channel \\
\hline Shan State Progressive Party & Bureaucracy \\
\hline Shanti Bahini - Peace Force & Bureaucracy \\
\hline Shining Path (Sendero Luminoso) & Hub-spoke ${ }^{a}$ \\
\hline Simon Bolivar Guerrilla Coordinating Board (CGSB) & Market \\
\hline Sipah-e-Sahaba (SSP) & All-channel \\
\hline South-West Africa People's Organization (SWAPO) & Bureaucracy \\
\hline Spanish Basque Battalion (BVE) & Market \\
\hline Sudan People's Liberation Army (SPLA) & Bureaucracy \\
\hline Taliban & Hub-spoke ${ }^{a}$ \\
\hline Tawhid and Jihad & All-channel \\
\hline Terra Lliure (TL) & All-channel \\
\hline The Extraditables & All-channel \\
\hline Tripura National Volunteers (TNV) & All-channel \\
\hline Tupac Amaru Revolutionary Movement (MRTA) & All-channel ${ }^{a}$ \\
\hline Tupac Katari Guerrilla Army (EGTK) & All-channel \\
\hline Tupamaros (Uruguay) (MLN) & Bureaucracy \\
\hline Turkish Communist Party/Marxist (TKP-ML) & Hub-spoke \\
\hline Turkish People's Liberation Army (TPLA) & All-channel \\
\hline Turkish People's Liberation Front (THKP-C) & Bureaucracy \\
\hline Uganda Freedom Movement (UFM) & All-channel \\
\hline Uganda People's Army & Bureaucracy \\
\hline Ulster Freedom Fighters (UFF) & Bureaucracy $^{a}$ \\
\hline Ulster Volunteer Force (UVF) & Bureaucracy $^{a}$ \\
\hline Unified Popular Action Front (FAPU) & Bureaucracy \\
\hline Union Guerrera Blanca (UGB) & Market \\
\hline United Freedom Front (UFF) & All-channel \\
\hline United Liberation Front of Assam (ULFA) & Bureaucracy \\
\hline
\end{tabular}

${ }^{a}$ Structure changes over time. 


\begin{tabular}{ll}
\hline Group Name & Structure \\
\hline United Popular Action Movement (Lautaro Faction) & Hub-spoke \\
United Self Defense Units of Colombia (AUC) & All-channel \\
Weather Underground & All-channel \\
White Wolves & All-channel \\
Workers' Self-Defense Movement (MAO) & Bureaucracy \\
Young Patriots & Bureaucracy \\
Zapatista National Liberation Army (EZLN) & Hub-spoke \\
Zimbabwe African Nationalist Union (ZANU) & Bureaucracy \\
Zimbabwe African People's Union (ZAPU) & Bureaucracy \\
al-Gama'at al-Islamiyya, Islamic Group (IG) & All-channel \\
\hline
\end{tabular}


Table 21: List of Ten Most Deadly Attacks (according to GTD)

\begin{tabular}{lcc}
\hline Group Name $^{a}$ & Date & \# Killed \\
\hline Al Qaeda & 09.11 .2001 & $1380.5^{b}$ \\
Al Qaeda & 09.11 .2001 & 1380.5 \\
Hutus & 04.13 .1994 & 1180 \\
Communist Party of Nepal - Maoist (CPN-M) & 03.21 .2004 & 518 \\
Mujahideen-I-Khalq (MK) & 08.19 .1978 & 430 \\
Tutsi & 03.23 .2004 & 400 \\
Mozambique National Resistance Movement (MNR) & 07.18 .1987 & 386 \\
Tutsi & 05.23 .1996 & 375 \\
Chechens & 09.01 .2004 & 344 \\
Sikh Extremists & 06.23 .1985 & 329 \\
\hline
\end{tabular}

${ }^{a}$ According to GTD.

${ }^{b} 9 / 11$ coded as two separate events. 
Table 22: Attention-Seeking Targets: Economic (Part I $)^{a}$

\begin{tabular}{llcl}
\hline Term & RRR & Standard Error & p-value \\
\hline Business & & & \\
Market structure & 2.6905 & 1.8082 & 0.141 \\
All-channel structure & 0.4761 & 0.1128 & $0.002 * * *$ \\
Hub-spoke structure & 1.1758 & 0.2287 & 0.405 \\
Is left-wing & 2.4268 & 0.4751 & $0.000 * * *$ \\
Is right-wing & 3.2338 & 3.2959 & 0.249 \\
Is religious & 0.5932 & 0.1759 & $0.078 \dagger$ \\
Year & 1.0006 & 0.0003 & $0.037 *$ \\
GDP per capita (chain) & 1.0639 & 0.0164 & $0.000 * * *$ \\
Freedom House & 1.0148 & 0.0625 & 0.811 \\
Group age & 0.9779 & 0.0053 & $0.000 * * *$ \\
Peak size & 1.7998 & 0.2169 & $0.000 * * *$ \\
\hline Airports \& Airlines & & & \\
Market structure & 1.5831 & 1.1518 & 0.528 \\
All-channel structure & 0.3039 & 0.0925 & $0.000 * * *$ \\
Hub-spoke structure & 0.3857 & 0.0970 & $0.000 * * *$ \\
Is left-wing & 1.0624 & 0.2521 & 0.799 \\
Is right-wing & 2.0144 & 2.3625 & 0.550 \\
Is religious & 1.5341 & 0.5433 & 0.227 \\
Year & 1.0001 & 0.0003 & 0.795 \\
GDP per capita (chain) & 1.0932 & 0.0188 & $0.000 * * *$ \\
Freedom House & 1.1783 & 0.0889 & $0.030 *$ \\
Group age & 0.9442 & 0.0076 & $0.000 * * *$ \\
Peak size & 1.0323 & 0.1565 & 0.834 \\
\hline Note & & & \\
\hline
\end{tabular}

Note: ${ }^{a}$ Pseudo R2 is $0.2705 . \mathrm{N}=34,492$. Base category is 'unknown'

$\dagger: p<.1 ;^{*}: p<.05 ;^{* *}: p<.01 ;^{* * *}: p<.005$ 
Table 23: Attention-Seeking Targets: Economic (Part II) ${ }^{a}$

\begin{tabular}{|c|c|c|c|}
\hline Term & RRR & Standard Error & p-value \\
\hline \multicolumn{4}{|l|}{ Maritime } \\
\hline Market structure & 5.1381 & 4.7724 & $0.078 \dagger$ \\
\hline All-channel structure & 1.2296 & 0.5047 & 0.615 \\
\hline Hub-spoke structure & 0.9921 & 0.3904 & 0.984 \\
\hline Is left-wing & 0.3763 & 0.1229 & $0.003 * * *$ \\
\hline Is right-wing & 3.2077 & 3.6732 & 0.309 \\
\hline Is religious & 0.1716 & 0.1056 & $0.004 * * *$ \\
\hline Year & 0.9993 & 0.0005 & 0.175 \\
\hline GDP per capita (chain) & 0.9392 & 0.0294 & $0.045 *$ \\
\hline Freedom House & 1.3566 & 0.1477 & $0.005 * * *$ \\
\hline Group age & 0.9673 & 0.0118 & $0.007 * * *$ \\
\hline Peak size & 1.2164 & 0.2627 & 0.364 \\
\hline \multicolumn{4}{|l|}{ Tourists } \\
\hline Market structure & 3.5691 & 2.9908 & 0.129 \\
\hline All-channel structure & 1.1067 & 0.4442 & 0.800 \\
\hline Hub-spoke structure & 1.0645 & 0.4025 & 0.869 \\
\hline Is left-wing & 0.9078 & 0.3011 & 0.771 \\
\hline Is right-wing & 2.2468 & 3.2349 & 0.574 \\
\hline Is religious & 3.2275 & 1.3143 & $0.004 * * *$ \\
\hline Year & 0.9993 & 0.0005 & 0.137 \\
\hline GDP per capita (chain) & 1.0485 & 0.0242 & $0.040 * *$ \\
\hline Freedom House & 0.9568 & 0.1081 & 0.696 \\
\hline Group age & 0.9731 & 0.0093 & $0.004 * * *$ \\
\hline Peak size & 1.2808 & 0.2528 & 0.210 \\
\hline
\end{tabular}

Note: ${ }^{a}$ Pseudo R2 is $0.2705 . \mathrm{N}=34,492$. Base category is 'unknown'

$\dagger: p<.1 ;^{*}: p<.05 ;^{* *}: p<.01 ;^{* * *}: p<.005$ 
Table 24: Attention-Seeking Targets: Economic (Part III) ${ }^{a}$

\begin{tabular}{|c|c|c|c|}
\hline Term & RRR & Standard Error & p-value \\
\hline \multicolumn{4}{|l|}{ Transportation } \\
\hline Market structure & 2.6657 & 1.8438 & 0.156 \\
\hline All-channel structure & 0.4710 & 0.1163 & $0.002 * * *$ \\
\hline Hub-spoke structure & 1.0904 & 0.2196 & 0.667 \\
\hline Is left-wing & 1.4894 & 0.3049 & $0.052 \dagger$ \\
\hline Is right-wing & 6.8837 & 7.0075 & $0.058 \dagger$ \\
\hline Is religious & 0.4329 & 0.1373 & $0.008 * * *$ \\
\hline Year & 1.0001 & 0.0002 & 0.578 \\
\hline GDP per capita (chain) & 0.9718 & 0.0163 & $0.088 \dagger$ \\
\hline Freedom House & 1.1771 & 0.0751 & $0.010 * *$ \\
\hline Group age & 0.9909 & 0.0057 & 0.113 \\
\hline Peak size & 1.7867 & 0.2221 & $0.000 * * *$ \\
\hline \multicolumn{4}{|l|}{ Utilities } \\
\hline Market structure & 2.3007 & 1.5844 & 0.226 \\
\hline All-channel structure & 0.2095 & 0.0524 & $0.000 * * *$ \\
\hline Hub-spoke structure & 1.7526 & 0.3408 & $0.006 * *$ \\
\hline Is left-wing & 7.1381 & 1.4641 & $0.000 * * *$ \\
\hline Is right-wing & 4.0871 & 4.2254 & 0.173 \\
\hline Is religious & 0.2476 & 0.0901 & $0.000 * * *$ \\
\hline Year & 1.0002 & 0.0002 & 0.517 \\
\hline GDP per capita (chain) & 0.9435 & 0.0160 & $0.001 * * *$ \\
\hline Freedom House & 1.1339 & 0.0721 & $0.048 *$ \\
\hline Group age & 0.9854 & 0.0056 & $0.009 * * *$ \\
\hline Peak size & 1.5438 & 0.1903 & $0.000 * * *$ \\
\hline
\end{tabular}

Note: ${ }^{a}$ Pseudo $\mathrm{R} 2$ is $0.2705 . \mathrm{N}=34,492$. Base category is 'unknown'

$\dagger: p<.1 ;^{*}: p<.05 ;^{* *}: p<.01 ;^{* * *}: p<.005$ 
Table 25: Coercive Targets: Hard Targets ${ }^{a}$

\begin{tabular}{llll}
\hline Term & RRR & Standard Error & p-value \\
\hline Police & & & \\
Market structure & 2.9679 & 2.0105 & 0.108 \\
All-channel structure & 0.6741 & 0.1595 & $0.096 \dagger$ \\
Hub-spoke structure & 1.3502 & 0.2632 & 0.123 \\
Is left-wing & 1.0106 & 0.1980 & 0.957 \\
Is right-wing & 0.5932 & 0.6199 & 0.617 \\
Is religious & 1.1175 & 0.3243 & 0.702 \\
Year & 1.0010 & 0.0003 & $0.001 * * *$ \\
GDP per capita (chain) & 0.9656 & 0.0150 & $0.024 *$ \\
Freedom House & 0.9829 & 0.0606 & 0.780 \\
Group age & 0.9951 & 0.0054 & 0.366 \\
Peak size & 1.8446 & 0.2231 & $0.000 * * *$ \\
\hline Military & & & \\
Market structure & 2.5932 & 1.7582 & 0.160 \\
All-channel structure & 0.6504 & 0.1532 & $0.068 \dagger$ \\
Hub-spoke structure & 1.8266 & 0.3541 & $0.002 * * *$ \\
Is left-wing & 1.3738 & 0.2671 & 0.102 \\
Is right-wing & 0.7696 & 0.7883 & 0.798 \\
Is religious & 0.6713 & 0.1954 & 0.171 \\
Year & 1.0001 & 0.0002 & $0.000 * * *$ \\
GDP per capita (chain) & 0.9412 & 0.0146 & $0.000 * * *$ \\
Freedom House & 1.0665 & 0.0653 & 0.293 \\
Group age & 1.0008 & 0.0054 & 0.884 \\
Peak size & 1.5749 & 0.1891 & $0.000 * * *$ \\
\hline Note: aPseudo R2 & & &
\end{tabular}

Note: 'Pseudo R2 is $0.2705 . \mathrm{N}=34,492$. Base category is 'unknown'

$\dagger: p<.1 ;^{*}: p<.05 ;^{* *}: p<.01 ;^{* * *}: p<.005$ 
Table 26: Coercive Targets: Soft Targets (Part I) ${ }^{a}$

\begin{tabular}{lccl}
\hline Term & RRR & Standard Error & p-value \\
\hline Education & & & \\
Market structure & 4.0562 & 2.8419 & $0.046 *$ \\
All-channel structure & 0.4299 & 0.1173 & $0.002 * * *$ \\
Hub-spoke structure & 0.6725 & 0.1552 & $0.086 \dagger$ \\
Is left-wing & 1.5961 & 0.3764 & $0.047 *$ \\
Is right-wing & 15.476 & 16.014 & $0.008 * *$ \\
Is religious & 3.2345 & 1.0691 & $0.000 * * *$ \\
Year & 1.0005 & 0.0003 & 0.123 \\
GDP per capita (chain) & 0.9487 & 0.0193 & $0.010 *$ \\
Freedom House & 0.9064 & 0.0650 & 0.171 \\
Group age & 0.9620 & 0.0067 & $0.000 * * *$ \\
Peak size & 1.4527 & 0.1967 & $0.006 * * *$ \\
\hline Journalists \& Media & & & \\
Market structure & 3.4156 & 2.3939 & $0.080 \dagger$ \\
All-channel structure & 0.5859 & 0.1549 & $0.043 *$ \\
Hub-spoke structure & 1.1361 & 0.2514 & 0.564 \\
Is left-wing & 3.9382 & 0.9040 & $0.000 * * *$ \\
Is right-wing & 10.663 & 11.219 & $0.024 *$ \\
Is religious & 1.8982 & 0.6458 & $0.060 \dagger$ \\
Year & 0.9997 & 0.0003 & 0.323 \\
GDP per capita (chain) & 1.0256 & 0.0182 & 0.154 \\
Freedom House & 1.0332 & 0.0723 & 0.640 \\
Group age & 0.9530 & 0.0067 & $0.000 * * *$ \\
Peak size & 1.5979 & 0.2143 & $0.000 * * *$ \\
\hline Note & & &
\end{tabular}

Note: ${ }^{a}$ Pseudo $\mathrm{R} 2$ is $0.2705 . \mathrm{N}=34,492$. Base category is 'unknown'

† : $p<.1 ;^{*}: p<.05 ;^{* *}: p<.01 ;^{* * *}: p<.005$ 
Table 27: Coercive Targets: Soft Targets (Part II) ${ }^{a}$

\begin{tabular}{|c|c|c|c|}
\hline Term & RRR & Standard Error & p-value \\
\hline \multicolumn{4}{|l|}{ NGO } \\
\hline Market structure & 5.8985 & 4.6059 & $0.023 *$ \\
\hline All-channel structure & 0.5429 & 0.1813 & $0.067 \dagger$ \\
\hline Hub-spoke structure & 0.5068 & 0.1352 & $0.011 *$ \\
\hline Is left-wing & 1.6349 & 0.4881 & 0.100 \\
\hline Is right-wing & 9.1060 & 10.005 & $0.044 *$ \\
\hline Is religious & 2.5475 & 1.0894 & $0.029 *$ \\
\hline Year & 0.9988 & 0.0004 & $0.001 * * *$ \\
\hline GDP per capita (chain) & 1.0179 & 0.0252 & 0.471 \\
\hline Freedom House & 1.6379 & 0.1512 & $0.000 * * *$ \\
\hline Group age & 0.9986 & 0.0103 & 0.895 \\
\hline Peak size & 1.0791 & 0.1664 & 0.621 \\
\hline \multicolumn{4}{|c|}{ Private citizen \& property } \\
\hline Market structure & 1.6842 & 1.1366 & 0.440 \\
\hline All-channel structure & 0.3971 & 0.0938 & $0.000 * * *$ \\
\hline Hub-spoke structure & 0.8607 & 0.1669 & 0.438 \\
\hline Is left-wing & 1.1285 & 0.2205 & 0.536 \\
\hline Is right-wing & 7.2726 & 7.3471 & $0.050 \dagger$ \\
\hline Is religious & 1.5953 & 0.4619 & 0.107 \\
\hline Year & 1.0016 & 0.0003 & $0.000 * * *$ \\
\hline GDP per capita (chain) & 0.9863 & 0.0153 & 0.372 \\
\hline Freedom House & 0.9179 & 0.0564 & 0.163 \\
\hline Group age & 0.9770 & 0.0053 & $0.000 * * *$ \\
\hline Peak size & 1.5070 & 0.1809 & $0.001 * * *$ \\
\hline
\end{tabular}

Note: ${ }^{a}$ Pseudo $\mathrm{R} 2$ is $0.2705 . \mathrm{N}=34,492$. Base category is 'unknown'

$\dagger: p<.1 ;^{*}: p<.05 ;^{* *}: p<.01 ;^{* * *}: p<.005$ 
Table 28: Infighting ${ }^{a}$

\begin{tabular}{|c|c|c|c|}
\hline Term & RRR & Standard Error & p-value \\
\hline \multicolumn{4}{|l|}{ Terrorist groups } \\
\hline Market structure & 3.4737 & 2.4747 & $0.080 \dagger$ \\
\hline All-channel structure & 0.1915 & 0.0615 & $0.000 * * *$ \\
\hline Hub-spoke structure & 0.3659 & 0.0920 & $0.000 * * *$ \\
\hline Is left-wing & 0.4713 & 0.1183 & $0.003 * * *$ \\
\hline Is right-wing & 16.653 & 17.364 & $0.007 * *$ \\
\hline Is religious & 3.6077 & 1.1423 & $0.000 * * *$ \\
\hline Year & 0.9923 & 0.0003 & 0.157 \\
\hline GDP per capita (chain) & 1.0444 & 0.0177 & $0.010 *$ \\
\hline Freedom House & 0.9427 & 0.0689 & 0.420 \\
\hline Group age & 0.9739 & 0.0061 & $0.000 * * *$ \\
\hline Peak size & 2.1769 & 0.3156 & $0.000 * * *$ \\
\hline \multicolumn{4}{|c|}{ Violent political parties } \\
\hline Market structure & 0.1523 & 0.1859 & 0.123 \\
\hline All-channel structure & 0.1298 & 0.0516 & $0.000 * * *$ \\
\hline Hub-spoke structure & 0.4523 & 0.1247 & $0.004 * * *$ \\
\hline Is left-wing & 0.1056 & 0.0305 & $0.000 * * *$ \\
\hline Is right-wing & 19.839 & 20.573 & $0.004 * * *$ \\
\hline Is religious & 0.3038 & 0.1264 & $0.004 * * *$ \\
\hline Year & 1.0011 & 0.0004 & $0.003 * * *$ \\
\hline GDP per capita (chain) & 0.9067 & 0.0198 & $0.000 * * *$ \\
\hline Freedom House & 0.8940 & 0.0730 & 0.170 \\
\hline Group age & 0.9534 & 0.0065 & $0.000 * * *$ \\
\hline Peak size & 1.5167 & 0.2469 & $0.011 *$ \\
\hline
\end{tabular}

Note: ${ }^{a}$ Pseudo R2 is $0.2705 . \mathrm{N}=34,492$. Base category is 'unknown'

$\dagger: p<.1 ;^{*}: p<.05 ;^{* *}: p<.01 ;^{* * *}: p<.005$ 
Table 29: Attention-Seeking Targets: Political (Part II) ${ }^{a}$

\begin{tabular}{|c|c|c|c|}
\hline Term & RRR & Standard Error & p-value \\
\hline \multicolumn{4}{|l|}{ Government (General) } \\
\hline Market structure & 3.3133 & 2.2397 & $0.076 \dagger$ \\
\hline All-channel structure & 0.5567 & 0.1324 & $0.014 *$ \\
\hline Hub-spoke structure & 1.0131 & 0.1989 & 0.947 \\
\hline Is left-wing & 1.7978 & 0.3558 & $0.003 * * *$ \\
\hline Is right-wing & 3.4765 & 3.5447 & 0.222 \\
\hline Is religious & 1.0726 & 0.3134 & 0.812 \\
\hline Year & 1.0008 & 0.0003 & $0.003 * * *$ \\
\hline GDP per capita (chain) & 0.9948 & 0.0156 & 0.740 \\
\hline Freedom House & 0.9946 & 0.0617 & 0.931 \\
\hline Group age & 0.97649 & 0.0053 & $0.000 * * *$ \\
\hline Peak size & 1.7366 & 0.2109 & $0.000 * * *$ \\
\hline \multicolumn{4}{|c|}{ Government (Diplomat) } \\
\hline Market structure & 2.1969 & 1.5327 & 0.259 \\
\hline All-channel structure & 0.5819 & 0.1552 & $0.042 *$ \\
\hline Hub-spoke structure & 0.7019 & 0.1578 & 0.116 \\
\hline Is left-wing & 1.2689 & 0.2803 & 0.281 \\
\hline Is right-wing & 4.4009 & 4.6204 & 0.158 \\
\hline Is religious & 1.8026 & 0.5808 & $0.067 \dagger$ \\
\hline Year & 1.0002 & 0.0003 & 0.626 \\
\hline GDP per capita (chain) & 1.0770 & 0.0181 & $0.000 * * *$ \\
\hline Freedom House & 1.2161 & 0.0844 & $0.005 * *$ \\
\hline Group age & 0.9312 & 0.0067 & $0.000 * * *$ \\
\hline Peak size & 1.1576 & 0.1579 & 0.283 \\
\hline
\end{tabular}

Note: 'Pseudo R2 is $0.2705 . \mathrm{N}=34,492$. Base category is 'unknown'

$\dagger: p<.1 ;^{*}: p<.05 ;^{* *}: p<.01 ;^{* * *}: p<.005$ 
Table 30: Attention-Seeking Targets: Political (Part II) ${ }^{a}$

\begin{tabular}{lccl}
\hline Term & RRR & Standard Error & p-value \\
\hline Religious & & & \\
Market structure & 3.5448 & 2.5776 & $0.082 \dagger$ \\
All-channel structure & 0.6808 & 0.1895 & 0.167 \\
Hub-spoke structure & 1.0665 & 0.2464 & 0.780 \\
Is left-wing & 1.7326 & 0.4262 & $0.025 *$ \\
Is right-wing & 9.4887 & 10.002 & $0.033 *$ \\
Is religious & 3.0539 & 1.0434 & $0.001 * * *$ \\
Year & 1.0002 & 0.0003 & 0.606 \\
GDP per capita (chain) & 0.9913 & 0.0196 & 0.654 \\
Freedom House & 1.0016 & 0.0778 & 0.984 \\
Group age & 0.9751 & 0.0069 & $0.000 * * *$ \\
Peak size & 1.1524 & 0.1650 & 0.322 \\
\hline
\end{tabular}

Note: ${ }^{a}$ Pseudo R2 is $0.2705 . \mathrm{N}=34,492$. Base category is 'unknown'

$\dagger: p<.1 ;^{*}: p<.05 ;^{* *}: p<.01 ;^{* * *}: p<.005$

Table 31: Lethality of market structures

\begin{tabular}{lccl}
\hline Term & IRR & Standard Error & p-value \\
\hline Is religious & 1.4279 & 0.9569 & 0.595 \\
Is right-wing & 0.4424 & 0.2810 & 0.199 \\
Is left-wing & 0.7160 & 0.3531 & 0.498 \\
Group age & 1.0135 & 0.0193 & 0.482 \\
Seeks policy change & 0.2212 & 0.1145 & $0.004 * * *$ \\
Seeks social revolution & 0.1765 & 0.0920 & $0.001 * * *$ \\
Seeks status quo & 1.4544 & 0.7245 & 0.452 \\
Seeks regime change & 0.1336 & 0.0648 & $0.000 * * *$ \\
Peak size & 2.0358 & 0.3639 & $0.000^{* * *}$ \\
Occupied/colonized & 2.0957 & 0.3650 & $0.018^{*}$ \\
GDP per capita $(\$ 1000)$ & 0.8853 & 0.0199 & $0.000 * * *$ \\
Freedom House & 1.2778 & 0.1159 & $0.007^{* *}$ \\
State sponsor & 1.9968 & 0.9778 & 0.158 \\
\hline
\end{tabular}

NOTE: Pseudo R2 is 0.0224 . Number of observations is 984 .

$\dagger p<.1 ;^{*} p<.05 ;^{* *} p<.01 ;^{* * *} p<.005$ 
Table 32: Lethality of all-channel structures

\begin{tabular}{lccl}
\hline Term & IRR & Standard Error & p-value \\
\hline Is religious & 9.0098 & 3.1262 & $0.000 * * *$ \\
Is right-wing & 5.5358 & 2.1519 & $0.000 * * *$ \\
Is left-wing & 3.4048 & 1.1025 & $0.000 * * *$ \\
Group age & 0.9638 & 0.0065 & $0.000 * * *$ \\
Seeks policy change & 0.0969 & 0.0065 & $0.000 * * *$ \\
Seeks social revolution & 0.2068 & 0.0721 & $0.000 * * *$ \\
Seeks status quo & 0.1153 & 0.0467 & $0.000 * * *$ \\
Seeks regime change & 0.1653 & 0.0562 & $0.000 * * *$ \\
Peak size & 2.9086 & 0.3480 & $0.000 * * *$ \\
Occupied/colonized & 0.4476 & 0.1111 & $0.001 * * *$ \\
GDP per capita (\$1000) & 1.0164 & 0.0132 & 0.213 \\
Freedom House & 1.1299 & 0.0541 & $0.011 *$ \\
State sponsor & 2.5646 & 0.3655 & $0.000 * * *$ \\
\hline
\end{tabular}

NOTE: Pseudo R2 is 0.0224 . Number of observations is 2900 .

$\dagger p<.1 ;{ }^{*} p<.05 ;^{* *} p<.01 ;^{* * *} p<.005$ 
Table 33: Lethality of hub and spoke structures

\begin{tabular}{lccl}
\hline Term & IRR & Standard Error & p-value \\
\hline Is religious & 1.8658 & 0.3519 & $0.001 * * *$ \\
Is right-wing & 1.3052 & 0.3107 & 0.263 \\
Is left-wing & 3.9331 & 0.8031 & $0.000 * * *$ \\
Group age & 0.9691 & 0.0035 & $0.000 * * *$ \\
Seeks policy change & 0.2201 & 0.0591 & $0.000 * * *$ \\
Seeks social revolution & 0.2243 & 0.0662 & $0.000 * * *$ \\
Seeks status quo & 0.5892 & 0.1073 & $0.004 * * *$ \\
Seeks regime change & 0.3776 & 0.0743 & $0.000 * * *$ \\
Peak size & 1.7689 & 0.1232 & $0.000 * * *$ \\
Occupied/colonized & 2.4768 & 0.5117 & $0.000 * * *$ \\
GDP per capita (\$1000) & 0.9567 & 0.0089 & $0.000 * * *$ \\
Freedom House & 1.4555 & 0.0556 & $0.000 * * *$ \\
State sponsor & 3.6112 & 0.6419 & $0.000 * * *$ \\
\hline
\end{tabular}

NOTE: Pseudo R2 is 0.0224. Number of observations is 10140.

$\dagger p<.1 ;^{*} p<.05 ;^{* *} p<.01{ }^{* * *} p<.005$ 
Table 34: Lethality of bureaucratic structures

\begin{tabular}{lccl}
\hline Term & IRR & Standard Error & p-value \\
\hline Is religious & 1.6998 & 0.3711 & $0.015 *$ \\
Is right-wing & 2.0199 & 0.4955 & $0.004 * * *$ \\
Is left-wing & 0.8148 & 0.1638 & 0.308 \\
Group age & 1.0014 & 0.0031 & 0.659 \\
Seeks policy change & 0.6259 & 0.0793 & $0.000 * * *$ \\
Seeks social revolution & 0.3071 & 0.0748 & $0.000 * * *$ \\
Seeks status quo & 1.1755 & 0.1792 & 0.289 \\
Seeks regime change & 1.0019 & 0.1796 & 0.991 \\
Peak size & 0.7431 & 0.0468 & $0.000 * * *$ \\
Occupied/colonized & 1.4259 & 0.2016 & $0.012 *$ \\
GDP per capita $(\$ 1000)$ & 0.8805 & 0.2016 & $0.000 * * *$ \\
Freedom House & 0.9838 & 0.0300 & 0.593 \\
State sponsor & 1.5696 & 0.1751 & $0.000 * * *$ \\
\hline
\end{tabular}

NOTE: Pseudo R2 is 0.0224 . Number of observations is 15228 .

$\dagger p<.1 ;^{*} p<.05 ; ;^{* *} p<.01 ; * * * 0.005$ 